\title{
CLIMATE IMPLICATIONS OF NEXT GENERATION BIOFUELS PRODUCED FROM ALGAE
}

\author{
A Dissertation Presented to the \\ Faculty of the School of Engineering and Applied Science \\ University of Virginia
}

In Partial Fulfillment

of the requirement for the Degree

Doctor of Philosophy

by

Xiaowei "Vivian" Liu

May 2014 


\section{APPROVAL SHEET}

This dissertation is submitted in partial fulfillment

of the requirements for the degree of

Doctor of Philosophy in Civil and Environmental Engineering

Xiaowei "Vivian" Liu

This dissertation has been read and approved by the Examining Committee:

\begin{tabular}{c} 
Andres Clarens \\
\hline Advisor \\
Lisa Colosi Peterson \\
\hline
\end{tabular}

Wu-Seng "Winston" Lung

James Rhodes

William Scherer

Accepted for the School of Engineering and Applied Science:

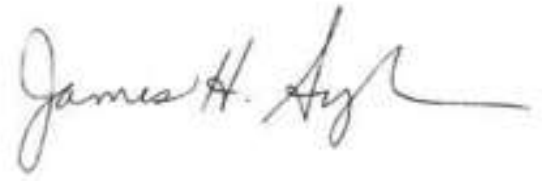

James H. Aylor, Dean

May 2014 


\begin{abstract}
Algae-based fuels are being widely investigated in an effort to develop renewable and carbon-neutral bioenergy feedstocks. Despite this, there is little evidence that largescale algae cultivation can achieve carbon reductions relative to conventional, petroleumderived liquid fuels. This work explores a variety of systems-level aspects of algae-toenergy processes in an effort to understand the real potential of algae fuels to achieve deep reductions in carbon emissions. This work is both challenging and important because the algae-to-energy industry is still in its nascent stage and few commercial scale facilities currently exist to model. Those that do exist are seeking guidance on how to produce low carbon fuels. To provide insights into this question, I made four specific contributions to the academic literature. The first contribution is the development of a meta-analysis of life cycle studies that modeled algae-to-energy systems. The literature is seemingly inconclusive about the anticipated impacts of algae-based biodiesel and this analysis was structured to reconcile these inconsistencies. The results indicate that algae biodiesel has environmental performance on par with that of traditional biofuels with room for improvement as the process is optimized. The second contribution of this work is the development of a comprehensive life cycle model of algae fuels produced via hydrothermal liquefaction. This model, which was developed in conjunction with an industry partner, is the first of its kind to use pilot-scale data. The model suggests that
\end{abstract}


algae fuels can achieve significant reduction in GHG emissions compared with petroleum alternatives and will have viable energy return on investment when algae are cultivated at full scale. The third contribution from this work is the development of a method for characterizing land use effects of biofuel feedstock cultivation. The novel approach that I propose is based on the use of historical cropland data, rather than indirect or direct land use. This approach addresses several persistent issues in existing frameworks and the results of this analysis side step much of the uncertainty intrinsic to existing models and represent the first step toward developing a more integrated and equitable land use emissions framework. The fourth and final contribution from this work is to develop a nation-wide model of $\mathrm{CO}_{2}$ industrial sources using newly available $\mathrm{CO}_{2}$ emissions data collected by the US Environmental Protection Agency. This model suggests that there are significant portions of the country without access to commercially relevant volumes of $\mathrm{CO}_{2}$ and this could impact pond location selection. The characteristics of the $\mathrm{CO}_{2}$ sources are such that much of the $\mathrm{CO}_{2}$ in the US is relatively 'dirty' coming from a source with a high carbon footprint of its own. This suggests that there are opportunities to optimize our $\mathrm{CO}_{2}$ supply chain in an effort to achieve system-scale reductions and improve the sustainability of algae-to-energy processes. 


\section{Acknowledgements}

I would like to thank Jesus Christ for His blessings to me. Although there were ups and downs in my professional path as well as personal life, His arrangement made so much sense to me when I look back. God has taught me how to overcome pride and ego with a humble heart. My experiences with Him have helped me with acquiring more knowledge, more skills and made me grow more mature.

I would like to thank my Ph.D. advisor, Prof. Andres Clarens. During my four years Ph.D. study, he has taught me much more than I ever imagined. He is not only a brilliant and hardworking scholar, but also strives to achieve excellence in every aspect in his life. Prof. Clarens is truly a role model for his students and I feel honored to be his graduate student.

I would like to thank my Ph.D. co-advisor, Prof. Lisa Colosi Peterson. She is very intelligent, knowledgeable and detail-oriented. She had taught me not only research skills, but also a professional attitude. She is so nice and genuine that every one of her graduate students has complimented her. My working experience with her is very enjoyable.

I would like to thank my Master of Science advisor, Prof. Wu-Seng (Winston) Lung. His approval had played an important role in making my journey to the U.S. for graduate study a reality. I truly appreciate his tolerance of my occasional inconsistent and 
immature decisions during my first two years' graduate study. His wisdom has paved a smooth path for my transition to Ph.D. program.

I would like to thank my co-advisor, Dr. James Rhodes. He is very bright and open-minded. He has taught me so much about energy policy and entrepreneurship. My working experience with his start-up company has tremendous influence on my plan for future career development. I'm also very grateful for his family's hospitality.

I would like to thank my defense committee member, Prof. William Scherer. I appreciate his time and efforts in helping with my completion of Ph.D. degree.

I would like to thank my colleagues and former colleagues. They have created a collegial and friendly environment, in which we enjoyed learning from each other and forming a professional network in the future.

I would like to thank my spiritual mentor, Anne Newman. She is my go-to person whenever I was confused with problems other than research. She has provided so much help to international students and her wisdom and kindness are my treasure. I feel blessed to have her in my life.

Lastly, I would like to thank my mother, Cailing Wu. Her unconditional love and support for me help me overcome so many difficulties. When I was in situations that seemed to be no easy way out, I could always rely on her encouragement to become stronger and braver. Her wisdom, generosity, honesty, positive attitude and humorous personality make me feel so lucky to be her daughter. 
Dedication

To the Lord Jesus Christ, and my mother Cailing $\mathrm{Wu}$ 


\section{Contents}

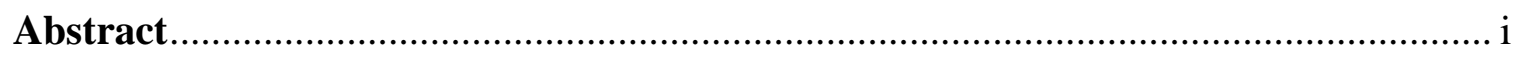

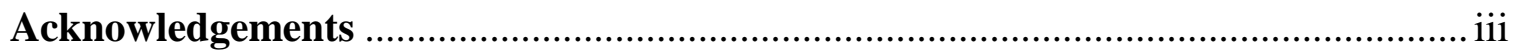

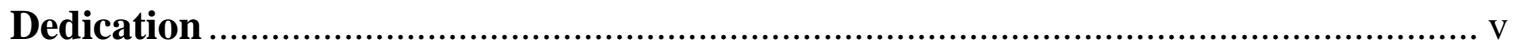

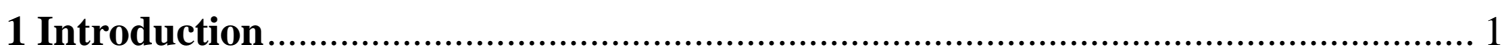

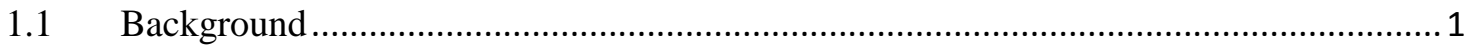

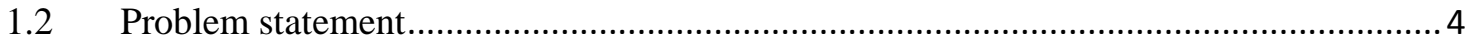

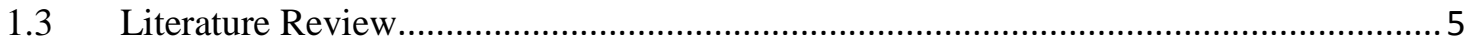

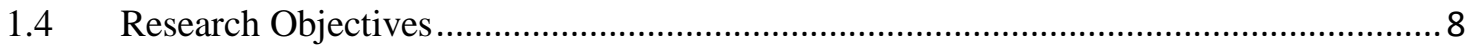

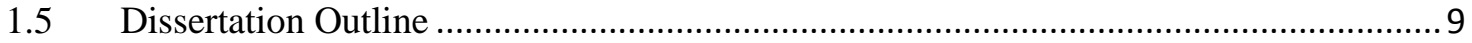

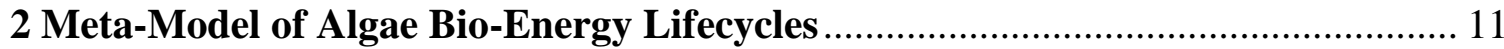

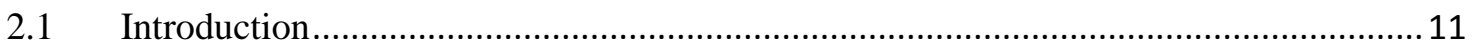

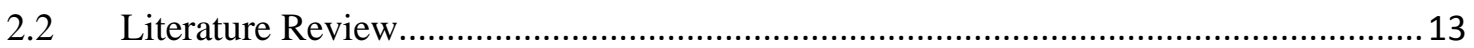

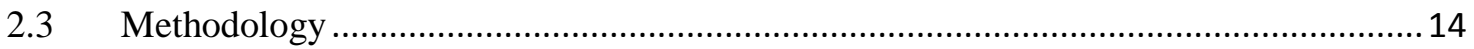

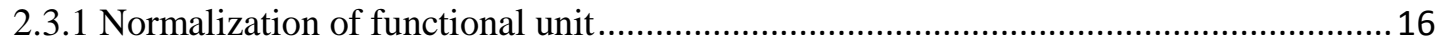

2.3.2 Standardizing upstream burdens and removal of co-product offsets ...........................20 


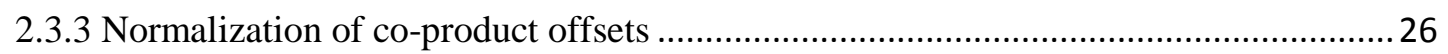

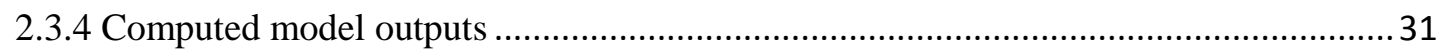

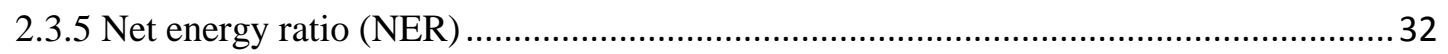

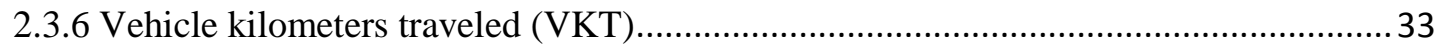

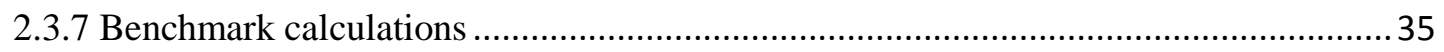

2.3.8 MABEL structure and model accessibility ............................................................... 36

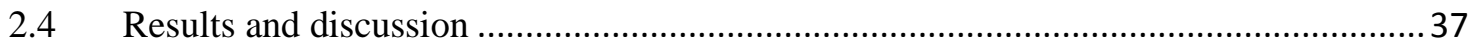

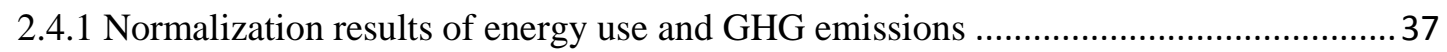

2.4.2 Energy use and GHG performance for four scenarios and comparison with terrestrial

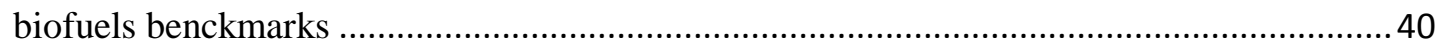

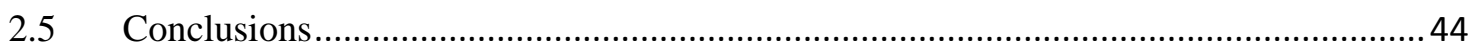

\section{Environmental Implications of Algal Liquid Fuels via Hydrothermal Liquefaction}

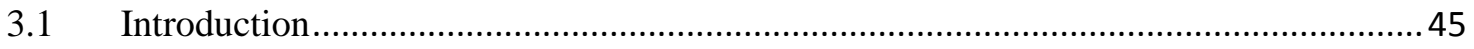

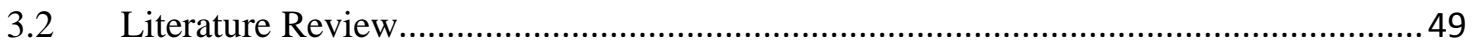

3.2.1 Hydrothermal liquefaction of algae ................................................................... 49

3.2.2 Direct air capture as $\mathrm{CO}_{2}$ supply source …......................................................... 50

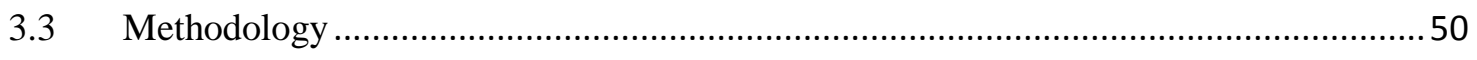

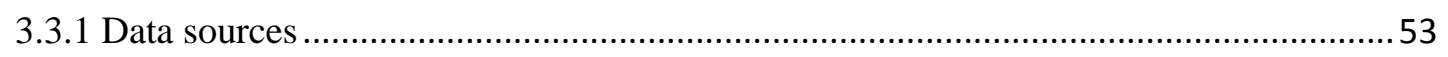

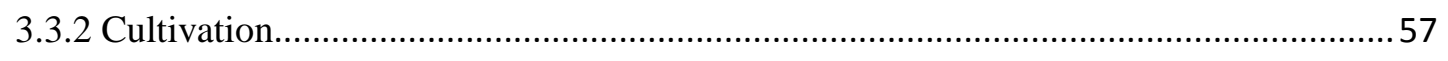




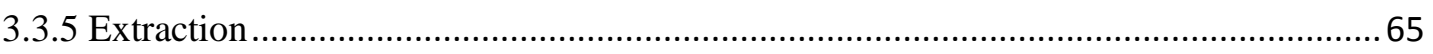

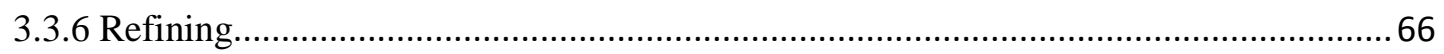

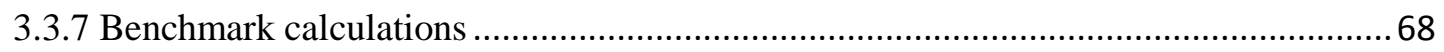

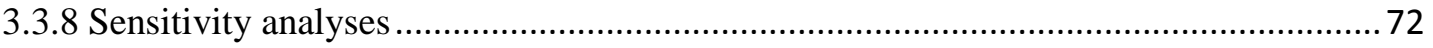

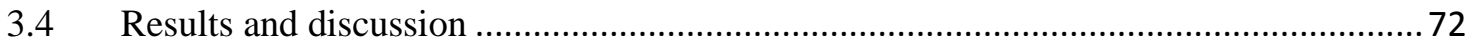

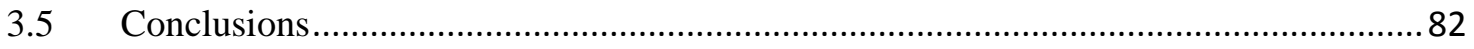

4 Historical Land Use Change: Implications for Biofuels Carbon Accounting ........ 84

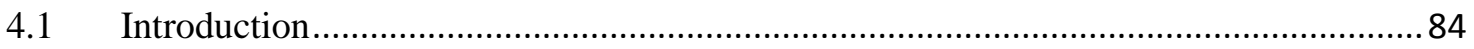

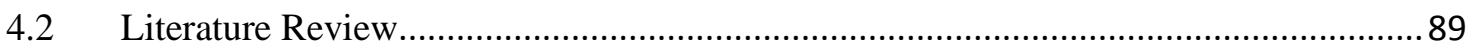

4.2.1 Carbon stocks of ecosystems and time profiles of carbon release ..............................90

4.2.2 Time-dependent effects on biofuel's GHG emissions and $\mathrm{CO}_{2}$ decay in the atmosphere

4.2.3 Current ILUC modeling approaches in biofuel policies and uncertainty of such estimates

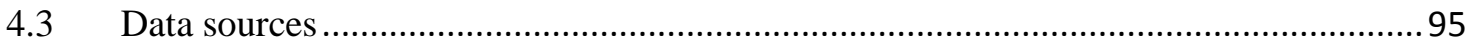

4.3.1 Historical cropland dataset and global vegetation land cover dataset...........................95

4.3.2 Carbon stocks in various ecosystems ............................................................... 96

4.3.3 Selected regions \& energy yield ..................................................................... 98 


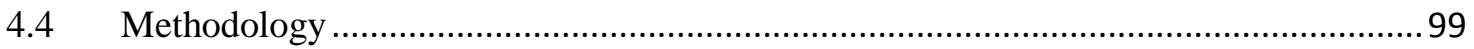

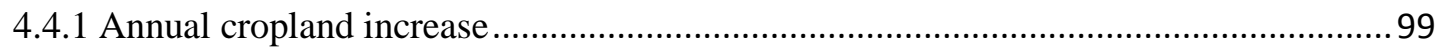

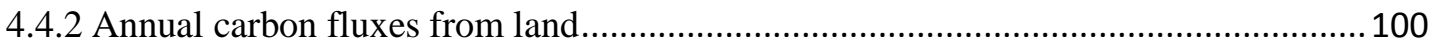

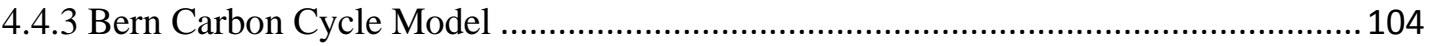

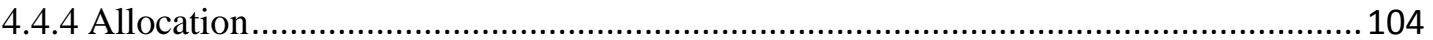

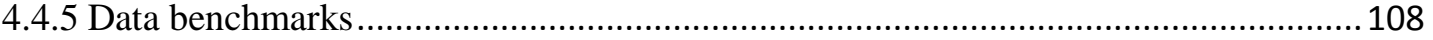

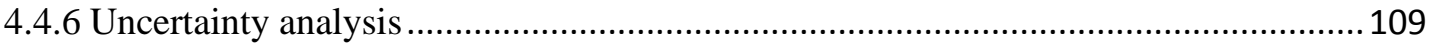

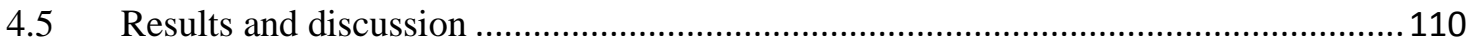

4.5.1 HLUC estimates - base case (US corn ethanol at IL) ........................................... 110

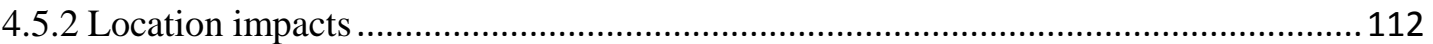

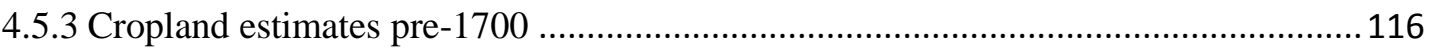

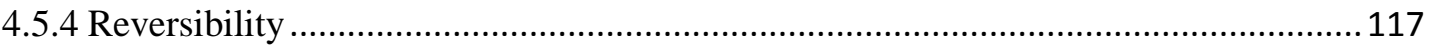

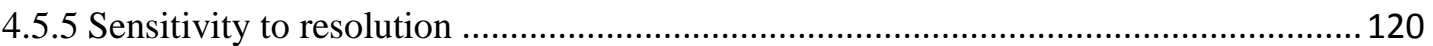

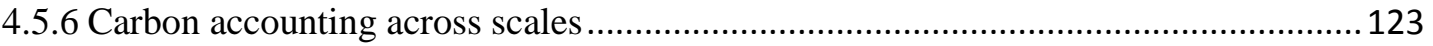

5 Life Cycle Burdens of $\mathrm{CO}_{2}$ Supply Sources...................................................... 124

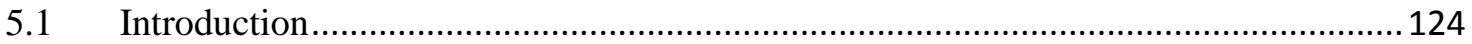

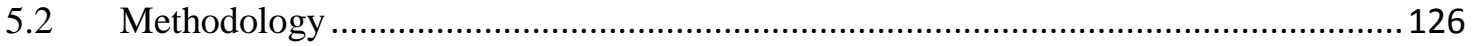

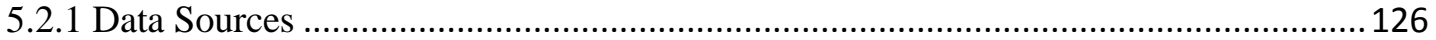

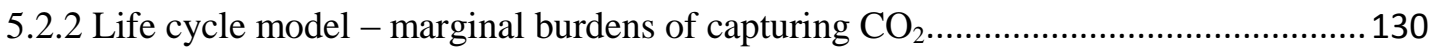

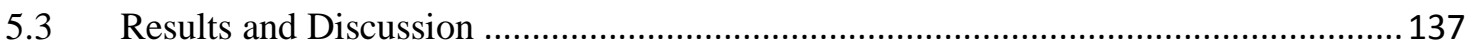




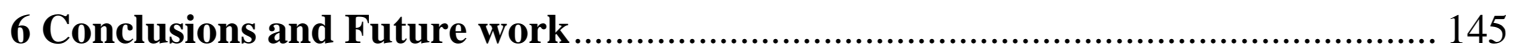

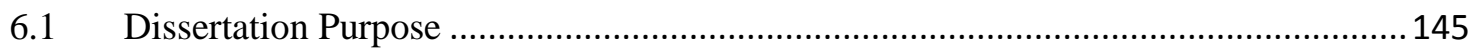

6.2 Conclusions and Major Contributions …........................................................... 146

6.2.1 Environmental performance of algae biodiesel.................................................... 146

6.2.2 Environmental performance of algae biofuels produced via hydrothermal liquefaction

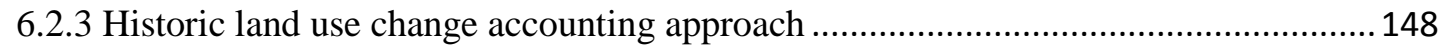

6.2.4 Carbon deserts and lifecycle burdens of different $\mathrm{CO}_{2}$ supply sources ...................... 148

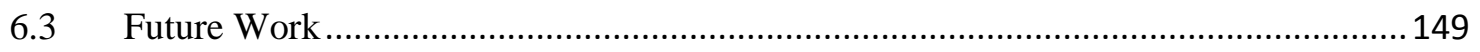

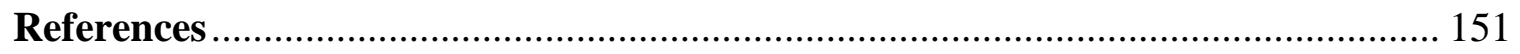

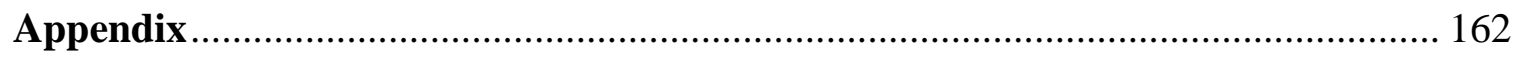




\section{List of Figures}

2.1 Scope of most algae LCA studies published to date

2.2 MABEL standardization of greenhouse gas emissions and energy use.

2.3 Smaller green circles depict net energy ratios and greenhouse gas (GHG) emissions associated with production of $1000 \mathrm{~L}$ algae biodiesel.

2.4 Net energy ratios and GHG emissions per kilometer traveled of four modeled scenarios in

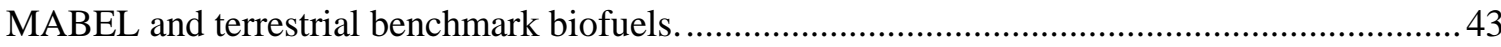

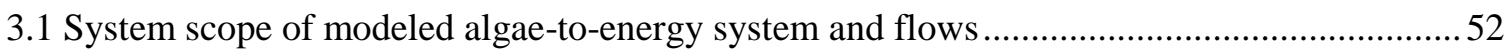

3.2 The EROI ratio and GHG emissions/MJ of algae-derived diesel and algae-derived gasoline

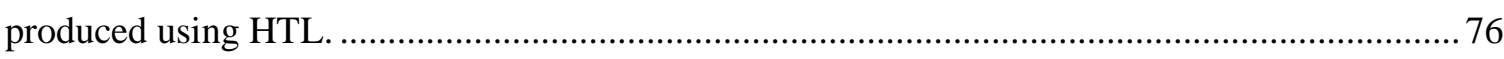

3.3 Energy use and GHG emissions per barrel biocrude.

3.4 Tornado plots from sensitivity analyses showing factors driving EROI and GHG emissions 82

4.1 Historical cropland and annual emissions estimates for this activity based on carbon intensity.

4.2 Methods for allocating burdens between current biofuels production and historical agricultural activity 105

4.3 HLUC distributions for six biofuel-producing regions around the world for different fuel types. 
4.4 HLUC probability distributions for ethanol, biodiesel from rapeseed and biodiesel from palm

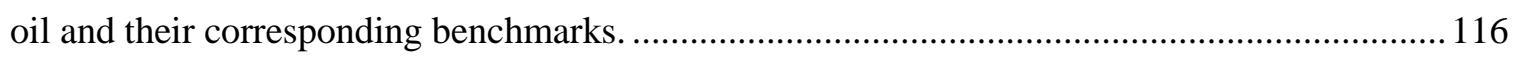

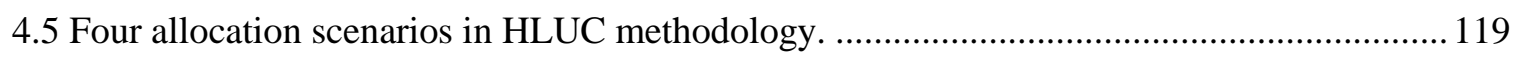

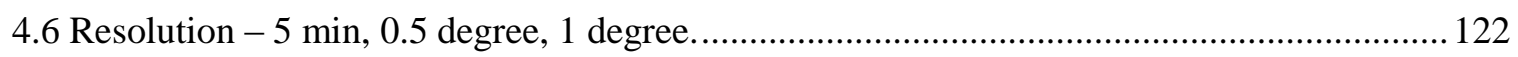

4.7 Comparison of HLUC model results with different resolutions. ....................................... 123

5.1 Sources of high-purity $\mathrm{CO}_{2}$ in the United States (U.S. EPA 2014) ................................. 128

5.2 Individual $\mathrm{CO}_{2}$ source in the United States plotted in terms of $\mathrm{CO}_{2}$ production potential relative to the number of facilities with this capacity......................................................... 129

5.3 Processes of pre-treating $\mathrm{CO}_{2}$ to be transported in pipelines........................................... 133

5.4 Map of the United States showing all commercial sources of $\mathrm{CO}_{2}$ and the quantity of $\mathrm{CO}_{2}$

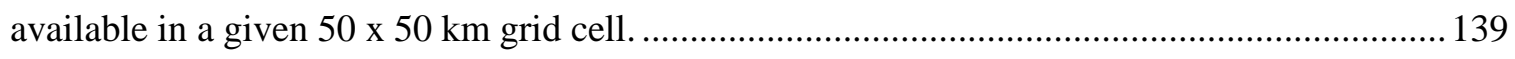

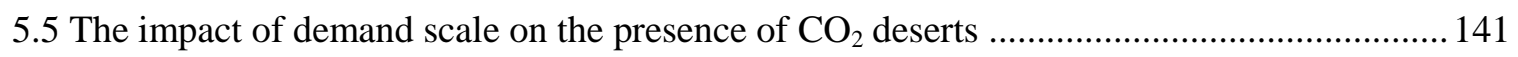

5.6 Regional pipeline networks have the capacity to alleviate some of the constraints associated with carbon deserts in the south central United States.......................................................... 142 


\section{List of Tables}

2.1 Summary of functional unit and relevant data from six algae system-level studies included in

MABEL.

2.2 Summary of meta-model results after normalization of each author's published data to a common functional unit, $1000 \mathrm{~L}$ biodiesel.

2.3 Environmental impacts of algae cultivation inputs

2.4 Adjustments required to transit from left to central bar grouping in Figure 2.2 …................25

2.5 Summary of meta-model results after standardization of upstream burdens and removal of co-

product offsets.

2.6 Parameters used to calculate the yields of bioelectricity generated via anaerobic digestion of algae non-lipid fractions.

2.7 Summary of calculations for various co-product offsets derived from anaerobic digestion of non-lipid algae biomass.

2.8 Components of the overall co-product adjustment for the MABEL-standardized anaerobic digestion process.

2.9 Summary of model results after normalization of co-product.

3.1 Input parameters of the three scenarios

3.2 Impact factors of energy and material inputs

3.3 Flow rates, algae concentration and mass balance - 'pilot-scale' scenario 
3.5 Nitrogen balance (lb) in the 'pilot-scale' scenario

3.7 Energy inputs to the fluid catalytic cracking unit (per bbl feed)

3.8 Energy inputs to fluid catalytic cracking unit (per bbl feed)

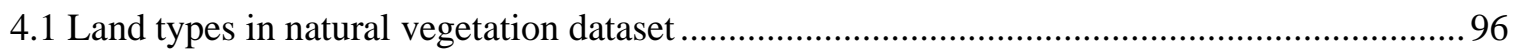

4.2 Carbon stocks in vegetation of different land types in HLUC model ....................................97

4.3 Carbon stocks in topsoil of different land types in HLUC model.......................................97

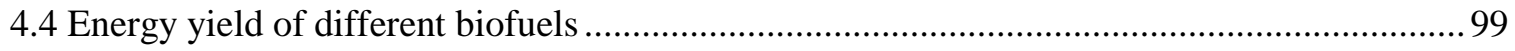

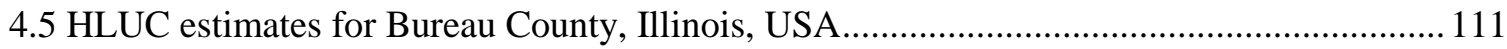

4.6 HLUC results of population derived historical cropland data ............................................ 117

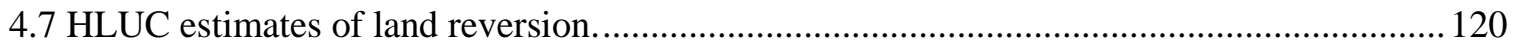

5.1 Values corresponding to material and energy flows in Figure 5.1 ..................................... 136

5.2 Summary of marginal life cycle burdens for capturing $\mathrm{CO}_{2}$ from four sources ................... 137 


\section{Chapter 1}

\section{Introduction}

\subsection{Background}

Large-scale anthropogenic activity, especially production of energy, has caused a series of vexing environmental challenges, notably climate change and dramatic reductions in biodiversity because of land-use patterns (1). Most energy comes from fossil fuels and when these are burned, significant amount of greenhouse gases (GHGs) are released to the atmosphere, which drives climate change and the depletion of natural resources including water resources (2). In addition to these serious environmental issues, society is facing a variety of other challenges related to our energy systems including the national security of our supply given that most of the fuels are imported (3). What is more, there is increasing concern that our rapid consumption of various energy forms will

ultimately exhaust their availability. The transportation sector, which accounts $\sim 30 \%$ of 
the total energy consumption (4), depends heavily on liquid fuels that are primarily derived from petroleum crude, which is especially limited in quantity and more difficult to recover from the environment than solid or gaseous fuels.

Vehicles that rely on gasoline and diesel dominate the transportation sector. Electric vehicles are being increasingly deployed though they still represent an insignificant portion of the market. Conventional liquid fuels, such as gasoline, diesel and jet fuel, are derived from petroleum crude (5). In the past decade, hydraulic fracturing technology has enabled the extraction of massive volumes of shale gas and oil, which have altered the domestic energy landscape. The fossil fuels coming from shale formations are being treated by many as a transition fuel that will give us the time to develop carbon neutral options that are sustainable in the long term.

Considerable research attention is being directed toward developing renewable energy technologies that can mitigate carbon emissions and achieve energy independence (6-9). Biofuels are considered ideal alternatives to traditional transportation fuels because of their energy density and their potential to reduce GHG emissions. In the United States, corn ethanol is the most widely deployed biofuel (6). However, a series of problems have emerged associated with the broader implications of corn ethanol consumption and its impact on food markets, its technical blending limits with petroleum gasoline, and its effects on engines. Biodiesel derived from soybean is also popular in the United States though the market for diesel is much smaller. Corn butanol and other energy carriers are emerging but these face many of the same life cycle challenges that conventional corn ethanol does. 
The feedstocks for biofuel production vary depending on the target fuels and the maturity of the technology. The most common feedstock for ethanol in the United States is corn and sugarcane in Brazil (5). Other feedstocks that do not directly compete with food are drawing growing interest. For example, cellulosic biomass such as wood, sorghum and forest residue are all being developed but the technological and economic limits to these feedstocks prevent their large-scale deployment at present. Soybean is the most common feedstock for biodiesel production in the US while rapeseed and palm oil are feedstocks for biodiesel production in the European countries and South Asia, respectively. Algae biomass is considered an emerging and promising feedstock for generating liquid fuels that would address many of the limitations associated with terrestrial feedstocks (8).

Besides the potential to achieve energy independence, the deployment of algae biofuels is also motivated by the perspective advantages of algae cultivation, which does not require agricultural land and agricultural water. Algae biomass can be cultivated in either open ponds or photobioreactors with sufficient sun light, water, nutrients and $\mathrm{CO}_{2}$. The diluted algae biomass is then harvested and dewatered to achieve the concentration that is required for downstream fuel production. Examples of such harvesting/dewatering technologies are autoflocculation, dissolved air flotation, centrifugation, etc. The concentrated algae biomass then goes to conversion processes to produce fuel products. In the biomass conversion process, co-products are often generated and, as with terrestrial crops like corn ethanol where the dry distillers grain greatly impact price, these coproducts can significantly impact the economics and overall environmental footprint of 
the overall process. Typical algae biomass conversion pathways are: (1) lipid extraction followed by transesterification, (2) hydrothermal liquefaction, (3) pyrolysis, and (4) gasification. Hydrothermal liquefaction of algae is a pathway that is being developed by a leading algae biofuel producer, Sapphire Energy Inc. (SEI). SEI expects to scale up their process to commercial production in the coming five years.

In the midst of all the promise and investment in algae biofuels, considerable effort has been devoted to performing lifecycle analyses (LCA) of the environmental performance of algae biofuels. The conclusions of these studies are highly inconsistent due to differences in model assumptions, operational parameters, system boundaries, etc. This critical lack of understanding is impacting the development of rational policy frameworks that will allow our objectives, e.g., deployment of low carbon fuels, to be met.

\subsection{Problem statement}

The emergent algae-to-energy industry will face a number of technological bottlenecks before large-scale production becomes economically viable and environmentally sustainable. Existing efforts to characterize the lifecycle performance of algae-to-energy systems are inadequate in a number of ways and no consensus has been reached by the industry or about policy makers about whether to pursue algae as a biofuel feedstock and which pathway to adopt. The lack of existing commercial-scale facilities makes systems-level modeling especially difficult because of the lack of reliable field data. A comprehensive assessment of algae-to-energy processes is needed that can be 
used to better understand the existing literature, the direction the industry is moving, and the specific characteristics of this sector including its connection to $\mathrm{CO}_{2}$ supply chains and land use.

\subsection{Literature Review}

Over the past several years, there has been a boom in lifecycle analyses (LCA) of algae biofuels, which seek to characterize the environmental performance of these energy production systems. The first group of algae biofuel LCA publications was mainly focused on depicting the environmental profiles of algal biodiesel (10-14). These LCA studies failed to reach a consensus: some of them focused on the advantages of algal biodiesel as an emerging energy source while others pointed out important shortcomings in the accounting that could impact the footprint of algae-to-energy processing (15). A second generation of algae biofuel LCA publications has emerged during the past few years and these have focused on different pathways like the hydrothermal liquefaction (HTL) pathway that converts algae biomass to biocrude. Biocrude is a type of liquid fuel with similar characteristics as petroleum crude (16-18). Unlike the production of algal biodiesel, which is not being practiced on any large scale, a number of other conversion processes are being actively pursued by several large industry players including direct ethanol production (19), direct combustion (15).

Algae biomass can be converted to a variety of fuel products via different fuel production pathways. Algal biodiesel is generated via several steps with a key chemical reaction called transesterification. First the lipid portion of algae cells is released in a 
homogenization unit and extracted using organic solvent. Then the lipid is converted to biodiesel through transesterification (20). In contrast, direct combustion of algae biomass is an option that could be used as a substitute for coal or other fuels at stationary power sources even though the required moisture content of biomass is below $50 \%$ dry weight (21). Anaerobic digestion is a mature technology that converts organic materials to biogas consisting primarily of methane and $\mathrm{CO}_{2}$ with insignificant traces of gases such as $\mathrm{H}_{2} \mathrm{~S}$ (22). Hydrothermal liquefaction (HTL) is one of the thermochemical conversion processes that convert the entire algae cell into liquid fuel, rather than converting only the lipid portion. The HTL process employs reaction conditions at low temperature ( $\sim 300$ $350{ }^{\circ} \mathrm{C}$ ) and high pressure (5-10 MPa) (23). This conversion process is studied in detail in Chapter 3 of this dissertation. Pyrolysis converts algae biomass to several energy products including biocrude, syngas and biochar. Pyrolysis requires anoxic conditions, which are difficult to achieve in algae biomass in a dilute water stream, and medium to high temperature $\left(350\right.$ to $\left.700^{\circ} \mathrm{C}\right)(23)$. Gasification converts algae biomass to syngas as an energy product at very high temperatures $\left(800-1000^{\circ} \mathrm{C}\right)(24)$.

One of the main arguments for using algae biomass in the first place is that it uses land more efficiently and so it would not have the same land use impacts as terrestrial biofuels. This is a topic that has been heavily debated - that the potential carbon mitigation from biofuels production can be jeopardized by large amount of carbon release from land clearing $(25,26)$. Because of the unique characteristics of biofuels, the quantification of carbon emissions associated with land use change can involve various aspects in agriculture, economy and natural vegetation. Integrating these areas 
numerically is complex and the outcomes are highly uncertain. The methodologies of computing land use change can be classified into two basic categories: direct land use change (DLUC) and indirect land use change (ILUC), which is the approach most adopted presently. Searchinger et al. (25) conducted extensive computation of land use change using the ILUC approach, which consists primarily of global agro-economic models, and he concluded that GHG emission profiles of biofuels will be higher than petroleum fuels. Nevertheless, the results from such models are highly uncertain. Plevin et al. developed a reduced-form model to capture the wide bounding range of emissions from US corn ethanol production, which is $10-340 \mathrm{gCO}_{2} / \mathrm{MJ}$ (27). In contrast, DLUC estimates are generally more certain to estimate but much less commonly encountered in practice (28).

Another factor that has been found to significantly impact the carbon footprint of algae biomass is the GHG emission profile of the $\mathrm{CO}_{2}$ that is used to supply the ponds. Therefore, identifying $\mathrm{CO}_{2}$ sources with lower lifecycle burdens is as important as overcoming technological bottlenecks. Currently in the U.S., there are primarily five industrial sectors supplying $\mathrm{CO}_{2}$ as a product to the market: ammonia plants, hydrogen plants, acid gas removal unit in natural gas processing, natural $\mathrm{CO}_{2}$ wells and ethanol plants (29). The lifecycle performance of some of these $\mathrm{CO}_{2}$ sources has been studied but there remain significant holes in the literature and no comprehensive evaluation of the $\mathrm{CO}_{2}$ supply chain has been published (30). The availability and quantity of $\mathrm{CO}_{2}$ suppliers are also factors in the site selection of algae cultivation facilities. Recently, EPA began releasing this information and so now facility-scale data is available for all industrial 
suppliers of $\mathrm{CO}_{2}$ around the country (31). When coupled with life cycle inventory results, this production data could provide a much-needed perspective on the landscape for supplying large volumes of $\mathrm{CO}_{2}$ to algae cultivation facilities.

\subsection{Research Objectives}

The overall objective of this dissertation is to understand current algal biofuels production systems, estimate greenhouse gas emissions and energy return on investment ratio of algae-to-energy systems, and analyze the broader land use and $\mathrm{CO}_{2}$ supply chain implications on the environmental performance of algal liquid fuels production. Using life cycle analysis and related methodologies, I explored four specific elements of advanced biofuels and their climate implications via:

- An open-source environmental life cycle meta-model of conventional algal biodiesel systems used to provide a clear understanding of how algae compare to conventional biofuel benchmarks;

- A life cycle model of the production system of algal liquid fuels using HTL based on field pilot-scale data from Sapphire Energy Inc.;

- A new method for accounting for land use change-related GHG emissions based on historical cropland data to improve the ease and reduce the uncertainty associated with these types of estimates;

- Quantify the life cycle burdens of different $\mathrm{CO}_{2}$ supply sources and identify regions that are incapable of providing sufficient $\mathrm{CO}_{2}$ to industrial consumers such as EOR facilities and algae cultivation facilities. 


\subsection{Dissertation Outline}

In this dissertation, Chapter 1 provides a broad overview of the current research efforts in the algae-to-energy space and describes the framework of this study. Chapter 2 describes a meta-analysis of previous life cycle studies with a focus on dry extraction and transestrification as conversion process. This meta-model incorporated six widely cited life cycle analyses of algal biodiesel and investigated the disparities in their results that were derived from different system scopes and model assumptions. Four scenarios are defined based on different $\mathrm{CO}_{2}$ supply strategies and coproducts. It provides insights to the modeling efforts of algae biodiesel production system and reflects on the bottlenecks of this technology.

In Chapter 3, the environmental impacts of an industrialized algae biomass conversion process - hydrothermal liquefaction - are estimated in a life cycle analysis. Algal diesel and algal gasoline are the fuel products from this process and they are benchmarked with traditional biofuels as well as their petroleum equivalents. Three sets of input data (i.e., lab and literature data, field data from a pilot scale facility, large scale with data projected from a professional at a leading algal biofuel company) enable the forecast of future development of algal liquid fuels.

In Chapter 4, a new method of accounting for land use change effects of biofuels production are developed using historical cropland data and original natural vegetation. The carbon emissions of terrestrial biofuels at any given locations can be estimated using 
this method. The result is a direct carbon accounting approach as an alternative to the indirect land use change method, which is currently applied in policy decisions.

In Chapter 5, the marginal life cycle impacts of various $\mathrm{CO}_{2}$ supply processes are quantified to determine 'cleaner' $\mathrm{CO}_{2}$ sources. ' $\mathrm{CO}_{2}$ deserts' are defined as regions where there is insufficient $\mathrm{CO}_{2}$ supply relative to demand. Model results provide insights into reducing total life cycle GHG emissions in the algal biofuels production and the site selection of algae cultivation facilities.

Chapter 6 concludes the major findings of this dissertation research and provides directions for future research. 


\section{Chapter 2}

\section{Meta-Model of Algae Bio-Energy Lifecycles}

\subsection{Introduction}

Over the past several years, a number of studies have appeared in the academic literature reporting on the life cycle environmental impacts of algae-to-energy systems (8, 10, 12). These papers have resulted from the great popular interest in algae as a biofuel feedstock and real questions about the environmental costs and opportunities that algae cultivation would incur. As discussed in Chapter 1, there are many pathways that can be used to turn algae biomass into fuel but the LCA community has been largely focused on one (Figure 2.1). In that pathway, algae are cultivated in open ponds, the lipid fraction is converted into biodiesel via transesterification, and the residual biomass is transformed 
into some useful byproduct (32-34). Interestingly, there is a large amount of discrepancy between the findings of the different papers and so this first study was predicated on normalizing or harmonizing the results of these studies to produce a more realistic depiction of algae's anticipated environmental footprint.

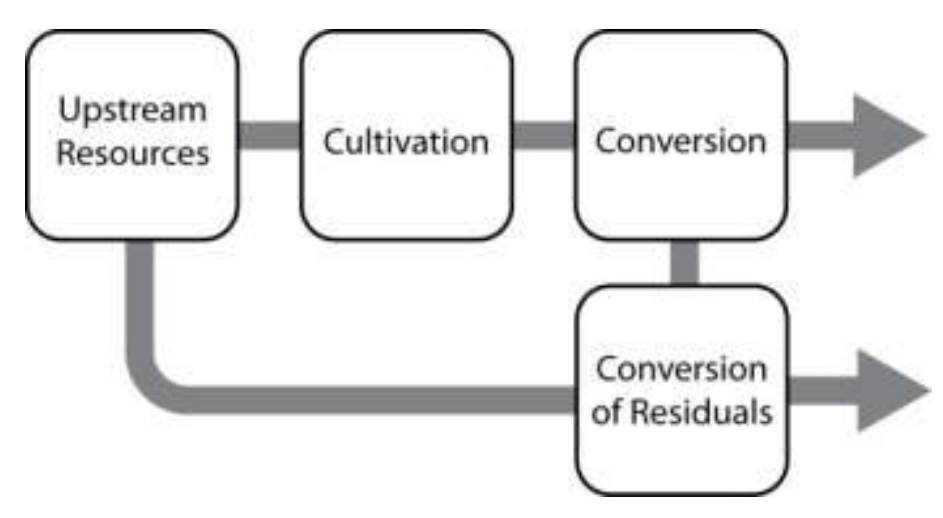

Figure 2.1 Scope of six algae LCA studies published to date. Upstream resources (e.g., fertilizer, $\mathrm{CO}_{2}$, etc.) are needed for algae cultivation, and residual non-lipid biomass is generally converted into certain usable co-product (e.g., bioelectricity).

Of the six algae-to-energy LCA papers that appeared in the academic literature between 2008 and 2010, all have seemingly disparate conclusions. Some of the studies suggest that algae-derived energy has significantly lower life cycle impacts than petroleum-based fuels or terrestrial crop benchmarks. Others have argued that important technological improvements are needed to substantially reduce the burdens of algaederived energy and allow such systems to reach their full potential. It is hypothesized that seeming disparities among published results could be attributed to methodological differences in system boundaries, scope, and modeling assumptions, rather than a fundamental lack of understanding of how these systems will perform. Overcoming these methodological differences could enable better understanding of algae's potential as a 
low carbon intensity bioenergy source and streamline comparison with well-studied conventional biofuels (9). The current lack of understanding about algae's potential as a feedstock for low carbon biofuels has arisen in the wake of seemingly conflicting life cycle assessment (LCA) results. This resembles the circumstances which gave rise to the ERG Bioenergy Meta-Model (EBAMM) in 2006 (6). At that time, it was unclear how corn-derived ethanol compared to petroleum fuels on the basis of life cycle energy use and greenhouse gas (GHG) emissions, because six independent LCA analyses had generated seemingly conflicting results $(2,6,7)$. EBAMM incorporated raw data from each of these analyses into a standardized modeling approach to generate composite estimates for both energy use and GHG emissions, ultimately showing that corn ethanol provides modest environmental benefits compared to conventional petroleum: on the order of 33\% reductions in net energy and smaller reductions in GHG emissions. The research work in this chapter describes the development of an analogous model for algaeto-energy production, the Meta-Model of Algae Bio-Energy Life Cycles (MABEL).

\subsection{Literature Review}

Despite the unique advantages of algae cultivation compared with biofuels from traditional feedstocks, recent papers have drawn different conclusions when analyzing algae biofuels from a life cycle perspective. Lardon et al. (12) concluded that microalgae are environmentally favorable as an energy source by comparing four scenarios involving different fertilizer supply and extraction process. Sander and Murthy (11) pointed out that a major obstacle was the dewatering process, which requires a large amount of energy. They stated that new technologies are needed to make algal biofuel a sustainable and 
commercial reality. Campbell et al (13) analyzed the potential environmental impacts and economic viability of algal biodiesel and found that when grown in open ponds in near coastal conditions using saline water, algae could be a viable source of biomass for biofuels. They found out the GHG emissions of algal biodiesel are very favorable yet it is not economically attractive compared with canola and ultra low sulfur diesel (ULSD). Jorquera et al (14) compared the net energy ratios of raceway open pond system with photobioreactors as cultivation processes and conclude that neither system is currently competitive with petroleum. Clarens et al (8) compared several environmental impacts of algae biomass with those from three conventional biofuel feedstocks and their results indicated that algae only perform favorably in total land use and eutrophication potential. Stephenson et al (10) examined the global warming potential (GWP) and fossil-energy requirement of algal biodiesel production systems with typical raceway ponds and tubular bioreactors as cultivation systems. Their analysis shows that the GWP from raceway ponds is about $80 \%$ lower than fossil-derived diesel. Several other papers also studied the environmental impacts from different aspects such as water use and nutrients balance (35), more efficient biomass harvest process (36).

\subsection{Methodology}

To overcome the disparities between these papers, this chapter develops a MetaModel of Algae Bio-Energy Life Cycles (MABEL). MABEL reports fuel cycle energy use and greenhouse gas (GHG) emissions (expressed as global warming potential (GWP)) based on data from six previously published algae life cycle assessment (LCA) studies (10-15). Life cycle inventory data corresponding to energy/materials 
manufacturing, cultivation in open ponds, conversion of algae lipids into biodiesel, and production of a useful co-product were extracted from each paper and used as inputs for four standardized cases. In each case, the functional unit is $1000 \mathrm{~L}$ of biodiesel produced from algae lipids. Two $\mathrm{CO}_{2}$ supply strategies were modeled (industrial $\mathrm{CO}_{2}$ or flue gas) and two coproduct assumptions (no coproduct or bioelectricity via anaerobic digestion as coproduct) were defined to generate four scenarios through which interpret the results of this work:

- Scenario 1. Algae cultivation using industrial $\mathrm{CO}_{2}$, produced via steam reforming of hydrocarbons (the current industry standard), with anaerobic digestion of residual (non-lipid) algae biomass to produce methane-derived bioelectricity as a co- product. This scenario constitutes the "base case".

- Scenario 2. Algae cultivation using industrial $\mathrm{CO}_{2}$, produced via steam reforming of hydrocarbons, for algae cultivation without production of any co-product.

- Scenario 3. Algae cultivation using recycled and compressed flue gas from coal fire power plant as $\mathrm{CO}_{2}$ source without production of a co-product.

- Scenario 4. Algae cultivation using recycled and compressed flue gas from coal fire power plant as a $\mathrm{CO}_{2}$ source with anaerobic digestion of residual (non-lipid) algae biomass to produce methane-derived bioelectricity as co-product.

Life cycle data of GHG emissions and energy consumption were abstracted from six selected LCA papers and individual models were deconstructed for normalization. Other published algae LCAs, most notably $(19,37)$, were excluded from the analysis 
because their process streams were dramatically different from the scheme depicted in Figure 2.1. These studies deviated from Figure 2.1 primarily because they modeled the use of photobioreactors as the algae cultivation configuration. Several of these papers included here provide direct comparisons between open ponds and photobioreactors (10, 14). Since these papers conclude that photobioreactors are generally untenable from a life cycle perspective, these systems were not included in MABEL for benchmarking against terrestrial biofuels.

Three steps were taken in normalization to a system scope defined in Figure 2.1. First, results of the six studies were normalized to a common functional unit of $1000 \mathrm{~L}$ algal biodiesel. Then assumptions about upstream burdens, nutrients and $\mathrm{CO}_{2}$ supply, were standardized. Last co-product allocation was standardized based on the potential direction of the algae biofuels industry. Details of the model construction can be found in Liu et al. (2012)(38) and in the supplemental information of that paper. The GHG emissions and energy consumption of corn ethanol in EBAMM (6) and the burdens of soybean biodiesel from Hill's 2006 study (9), both widely cited meta-analyses, were normalized on an energy basis here and used as a benchmark.

\subsubsection{Normalization of functional unit}

To make the results of all six LCA studies directly comparable, it was first necessary to apply a standardized functional unit (FU). This is because each of the six original LCAs used a different FU, which makes it impossible to plot all of the results on the same axes. The FU chosen for this analysis was $1000 \mathrm{~L}$ algal biodiesel, in consistency 
with three of the four studies in which authors accounted for conversion of the raw algae biomass into a usable energy carrier. Two studies did not identify a usable energy carrier. This consistency in FU maximized the amount of original LCA data that could be used in the meta-model and also facilitated more meaningful comparisons with published LCA data for two currently-deployed liquid biofuels: soybean-derived biodiesel and cornderived ethanol. Table 2.1 summarizes each paper's original functional unit and reported values for several key biomass and biodiesel characteristics.

Table 2.1 Summary of functional unit and relevant data from six algae system-level studies included in MABEL.

\begin{tabular}{|l|r|r|r|r|r|}
\hline \multicolumn{1}{|c|}{ Study } & Original FU & $\begin{array}{r}\text { Biodiesel } \\
\text { volume } \\
\text { embodied by } \\
\text { original FU (L) }\end{array}$ & $\begin{array}{r}\text { Biodiesel } \\
\mathrm{HHV}^{\mathrm{b}}\end{array}$ & $\begin{array}{r}\text { Biodiesel } \\
\text { density } \\
(\mathrm{kg} / \mathrm{L})\end{array}$ & $\begin{array}{c}\text { Algae } \\
\text { lipid } \\
\text { content }\end{array}$ \\
\hline Lardon et al. & $\begin{array}{r}1 \mathrm{MJ} \text { as } \\
\text { biodiesel }\end{array}$ & 0.03 & $\begin{array}{r}37.8 \\
\mathrm{MJ} / \mathrm{kg}\end{array}$ & $\mathrm{N} / \mathrm{A}$ & $38.5 \%$ \\
\hline Clarens et al. & $\begin{array}{r}317 \mathrm{GJ} \text { as } \\
\text { biomass }\end{array}$ & 5311 & $\mathrm{~N} / \mathrm{A}$ & $\mathrm{N} / \mathrm{A}$ & $21 \%$ \\
\hline Campbell et al. & $\begin{array}{r}1 \text { tonne-km in } \\
\text { a diesel truck }\end{array}$ & 0.027 & $\mathrm{~N} / \mathrm{A}$ & $\mathrm{N} / \mathrm{A}$ & $\mathrm{N} / \mathrm{A}$ \\
\hline $\begin{array}{l}100 \mathrm{Mg} \\
\text { biomass }\end{array}$ & 32900 & $\begin{array}{r}35.1 \\
\mathrm{MJ} / \mathrm{L}\end{array}$ & $\mathrm{N} / \mathrm{A}$ & $29.6 \%$ \\
\hline $\begin{array}{l}\text { Sander } \\
\text { Murthy }\end{array}$ & $\begin{array}{r}1000 \mathrm{MJ} \text { as } \\
\text { biodiesel }\end{array}$ & 27.9 & $\begin{array}{r}41.2 \\
\mathrm{MJ} / \mathrm{kg}\end{array}$ & 0.88 & $30 \%$ \\
\hline $\begin{array}{l}\text { Stephenson et } \\
\text { al. }\end{array}$ & $\begin{array}{r}1000 \mathrm{~kg} \\
\text { biodiesel }\end{array}$ & 1136 & $\begin{array}{r}37.2 \\
\mathrm{MJ} / \mathrm{kg}\end{array}$ & $\mathrm{N} / \mathrm{A}$ & $40 \%$ \\
\hline
\end{tabular}

${ }^{\mathrm{a}} \mathrm{FU}$ - Functional unit; ${ }^{\mathrm{b}} \mathrm{HHV}$ - high heating value; ${ }^{\mathrm{c}} \mathrm{N} / \mathrm{A}$ - not reported in the original study

Lardon, Sander, and Stephenson used biodiesel-based FUs in their original studies; however, Lardon and Sander used an energy basis, while Stephenson used a mass basis. Lardon's and Sander's original FUs were converted from energy basis to volume 
basis using their respective biodiesel high heating values (HHV) and an estimated biodiesel density of $0.88 \mathrm{~kg} / \mathrm{L}$. This density figure represents the average of two reported values, one from Sander and the other from a US government report on biodiesel (11, 39). Stephenson's original FU was converted from mass basis to volume basis using the same estimated biodiesel density. Following conversion of all three FUs to volume basis, energy use and GHG emissions results from each paper were multiplied by a scaling factor equal to the common functional unit $(1000 \mathrm{~L})$ divided by their original functional unit expressed on a volume basis. In this way, results from these three studies were used directly to generate estimates of how much energy use and GHG emissions are required to produce $1000 \mathrm{~L}$ of algae-derived biodiesel.

Alternative normalization strategies were used for the three papers that did not originally use a biodiesel FU. For Campbell, it was necessary to convert from an implicit energy basis (1 tonne-km) to an explicit energy basis using their reported equivalency factor: 1 tonne-km comprises $0.89 \mathrm{MJ}$ diesel energy. This FU was then converted from an energy basis to a volume basis using a biodiesel $\mathrm{HHV}$ of $37.8 \mathrm{MJ} / \mathrm{kg}$ (the average of reported values from Lardon, Jorquera, Sander, and Stephenson because Campbell did not specify a value) and $0.88 \mathrm{~kg} / \mathrm{L}$ for biodiesel density. Campbell, Clarens, and Jorquera did not report energy use for conversion of raw biomass into biodiesel, so it was necessary to append a conversion model based on the protocol of Clarens et al onto their reported cultivation-phase burdens. Lipid contents were first used to determine what amount of each author's biomass would be required to produce $1000 \mathrm{~L}$ of algae biodiesel. An average from all four other papers was used for the Clarens analysis and Campbell 
analysis because these two papers did not report a specific value for lipid content. It should be emphasized that cultivation and biomass data from the original papers (e.g., yields, lipid content, presumed stoichiometry, etc.) were used wherever possible when estimating conversion-phase burdens, so that modeling differences among the original LCA papers would remain largely intact despite the standardized modeling framework.

For those studies in which multiple cultivation and/or conversion analyses were compared within a single analysis, energy use and GHG emissions data corresponding to each author's best-case scenario were selected for use in MABEL. These values were used in the FU normalization and scaling procedures described above. For Lardon, metacalculations correspond to data from the "low-nitrogen, wet extraction" scenario. For Clarens, meta-calculations correspond to data from the "base case in Virginia" scenario. For Campbell, his " $100 \% \mathrm{CO}_{2}$ from adjacent ammonia plant" scenario was used. For Jorquera, meta-calculations correspond to data from the "raceway pond" scenario, although, this was because photobioreactor systems were excluded from MABEL analysis. For Sander, meta-calculations correspond to his "filter press primary dewatering" case. For Stephenson, meta-calculations correspond to her "raceway growth using nitrogen-deprivation methods" scenario. Table 2.2 summarizes MABEL results after FU normalization (assuming Scenario 1).

Table 2.2 Summary of meta-model results after normalization of each author's published data to a common functional unit, $1000 \mathrm{~L}$ biodiesel. Energy values correspond to left grouping in Figure 2.2.

\begin{tabular}{|l|lr|lr|}
\hline Study & $\begin{array}{l}\text { Energy } \\
\text { (GJ) }\end{array}$ & use & $\begin{array}{l}\text { GHG } \\
(\mathrm{kg})\end{array}$ & emissions \\
\hline Lardon & \multicolumn{14}{|c}{} & 14 & 4009 \\
\hline
\end{tabular}




\begin{tabular}{|l|r|r|}
\hline Clarens & 65 & 8661 \\
\hline Campbell & 1 & -1066 \\
\hline Jorquera & 22 & N/A \\
\hline Sander & -237 & -763 \\
\hline Stephenson & 6 & 627 \\
\hline
\end{tabular}

\subsubsection{Standardizing upstream burdens and removal of co-product offsets}

Several of the papers modeled here demonstrated that production of cultivationphase material inputs is a significant driver of energy use and GHG emissions for algaeto-energy systems $(8,32)$. Still, some of the papers did not fully account for upstream burdens associated with procurement of carbon dioxide and nitrogen/phosphorus fertilizers. For this reason, the next step of MABEL standardization was manual realignment of all system boundaries to include manufacture of as much $\mathrm{CO}_{2}$ and fertilizer as is required to produce the amount of biomass corresponding to $1000 \mathrm{~L}$ biodiesel in each study. These quantities were computed based on each author's own estimations of how much nitrogen, phosphorus, and $\mathrm{CO}_{2}$ are required per functional unit, or their assumed algae molecular composition and nutrient use efficiency. Lardon provided biomass fractions comprising lipids, proteins, and carbohydrates, and also provided $\mathrm{CO}_{2}$ and $\mathrm{Ca}\left(\mathrm{NO}_{3}\right)_{2}$ requirements for his selected algae strain. Campbell indicated the mass of algae required per his functional unit and also reported the mass of fertilizer required to produce this amount of biomass. Stephenson reported her algae stoichiometry as $\mathrm{CH}_{1.83} \mathrm{O}_{0.48} \mathrm{~N}_{0.11} \mathrm{P}_{0.01}$, but also directly noted what quantities of nitrogen 
and phosphorus would be required. Because Clarens, Sander and Jorquera reported neither their assumed algae stoichiometry nor how much fertilizers would be needed, these quantities for these three papers were computed using the so-called Redfield Ratio, $\mathrm{C}_{106} \mathrm{H}_{181} \mathrm{O}_{45} \mathrm{~N}_{15} \mathrm{P}$ (40). It was also assumed that fertilizers are used optimally (amount added is exactly the amount required), as noted by Lardon. Environmental burdens were computed for three possible fertilizer procurement strategies to determine which combination of chemical fertilizers is associated with the lowest environmental footprint. The three strategies are as follows: (1) $\mathrm{H}_{12} \mathrm{~N}_{3} \mathrm{O}_{4} \mathrm{P}$ provides sufficient $\mathrm{P}$ and partial $\mathrm{N}$, with supplemental $\mathrm{N}$ delivered as urea; (2) urea provides $\mathrm{N}, \mathrm{CaH}_{2} \mathrm{P}_{2} \mathrm{O}_{8}$ provides $\mathrm{P}$; and (3) $\mathrm{H}_{12} \mathrm{~N}_{3} \mathrm{O}_{4} \mathrm{P}$ provides sufficient $\mathrm{N}$ and excess $\mathrm{P}$ (assuming stoichiometry of $\left.\mathrm{CH}_{1.83} \mathrm{O}_{0.48} \mathrm{~N}_{0.11} \mathrm{P}_{0.01}\right)$. The third strategy was found to be best overall when considering both life cycle energy use and GHG emissions performance, so this strategy was used to assign environmental burdens for standardized nutrient procurement in MABEL. Life cycle inventory data for the selected fertilizer types and virgin $\mathrm{CO} 2$ are summarized in Table 2.3.

Table 2.3 Environmental impacts of algae cultivation inputs. Data are from Ecoinvent version 2.013, and slightly modified for units consistency or allocation where appropriate.

\begin{tabular}{|l|l|r|r|}
\hline \multicolumn{1}{|c|}{$\begin{array}{c}\text { Cultivation } \\
\text { Input }\end{array}$} & \multicolumn{1}{c|}{ Quantity } & \multicolumn{1}{c|}{$\begin{array}{c}\text { Energy Use } \\
(\mathrm{MJ} / \mathrm{kg})\end{array}$} & $\begin{array}{c}\text { GHG }\left(\mathrm{kg} \mathrm{CO}_{2}\right. \\
\mathrm{eq} / \mathrm{kg})\end{array}$ \\
\hline $\mathrm{CO}_{2}$ & $\begin{array}{l}\text { Per } 1 \mathrm{~kg} \\
\mathrm{CO}_{2}{ }^{\mathrm{a}}\end{array}$ & 4.2 & 0.8 \\
\hline $\mathrm{H}_{12} \mathrm{~N}_{3} \mathrm{O}_{4} \mathrm{P}$ & Per $1 \mathrm{~kg} \mathrm{~N}$ & 63 & 1.3 \\
\hline $\mathrm{Urea}$ & Per $1 \mathrm{~kg} \mathrm{~N}$ & 62 & 3.4 \\
\hline $\mathrm{Ca}(\mathrm{NO} 3)_{2}$ & Per $1 \mathrm{~kg} \mathrm{~N}$ & 62 & 1.3 \\
\hline $\mathrm{CaH}_{2} \mathrm{P}_{2} \mathrm{O}_{8}$ & Per $1 \mathrm{~kg} \mathrm{P}$ & 14.8 & 1.2 \\
\hline
\end{tabular}


${ }^{\text {a }} \mathrm{CO}_{2}$ impact factors from Ecoinvent have been multiplied by 0.5 to account for allocation between two products arising concurrently in approximately equal quantities $\left(\mathrm{CO}_{2}\right.$ and $\left.\mathrm{H}_{2}\right)$ from steam reforming of hydrocarbons to generate. The majority of the $\mathrm{H}_{2}$ consumed in the United States the US is used to generate ammonia; therefore, Ecoinvent models $\mathrm{CO}_{2}$ generation as a co-product of this process.

It was assumed that supplemental $\mathrm{CO}_{2}$ required to account for differences between stoichiometric $\mathrm{C}$ demand and as much $\mathrm{CO}_{2}$ demand as was modeled by each LCA author can be delivered in two different forms: industrial or recycled. Energy use and GHG emissions associated with industrial $\mathrm{CO}_{2}$ procurement were computed using database impact factors for commercial $\mathrm{CO}_{2}$, as produced via steam reforming of hydrocarbons. This is the primary source of industrial-grade carbon dioxide in most regions of the United States. Because this process creates roughly equal masses of both commercial $\mathrm{CO}_{2}$ and commercial $\mathrm{NH}_{3}, \mathrm{CO}_{2}$ impact factors were multiplied by 0.5 to reflect 50/50 mass allocation of process burdens between both products (Table 2.3). Electricity demand for flue gas compression to deliver recycled $\mathrm{CO}_{2}$ from power plants was computed using Equation 2.1.

$$
W_{C}=\frac{C_{P} T_{i}}{\eta}\left[\left(\frac{p_{o}}{p_{i}}\right)^{\left(\frac{\gamma}{\gamma-1}\right)}-1\right]
$$

Equation 2.1

Here $c_{p}$ is specific heat $(1 \mathrm{~J} / \mathrm{kg}-\mathrm{K}) ; \mathrm{Ti}$ is inlet temperature $(300 \mathrm{~K}) ; \eta$ is adiabatic efficiency of the compressor $(0.85)$; $\mathrm{Po} / \mathrm{P}_{\mathrm{i}}$ is the ratio of exit to inlet pressure, assuming compression from ambient pressure (1 atm) to $2 \mathrm{~atm}(41)$; and $\gamma$ is specific heat ratio (1.4). The $\mathrm{W}_{\mathrm{C}}$ derived from Equation 1 (in $\mathrm{kJ} / \mathrm{kg}$ flue gas pumped) was divided by the 
estimated fraction of $\mathrm{CO}_{2}$ in flue gas $(12.5 \%$ (10)) to compute flue gas pumping energy per $\mathrm{kg} \mathrm{CO}_{2}$. Since the use of flue gas in an algae cultivation capacity nominally benefits both the algae cultivation facility and the power plant, by sequestering their $\mathrm{CO}_{2}$ rather than releasing it directly to the atmosphere, the burdens of this operation were allocated between both entities. This was carried out on an energy basis, wherein the energy outputs from an algae cultivation facility and a power plant were determined, i.e., via the system expansion method, and a ratio of the facility outputs was established based on a normalized sharing of $\mathrm{CO}_{2}$ between the plants. The energy needed to compress and deliver this $\mathrm{CO}_{2}$ was then multiplied by the ratio of energy outputs from each entity to determine the burdens that should be allocated to the algae production facility and the power plant. On average, the algae cultivation energy was allocated roughly $60 \%$ of the flue gas compression burden (15).

Upstream adjustments were also required to fully account for electricity and heat demands. This is because Lardon, Stephenson, and Clarens did account for upstream indirect energy burdens, but Campell, Jorquera, and Sander did not. Different approaches were used for various groups of studies. Although both Lardon and Stephenson note that they have accounted for upstream energy burdens, neither explicitly mentioned what impact factor they used, and it appears they did not consistently account for heat's upstream burdens or GHG emissions corresponding to upstream energy consumption. For this reason, upstream energy burdens were removed from their reported cultivation and conversion phase energy use data. New upstream energy use and GHG emissions were then computed using impact factors from Ecoinvent v 2.0, i.e., $3.5 \mathrm{MJ} / \mathrm{MJ}$ and 0.06 
$\mathrm{kgCO}_{2}$-eq/MJ for electricity from the US grid, and $1.3 \mathrm{MJ} / \mathrm{MJ}$ and $0.09 \mathrm{~kg} \mathrm{CO}_{2}$-eq/MJ for heat delivered as light heating oil. For Clarens, it was necessary to apply these same impact factors to conversion-phase electricity and heat demands, since the authors had already accounted for upstream energy uses associated with cultivation-phase processes. Finally, for Campbell, Jorquera, and Sander, it was necessary to multiply their reported cultivation-phase and conversion-phase electricity and heat demands by the Ecoinvent impact factors, because these authors did not report any upstream energy burdens.

In addition to ensuring that all six papers fully accounted for upstream burdens associated with heat, electricity, and nutrients/ $\mathrm{CO}_{2}$ demands, it was also necessary to align systems boundaries related to direct GHG emissions. MABEL standardization requires that the amount of GHG taken up via photosynthesis be equal to the amount of GHG released during biodiesel/biomass combustion, since none of the individual authors indicated that some portion of the algae biomass (embodying photosynthesis $\mathrm{CO}_{2}$ ) would be routed to a landfill (i.e., permanently sequestered). For this reason, direct GHG emissions associated with biodiesel combustion were removed from Lardon's and Stephenson's analyses. Direct GHG emissions data from Clarens were modified to remove their "direct" GHG offset; i.e., the negative quantity accounting for photosynthesis $\mathrm{CO}_{2}$ uptake but not combustion because their $\mathrm{FU}$ was dry biomass instead of biodiesel.

The final adjustment associated with the second phase of MABEL normalizations was the removal of various co-product offsets. This is reflected in the process flow diagram atop the middle portion of Figure 2.3, wherein the box corresponding to 
"conversion of residuals" in Figure 2.1, is completely blank. These adjustments were necessary because the original LCAs made dramatically different assumptions about what co-products, if any, would be delivered from non-lipid algae biomass. Lardon, Campbell, and Stephenson assumed that algae residuals would be subject to anaerobic digestion for conversion into methane, which could then be combusted to produce bioelectricity. Clarens and Jorquera did not include any co-product offsets in their studies, because they did not use a biodiesel FU. Sander assumed that algae residuals would be fermented into ethanol, and as such, several changes were required to make his data compatible with MABEL's assumption that anaerobic digestion is used to convert algae residual biomass into electricity. In particular, Sander's extensive drying assumption was relaxed and the energy use associated with wet homogenization and belt filter press drying of digestate were added to his model(42). For this step of MABEL standardization, all offsets were removed from each study to disallow accounting for conversion of algae residuals into a useful co-product. Table 2.4 summarizes the correction factors that are used to normalize the upstream and co-product impacts. The results of the normalization are provided in Table 2.5.

Table 2.4 Adjustments required to transit from left to central bar grouping in Figure 2.2, including calculation of upstream impacts $\left(\mathrm{CO}_{2}\right.$ and nutrients) and removal of coproducts generated downstream. All values are in GJ.

\begin{tabular}{|l|r|r|r|r|r|}
\hline Energy (GJ) & \multicolumn{2}{|c|}{ Upstream impacts } & \multicolumn{2}{c|}{ Co-product offsets } & \multirow{2}{*}{$\begin{array}{c}\text { Total } \\
\text { adjustment }\end{array}$} \\
\cline { 2 - 5 } & Original & Adjusted & Original & Adjusted & 77 \\
\hline Lardon & 37 & 73 & -41 & 0 & 10 \\
\hline Clarens & 55 & 65 & 0 & 0 & 74 \\
\hline Campbell & 0 & 65 & -8.9 & 0 & 104 \\
\hline Jorquera & 2.2 & 106 & 0 & 0 & 314 \\
\hline Sander & 7.7 & 67 & -357 & 0 & \multicolumn{1}{c|}{0} \\
\hline
\end{tabular}




\begin{tabular}{|l|r|r|r|r|r|}
\hline Stephenson & 39 & 69 & -44 & 0 & 76 \\
\hline
\end{tabular}

Table 2.5 Summary of meta-model results after standardization of upstream burdens and removal of co-product offsets. Energy values correspond to the center bar grouping in Figure 2.2.

\begin{tabular}{|l|rr|rr|}
\hline Study & $\begin{array}{l}\text { Energy } \\
\text { (GJ) }\end{array}$ & use & $\begin{array}{l}\text { GHG } \\
(\mathrm{kg})\end{array}$ & emissions \\
\hline Lardon & 91 & & 8222 \\
\hline Clarens & 75 & & 6240 \\
\hline Campbell & 75 & & 5860 \\
\hline Jorquera & 126 & & N/A \\
\hline Sander & 76 & & 6672 \\
\hline Stephenson & & 82 & & 7683 \\
\hline
\end{tabular}

\subsubsection{Normalization of co-product offsets}

The last step of MABEL standardization accounted for production of useful coproducts. To reiterate from Section 2.2, several of the original studies had accounted for different co-products using different strategies. MABEL assumes that non-lipid algae residues are digested in an anaerobic digester to produce methane, which is then combusted to produce bioelectricity. Anaerobic digestion was selected as MABEL's coproduct conversion strategy because it is a mature and widely-deployed technology and also because preliminary data was available from Lardon, Campbell, and Stephenson.

In the calculation of co-product offset, bioelectricity derived from methane via anaerobic digestion of non-lipid biomass is the only co-product thus the offset is computed as the amount of avoided lifecycle burdens by replacing an existing product in the market using the system expansion approach. This combination of allocation schemes may introduce methodological inconsistencies. 
Values for electricity production from digestion-derived methane were taken directly from Lardon, Campbell, and Stephenson and scaled to the common functional unit for use in MABEL. An anaerobic digestion model based on Sialve (33), (as cited by Stephenson (10), Lardon (12), and Clarens 2011(8)) was then used to estimate how much methane could be produced from the amount of algae residuals resulting from production of one FU in Clarens, Sander, and Jorquera. Algae biomass characteristics of the type summarized in Table 2.1 were used for these analyses to maintain as much information from each original paper as possible; however, some additional parameters were also required. Table 2.6 summarizes these additional digestion parameters. Table 2.7 summarizes resulting estimates of bioelectricity and $\mathrm{CO}_{2}$ production.

Table 2.6 Parameters used to calculate the yields of bioelectricity generated via anaerobic digestion of algae non-lipid fractions.

\begin{tabular}{|l|l|}
\hline Parameter & Value \\
\hline $\begin{array}{l}\text { Volatile suspended solids (VSS) removal } \\
\text { efficiency }(\%)\end{array}$ & 66.7 \\
\hline $\mathrm{CH}_{4}$ production efficiency $\left(\mathrm{m}^{3} / \mathrm{CH}_{4} / \mathrm{kg}\right.$ VSS) & 16 \\
\hline $\mathrm{CH}_{4}$ energy content $\left(\mathrm{MJ} / \mathrm{m}^{3}\right)$ & $0.41,0.48^{\text {a }}$ \\
\hline $\mathrm{CO}_{2} / \mathrm{CH}_{4}$ volume ratio in biogas & 50 \\
\hline $\mathrm{CO}_{2}$ density $\left(\mathrm{kg} / \mathrm{m}^{3}\right)$ & 0.31 \\
\hline $\mathrm{CH}_{4}$ density $\left(\mathrm{kg} / \mathrm{m}^{3}\right)$ & 1.799 \\
\hline $\mathrm{CH}_{4}$ turbine efficiency (\%) & 0.656 \\
\hline
\end{tabular}

${ }^{a}$ Stephenson and Lardon used theoretical yield, $0.48 \mathrm{~m}^{3} \mathrm{CH}_{4} / \mathrm{kg}$ VSS as reported by Sialve(33). Clarens, Campbell and Sander used empirical yield, $0.41 \mathrm{~m}^{3} \mathrm{CH}_{4} / \mathrm{kg}$ VSS as reported by Sialve (33).

Table 2.7 Summary of calculations for various co-product offsets derived from anaerobic digestion of non-lipid algae biomass.

\begin{tabular}{|l|r|r|r|r|r|}
\hline LCA Study & $\begin{array}{r}\text { Total algae } \\
\text { residue }(\mathrm{kg})\end{array}$ & $\begin{array}{r}\mathrm{VSS}^{\mathrm{a}} \text { for } \\
\text { anaerobic } \\
\text { digestion } \\
\end{array}$ & $\begin{array}{r}\mathrm{CH}_{4} \\
\text { produced } \\
(\mathrm{kg})\end{array}$ & $\begin{array}{r}\text { Electricity } \\
\text { produced }\end{array}$ & $\begin{array}{r}\mathrm{CO}_{2} \\
\text { produced }\end{array}$ \\
& & $(\mathrm{MJ})$ & $(\mathrm{kg})$ \\
\end{tabular}




\begin{tabular}{|l|r|r|r|r|r|}
\hline Lardon & 1362 & 817 & 392 & $11770^{\mathrm{b}}$ & 219 \\
\hline Clarens & 1671 & 1002 & 411 & 11097 & 229 \\
\hline Campbell & 1671 & 804 & 330 & $8899^{\mathrm{b}}$ & 184 \\
\hline Jorquera & 2093 & 1256 & 515 & 13902 & 287 \\
\hline Sander & 2030 & 1218 & 499 & 13483 & 278 \\
\hline Stephenson & 1320 & 1073 & 515 & $13904^{\mathrm{b}}$ & 287 \\
\hline
\end{tabular}

${ }^{a}$ VSS - volatile suspended solids.

${ }^{\mathrm{b}}$ Lardon, Campbell and Stephenson provided their own values for electricity production; therefore, these values correspond to their original data, as scaled to the common functional unit.

Among the three studies accounting for methane-derived bioelectricity production, only Stephenson computed the electricity use required to operate an anaerobic digestion system. Thus, a second element of the third MABEL normalization step was determining how much energy use and GHG emissions are associated with digestion and subsequent belt-filter press dewatering of algae residuals during production of $1000 \mathrm{~L}$ algae biodiesel. It was assumed that digestion electricity and heat demand were 286.2 and $10 \mathrm{MJ} / \mathrm{Mg}$ algae residuals, respectively, based on empirical relationships from Soda et al. (42). Similarly, belt-filter press electricity demand was assumed to be 436 $\mathrm{MJ} / \mathrm{Mg}$ algae digestate based on empirical data from the same paper. Finally, upstream burdens associated with heat and electricity production were computed using database impact factors from Ecoinvent v2.013; i.e., 1.3 MJ/MJ heat (as supplied by light heating oil) and 3.5 MJ/MJ electricity from the US grid.

The final type of offset accounting associated with MABEL co-product standardization relates to nutrient recovery during anaerobic digestion and carbon 
sequestration in algae digestate. In particular, nitrogen and $\mathrm{CO}_{2}$ recoveries were computed for digestion of as much residual biomass as is created during production of $1000 \mathrm{~L}$ algae biodiesel. Nitrogen recovery was based on a normalized empirical factor from Sialve (38 $\mathrm{g} \mathrm{NH}_{3}-\mathrm{N} / \mathrm{Mg}$ algae biomass digested)(33), and it was assumed that ammonia constitutes $80 \%$ of total nitrogen released into digester effluent $17 . \mathrm{CO}_{2}$ recycle was assumed to proceed via both direct and indirect processes. Direct recycle was computed using $\mathrm{CO}_{2}$ and $\mathrm{CH}_{4}$ fractions in digester biogas, 62-64\% and 36-38\%, respectively, from Sialve et al (33). Indirect recycle $\mathrm{CO}_{2}$ was computed assuming that methane undergoes stoichiometric conversion to $\mathrm{CO}_{2}$ during combustion to produce bioelectricity (i.e., $1 \mathrm{Mg} \mathrm{CH}_{4}$ yields $2.75 \mathrm{Mg} \mathrm{CO}_{2}$ ). It was assumed that recycling these quantities of nitrogen and $\mathrm{CO}_{2}$ would decrease the total amounts of nutrients required to produce one FU, decreasing the amounts of upstream energy use and GHG emissions computed in Section 2.3.2 (see impact factors in Table 2.3). It was also assumed that dewatered digestate may be applied as soil amendment. From Hue and Sobieszczyk (43), it was assumed that $32 \%$ of the digestate is carbon, which was sequestered from the atmosphere as $\mathrm{CO}_{2}$ during photosynthesis. The amount of $\mathrm{CO}_{2}$ corresponding to the carbon fraction of algae digestate was accounted for as negative direct greenhouse emissions, since it was assumed that this carbon would be biologically unavailable following sequestration in the soil.

To summarize this methods section, energy consumption and production were computed for analysis of the MABEL-standardized co-product system (anaerobic digestion). Energy consumption calculations accounted for: electricity demand during 
digestion and belt-filter pressing of digestate; heat demand during digestion; and upstream burdens associated with production of light heating oil and/or US grid electricity. Energy production calculations accounted for: electricity production from methane; upstream offsets for nitrogen and $\mathrm{CO}_{2}$ recycled from anaerobic digestion; and, "virtual upstream offsets" for surplus methane-derived bioelectricity. Energy consumption and production calculations pertaining to methane production via digestion of algae residuals are summarized in Table 2.8. These adjustments give rise to the dataset plotted at far right in Figure 2.2 of section 2.4.1 later in this chapter. Numerical values for this data, corresponding to the final output of MABEL standardization, are presented in Table 2.9.

Table 2.8 Components of the overall co-product adjustment for the MABEL-standardized anaerobic digestion process. These results help explain the transition between middle and far right datasets in Figure 2.2.

\begin{tabular}{|c|c|c|c|c|c|}
\hline \multirow[t]{2}{*}{ Energy (GJ) } & \multicolumn{2}{|c|}{ Electricity $^{\mathrm{a}}$} & \multicolumn{2}{|c|}{ Recycling } & \multirow{2}{*}{$\begin{array}{c}\text { Total } \\
\text { adjustment }\end{array}$} \\
\hline & Use & Generation & Nutrients & $\mathrm{CO}_{2}$ & \\
\hline Lardon & 2.1 & 53 & 1.6 & 3.8 & 55 \\
\hline Clarens & 2.6 & 50 & 2 & 4 & 53 \\
\hline Campbell & 2.7 & 40 & 2.6 & 3.2 & 44 \\
\hline Jorquera & 3.3 & 62 & 2.5 & 5 & 66 \\
\hline Sander & 3.2 & 60 & 2.4 & 4.9 & 64 \\
\hline Stephenson & 0.9 & 62 & 0.7 & 10.1 & 72 \\
\hline
\end{tabular}

${ }^{a}$ Includes the electricity used and generated via anaerobic digestion process, as computed using the parameters provided by each set of authors or the average of the other studies if specific values were not reported (Table 2.6). These electricity numbers include the upstream indirect burden that would be realized by buying or offsetting electricity generated by the US grid. 
${ }^{\mathrm{b}}$ Total adjustment includes the contribution and credit realized by adding an anaerobic digestion system to the algae biofuel production facility. Proposed systems would include the digester, a belt filter press, and other unit operations required to support this activity, but I did not model the capital infrastructure for these items. The total adjustment is a sum of the electricity generated along with the offsets realized by recycling some of the nutrients and the $\mathrm{CO}_{2}$ minus the electricity (and a small amount of heat) that would be required to operate this process.

Table 2.9 Summary of model results after normalization of co-product. Energy values correspond to the right side grouping in Figure 2.2.

\begin{tabular}{|l|rr|rr|}
\hline Study & $\begin{array}{l}\text { Energy } \\
\text { (GJ) }\end{array}$ & use & $\begin{array}{l}\text { GHG } \\
(\mathrm{kg})\end{array}$ & emissions \\
\hline Lardon & 36 & & 4228 \\
\hline Clarens & & 22 & & 2386 \\
\hline Campbell & 32 & & 2305 \\
\hline Jorquera & 60 & & N/A \\
\hline Sander & 12 & & 1990 \\
\hline Stephenson & 10 & & 2471 \\
\hline
\end{tabular}

\subsubsection{Computed model outputs}

A variety of modeling endpoints could have been selected for this analysis, but I chose two that have been widely discussed in the context of biofuels: net energy ratio (NER) and greenhouse gas emissions as normalized by usable transportation output. NER is a useful metric because it readily suggests the viability of a process from an energy balance perspective. Greenhouse gas emissions here are reported as normalized to vehicle kilometers travelled (VKT). As discussed in Clarens et al 2010, this metric favors algaebased fuels, since they have inherently larger yields than terrestrial crops. But I thought that this was the most representative metric since ultimately, the function that biofuels provide is not fuel itself but rather transportation delivered. Subsections 2.3.5 and 2.3.6 
provide additional detail on each output and also outline how each parameter is calculated.

\subsubsection{Net energy ratio (NER)}

Net energy ratio is an increasingly common metric for assessing the overall viability of biofuel options and is based on an energy balance approach. Defined as the ratio of net energy output to net energy input from a system, it is an efficient way to report the tenability of a process. NER is sometimes also referred to as energy return on (energy) investment (EROI).

$$
\text { Net energy ratio }=\frac{E_{\text {out }}}{E_{\text {in }}}
$$

Those processes with a NER lower than one are not worth pursuing for the purposes of generating power, which is ultimately the driver behind the processes being modeled here. NER is also useful in that it lets us capture multiple energy inputs and outputs into one simple metric. Specifically, it allows us to report the production of energy associated with biodiesel along with the energy generated by the combustion of the electricity produced from the non-lipid fraction of the algae cell. In some cases, the electricity generated is not enough to offset the electricity needed to operate the algae cultivation and conversion facilities and in these cases, the NER must be computed differently.

- If there is an surplus electricity surplus per FU (i.e., more electricity is created than consumed): 
$E_{\text {out }}=$ Energy content embodied in 1000 L biodiesel + surplus electricity + indirect burdens associated with surplus electricity

$E_{i n}=$ Upstream burden of fertilizers, $\mathrm{CO}_{2}+$ heat use + indirect burden associated with heat use

- If there is an electricity deficit per FU (i.e., less electricity is created than consumed):

- If electricity must be provided to the algae cultivation facility:

$E_{\text {out }}=$ Energy content embodied in $1000 \mathrm{~L}$ biodiesel

$E_{i n}=$ Upstream burden of fertilizers and $\mathrm{CO}_{2}+$ electricity use + indirect burdens associated with surplus electricity + heat use + indirect burden associated with heat use

For three of the original six LCA studies (10-12), it was determined that more bioelectricity could be produced from methane than would be required on-site during production of $1000 \mathrm{~L}$ biodiesel. For these papers, the net 'positive' electricity surplus was multiplied by database impact factors for US-grid electricity $(3.5 \mathrm{MJ} / \mathrm{MJ}$ and $0.06 \mathrm{~kg}$ $\mathrm{CO}_{2}$-eq/MJ) to compute the amounts of upstream burdens that could be avoided by production of bioelectricity from algae. Because these burdens would have accrued on the US grid electricity that would have otherwise been used by a hypothetical third party, these amounts were credited back to studies reporting a positive electricity surplus as "virtual upstream energy use offsets". This is consistent with industry-standard GREET protocols (19).

\subsubsection{Vehicle kilometers traveled (VKT)}

As described 2.3.5, energy output has two components: biodiesel and bioelectricity. Biodiesel VKT and ethanol VKT (for benchmarking corn ethanol results from Farrell et al(6) were calculated using average fuel efficiency for internal combustion 
vehicles $\left(\eta_{\mathrm{Icv}}\right)$. Data accounting for the overall average of the city and highway mileage were extracted from data originally published by US EPA and reported in Campbell et al (44). Published values of $\eta_{\text {Icv }}$ for biodiesel was assumed to be $0.39 \mathrm{~km} / \mathrm{MJ}$ from Campbell et al (20). Similarly $\eta_{\text {Iсv }}$ of ethanol is $0.328 \mathrm{~km} / \mathrm{MJ}$. The VKT of biodiesel and ethanol is calculated using Equation 2.3.

$$
V K T_{I C V}=E_{B i o D} \cdot \eta_{I C V}
$$

Equation 2.3

Bioelectricity is produced via methane combustion. It was assumed that transmission losses and other inefficiencies reduce the amount of transportation electricity that is achievable in a battery electric vehicle (BEV) relative to the amount of electricity which leaves the power plant. Thus it was necessary to multiply biomass bioelectricity (EBIO) by several factors before computing VKT from the amount of electricity that makes its way into the battery of a BEV. Equation 2.4 summarizes calculation of bioelectricity-derived VKT as a function of EBIOE.

$$
V K T_{B E V}=E_{\text {Bio }} \cdot \eta_{\text {transmission }} \cdot \eta_{\text {charge }} \cdot \eta_{B E V}
$$

Equation 2.4

Values for $\eta_{\text {transmission }}$ (transmission efficiency) and $\eta_{\text {charge }}$ (battery charging efficiency) were taken from Campbell et al. (2009) 20. These were 92\% and 90\%, respectively. Battery efficiency in a BEV ( $\left.\eta_{\mathrm{BEV}}\right)$ was assumed to be 1.3 from Campbell et al. (44). This figure accounts for both city and highway mileage (44).

For those studies with surplus electricity (10-12), total VKT consists of two components: VKT from biodiesel plus VKT from bioelectricity. For those studies without 
surplus electricity $(8,13,14)$, total VKT is only from biodiesel. Given the functional unit in this study, VKT ranges from $12,973 \mathrm{~km}$ to $19,743 \mathrm{~km}$ per functional unit $(1000 \mathrm{~L}$ biodiesel).

\subsubsection{Benchmark calculations}

As mentioned above, the values of energy use and GHG emission per VKT of soybean-biodiesel and corn-ethanol are used as benchmarks for algal biodiesel. Soybeanbiodiesel data is from Hill et al. (9), and corn-ethanol data is from the EBAMM model developed by Farrel et al. (6).

\section{Soybean biodiesel}

In Hill's study, it is reported that GHG emissions per net energy balance (what he calls NEB and I call NER) are equal to $49 \mathrm{~g} \mathrm{CO}_{2}$ eq per $1 \mathrm{MJ}$ total energy output. Of the $1 \mathrm{MJ}$ total energy output, $0.81 \mathrm{MJ}$ comprises biodiesel; therefore, it was assumed that $81 \%$ of the GHG emissions associated with the 1 MJ total energy output could be allocated to biodiesel (i.e., $0.81 \times 49 \mathrm{~g} \mathrm{CO}_{2} / \mathrm{MJ}=39.7 \mathrm{~g} \mathrm{CO}_{2} / \mathrm{MJ}$ biodiesel). NER of soy biodiesel with co-products is 1.93 . Hill also provided net GHG emissions for soybean biodiesel, as follows:

$$
39.7 \frac{\mathrm{gCO}_{2}-e q}{\text { MJ biodiesel }} * \frac{1 \mathrm{MJ}}{0.39 \mathrm{~km}} * \frac{1 \mathrm{~kg}}{1000 \mathrm{~g}}=0.102 \frac{\mathrm{kg} \mathrm{CO}_{2-e q}}{\mathrm{~km}}
$$




\section{Corn ethanol}

Corn derived ethanol data is extracted from EBAMM's "Ethanol Today" scenario. The total energy output is $25.3 \mathrm{MJ} / \mathrm{L}$ and total energy input is $21 \mathrm{MJ} / \mathrm{L}$. Thus the NER is:

$$
25.3^{M J} / L^{\div} \div 21 M J / L=1.20
$$

The GHG emission of "Ethanol Today" is found in Farrell's "GHGs" worksheet, 77.25 $\mathrm{gCO}_{2}$-eq/MJ. Using mileage efficiency per MJ from (6), this factor can be used to compute GHG emissions per corn ethanol-derived VKT as follows:

$$
77.25 \frac{\mathrm{gCO}_{2}-e q}{\text { MJ cornethanol }} * \frac{1 \mathrm{MJ}}{0.328 \mathrm{~km}} * \frac{1 \mathrm{~kg}}{1000 \mathrm{~g}}=0.236 \frac{\mathrm{kg} \mathrm{CO} \mathrm{CO}_{-\mathrm{eq}}}{\mathrm{km}}
$$

\subsubsection{MABEL structure and model accessibility}

MABEL was built in Microsoft Excel to enable widespread use by the research community. Work sheets were developed to correspond to each of the six LCA papers selected for study in this analysis. MABEL's twenty-four 'study sheet's were created using identical model architecture for ease of interpretation among values taken directly from each paper and values that were computed based on published data. Uniform architecture also facilitates manipulation of individual input data or modeling assumptions. An 'Intro' sheet defines the different colors of cells and numbers in the model. Normalized data from each study sheet are used to populate the 'Summary' worksheet that also contains the results in table and graphical format. There are then four 
sheets corresponding to the four scenarios outlined in Section 1 of this document. These sheets summarized data for five of the six LCA studies, since Jorquera could only be used for the base case. 'Benchmarks' worksheet provides details of soybean biodiesel and corn ethanol calculations. MABEL is currently available via download from the internet at http://people.virginia.edu/ afc7r/MABEL/MABEL.html.

\subsection{Results and discussion}

\subsubsection{Normalization results of energy use and GHG emissions}

The normalization results of total energy use and GHG emissions per $1000 \mathrm{~L}$ biodiesel are depicted in Figure 2.2 (A) and (B) respectively. The left group presents the GHG emissions or energy use after normalization of functional unit in each study. One study (i.e., (14)) was excluded because energy use was reported by the authors but not GHG emissions. As shown in Table 2.1, the functional units that the selected papers employed are in different scales (e.g., 1 tonne dry biomass). It was necessary to append a conversion step to the two of the papers that have only accounted for delivery of semi-dry algae biomass. The preliminary adjustments made it possible to plot all of the previously published data on the same axes. Despite this, the results still exhibit substantial variability, which ranges from -1066 to $8222 \mathrm{~kg} \mathrm{CO}$-eq and -237 to $65 \mathrm{GJ}$ per $103 \mathrm{~L}$ algal biodiesel. These values are still too disparate to enable meaningful comparison with benchmark terrestrial biofuels.

The middle group of bars describes the results after standardization of upstream burdens without co-products offset. Each of the LCA paper was modified to account for 
the upstream burdens associated with the production of nitrogen and phosphorus fertilizers and $\mathrm{CO}_{2}$ demand for delivering the common FU. Offsets are removed from the studies that have accounted for the production of usable co-product. The variability of results is reduced significantly compared to the first step normalization as the quantified standard deviation demonstrates because several studies had not fully accounted for the upstream burdens and a few others had modeled different co-products from non-lipid algae residue.

The right portion of Figure 2.2 shows estimates after the further adjustment of coproduct offsets from methane-derived bioelectricity via anaerobic digestion of non-lipid algae residue. Three studies out of six reported their estimates of biogas production from anaerobic digestion directly $(10,12,13)$ thus their original values are adopted. The offsets of the other three studies are computed in MABEL given the amount of non-lipid fraction of algae residuals. Though anaerobic digestion is not the only option for utilizing the algae residue, it is the most commonly discussed thus it is favorable to maintain the original models' respective architectures. The results are slightly more consistent and lower in magnitude than the second step of normalization, ranging from 1990 to 4229 $\mathrm{kgCO}_{2}$-eq and 10 to $60 \mathrm{GJ}$ per $1000 \mathrm{~L}$ algal biodiesel. The significant consistency achieved from the three-step normalization enables the comparison between algal biodiesel and terrestrial biofuels as benchmarks. 


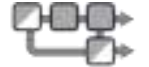

Published results

A.

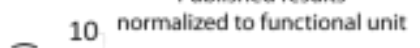

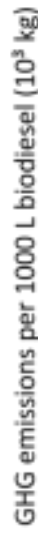

4

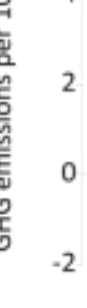

B.

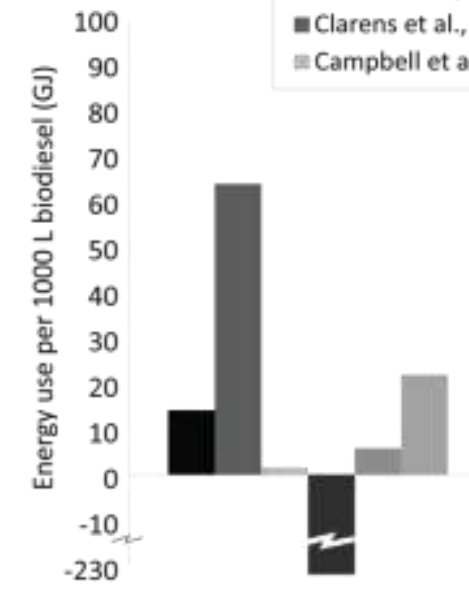

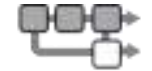

Upstream burdens normalized
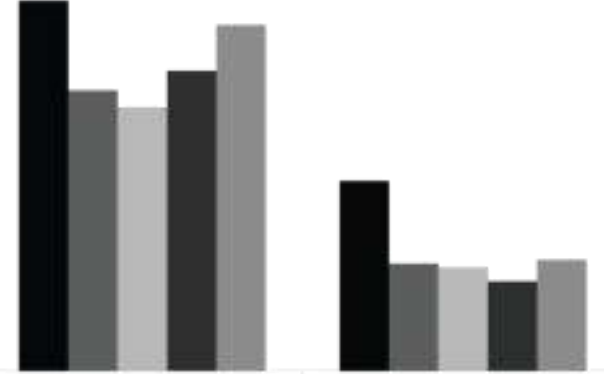

Upstream and downstream processes normalized 
Figure 2.2 MABEL standardization of greenhouse gas emissions (A) and energy use (B). Left group: GHG emissions and energy use required to deliver one common functional unit (103 L biodiesel), as computed using published data. Middle group: GHG emissions and energy use per FU following FU standardization plus adjustment for upstream burdens. Right: and GHG emissions and energy use per FU following the first step and second step of standardization for upstream burdens and offsets for methane-derived bioelectricity. Shaded boxes in schematics at top indicate which stages from Figure 2.1 were included in each set of results. Partially shaded boxes indicate stages included in some but not all studies. Standard deviations are $\sigma=4089$, 990, and 886 from left to right for $\mathrm{GHG}$ emissions and $\mathrm{r}=108,20$, and 18 for energy use.

\subsubsection{Energy use and GHG performance for four scenarios and}

\section{comparison with terrestrial biofuels benckmarks}

Figure 2.3 compares the net energy ratio and GHG emissions for MABEL base case scenario (i.e., industrial $\mathrm{CO}_{2}$, methane-derived bioelectricity as the co-product) and that of soybean biodiesel and corn ethanol. Results show that as an emerging technology, algae bioenergy has energy return and GHG emissions that are on par with terrestrial biofuels. The first generation conceptualization of algae-to-energy system, as presented in Figure 2.1, still holds room for improvement in future development in various aspects (e.g., pyrolysis, thermochemical liquefaction as the conversion processes). 


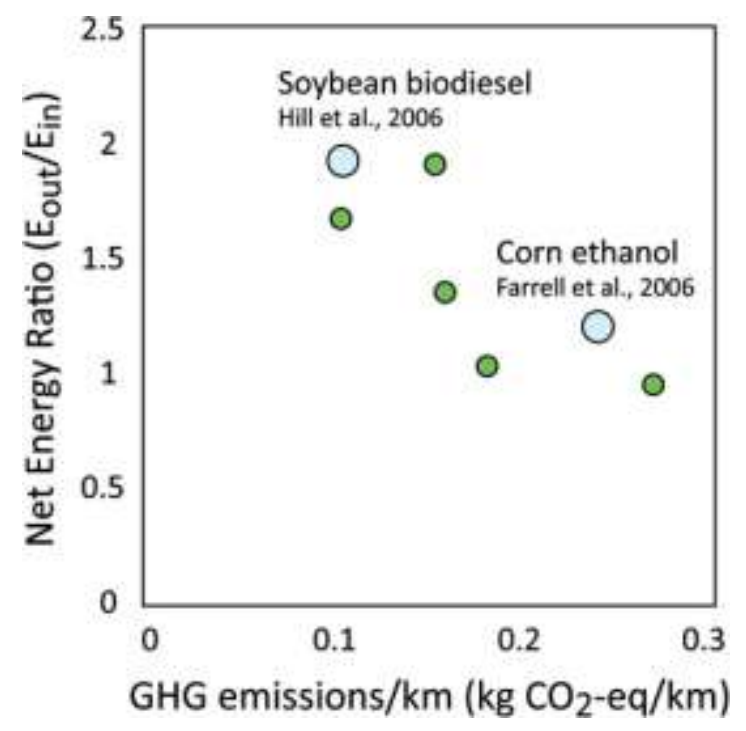

Figure 2.3 Smaller green circles depict net energy ratios and greenhouse gas (GHG) emissions associated with production of $1000 \mathrm{~L}$ algae biodiesel, as computed using MABEL-normalized data from five published systems-level studies. Larger blue circles depict energy and GHG performance for well-understood terrestrial benchmark biofuels, soybean biodiesel and corn ethanol. (For interpretation of the references to color in this figure legend, the reader is referred to the web version of this article.)

MABEL also provides insights on forecasting the possible pathways to improve the sustainability of algal biodiesel. In Figure 2.4, the energy and GHG performances of possible $\mathrm{CO}_{2}$ supply from coal flue gas for algae cultivation and residual biomass conversion scenarios are depicted. Scenario 1 is defined as base case which reflects the biodiesel production from algae with industrial-grade $\mathrm{CO}_{2}$ source and anaerobic digestion, which is a well understood technology. Scenario 2 assumes the same $\mathrm{CO}_{2}$ source but without co-product offset. Scenario 3 and Scenario 4 assumes $\mathrm{CO}_{2}$ can be delivered from coal fire power plant flue gas with and without anaerobic digestion of algae biomass residue. Anaerobic digestion of non-lipid algal biomass can provide bioelectricity as supplemental energy and $\mathrm{CO}_{2}$ /nutrients recycle to utilize material inputs more efficiently. It should be noted that neither flue gas derived $\mathrm{CO}_{2}$ supply chain nor 
digestion-mediated nutrient recycling has been implemented at commercialized scale thus far, although research initiatives have been emerging rapidly to accelerate the algae biofuels deployment.

The impacts of two key operational parameters - nutrient procurement and utilization of non-lipid algal biomass, have been demonstrated to be significant comparing the four scenarios. The estimates of net energy ratio and GHG emissions in Scenario 1 imply that the environmental performance of current algal biodiesel production system is on par with traditional biofuels. Without co-product offset, algal biodiesel is neither economic viable nor able to mitigate GHG emissions as a transportation fuel, as indicated by Scenario 2 and 3. The most optimal technical path, Scenario 4 , is to use recycled $\mathrm{CO}_{2}$ from coal-fired power plants and produce bioelectricity as co-product. The energy yield is nearly three times as that of life cycle energy input and the system sequesters slight amount of $\mathrm{CO}_{2}$ from the environment over the its entire life cycle. The negative life cycle GHG emissions result from surplus bioelectricity replacing grid electricity after internal electricity use. If Scenario 4 can be achieved, it would be dramatically favorable than both soybean biodiesel and corn ethanol. 


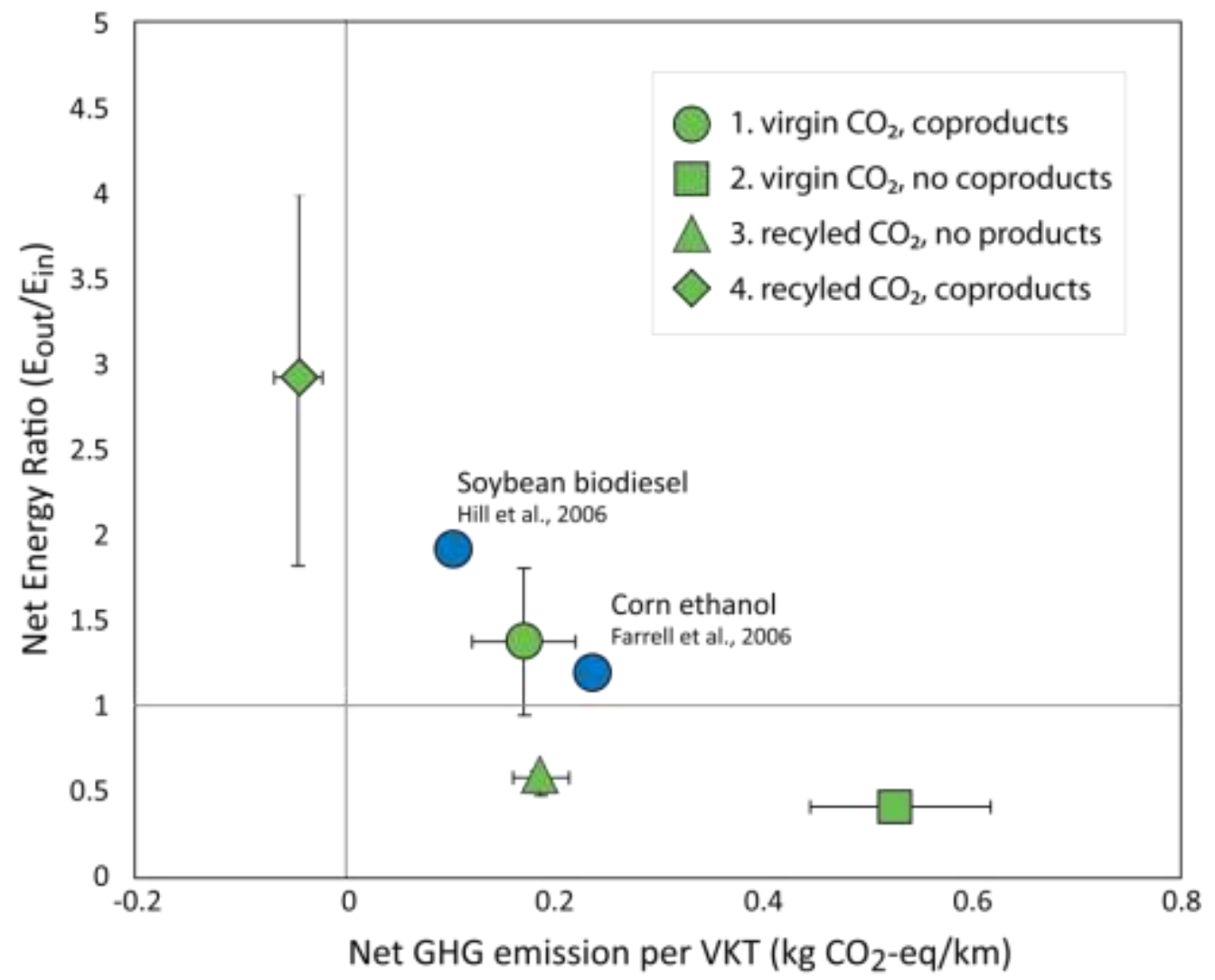

Figure 2.4 Net energy ratios and GHG emissions per kilometer traveled of four modeled scenarios in MABEL and terrestrial benchmark biofuels. Error bars correspond to $90 \%$ confidence intervals. The prospect of sustainable algae-derived fuels will depend on technological innovation in the coming years. Here, four scenarios suggest how algae-toenergy systems compare to conventional biofuels using combinations of systems with and without novel nutrient recovery (e.g., flue gas compression for $\mathrm{CO}_{2}$ recycling) and systems with or without advanced anaerobic digestion of non-lipid algae biomass for production of methane-derived electricity. Error bars correspond to $90 \%$ confidence intervals.

All the six studies in MABEL and benchmarks do not include land use change impacts that could be significant for biofuels derived from agricultural crops. Since algae farms can be build on non-arable marginal land, such effects can be avoided and make algal biodiesel more competitive than traditional biofuels. There are certainly more methodological questions that must be addressed to provide a more comprehensive 
understanding of how the large-scale algae-to-energy systems will impact the environment. These effects are explored in greater detail in Chapter 5 of this dissertation.

In Scenario 1 and 2, $\mathrm{CO}_{2}$ delivered to algae cultivation is from ammonia plant and it bears huge lifecycle impacts; in Scenario 3 and $4, \mathrm{CO}_{2}$ is from flue gas, which bears lower burdens than that from ammonia plants. $\mathrm{CO}_{2}$ burdens are counted in denominator and co-product offsets are integrated in numerator. Numerically, when the change in numerator is the same, the ratio with greater denominator (Scenario 1 and 2) will change less than that with smaller denominator (Scenario 3 and 4).

\subsection{Conclusions}

From MABEL results, it can be concluded that first-generation algal biodiesel production systems will most likely offer energy efficiency and GHG performance that are comparable to existing biofuels. This conclusion arises from the normalization of original data from a number of research groups in multiple locations and suggests that algae-derived biofuels could hold significant potential they are unlikely to represent a dramatic improvement over terrestrial biofuels in the short term. Comparison of several production scenarios highlights the potential improvement of algae's performance that further research could achieve. In addition, MABEL can be a valuable tool to analyze the anticipated effects of new technology in this rapidly emerging field. 


\section{Chapter 3}

\section{Environmental Implications of Algal Liquid}

\section{Fuels via Hydrothermal Liquefaction}

\subsection{Introduction}

In the previous chapter, the production of biodiesel from algae using transesterification of the algae lipid fraction was explored in detail. Many groups in the algae-to-energy industry have been exploring a variety of alternative pathways for converting algae biomass into energy including direct ethanol production (19), heterotrophic metabolism (45), or thermochemical conversion of the entire algae cell (46, 47). Thermochemical conversion via hydrothermal liquefaction (HTL) is of particular commercial interest because it seamlessly integrates with existing petroleum refining 
infrastructure $(46,48)$. In HTL, wet algae biomass (with a water content of $10-15 \%$ ) is converted through high pressure and temperature reaction processes into four streams: 1) biocrude (fatty acids, phenolic compounds, long-chain alkanes, etc.) $(20-60 \%)(47,49)$, 2) an aqueous phase containing organic acids and most of the nitrogen and phosphorus in the biomass (30-50\%), 3) a gas phase containing $\mathrm{CO}_{2}, \mathrm{CH}_{4}$, and other volatile organic compounds (1-8\%), and 4) a solid phase consisting primarily of charred carbon (3\%). Fundamental studies on the effects of algae species (50-52), temperature $\left(250-350^{\circ} \mathrm{C}\right)$ $(48,50)$, pressure (5-20 MPa)(48), and catalyst chemistry (49) have been carried out. Under steady state conditions, biocrude can be recovered from the aqueous phase using organic solvents (53) and subsequently blended with petroleum crude to produce a variety of drop in fuels in conventional refineries (54). Nutrients in the aqueous phase can be recovered to recycle along with $\mathrm{CO}_{2}$ in the gas phase (55). Natural gas and biochar can be used for supplemental energy generation at the conversion facility.

There are a number of important differences between HTL and transesterification that could have implications in the life cycle profiles of both pathways. In HTL, dewatering energy consumption is reduced considerably because the wet algae slurry entering the reactor can contain up to $90 \%$ water (56). Lipid extraction from algae cells using homogenization requires that algae biomass be at a relatively low moisture content (15), which is highly energy- and cost- intensive. HTL increases the oil yield in low-lipid algae species because the non-lipid carbon in algae cells (i.e., carbohydrates and protein) is also converted to biocrude. Several studies have reported that HTL yields an oil content exceeding the lipid content of the algae biomass $(52,57,58)$. Since biocrude 
contains little or no sulfur or chlorine components, it is compatible and even desirable to blend with conventional crude because it eliminates the necessity for atmospheric distillation, which removes chloride salts that cause corrosion and deactivation of catalysts in downstream units (59).

To date, only a few studies have attempted to assess the systems-level implications of large-scale algae-to-energy processing using HTL (60, 61). Frank et al. used the Greenhouse Gases, Regulated Emissions, and Energy Use in Transportation (GREET) Model and supplemented it with literature data to understand the systems-level implications of HTL process (62). They concluded that even though HTL uses biomass more efficiently, it generates approximately 1.5 times more GHG emissions and requires 5.2 times more nitrogen fertilizer than the conventional lipid extraction and transesterification process. This study is an important first step in understanding the implications of producing bioenergy from HTL but there were a number of assumptions that could be explored to better understand the implications of this technology. Most importantly, many of their modeling assumptions are based on parameters, e.g., growth rates, etc. that were collected at the bench scale and will likely not reflect conditions after scale-up. In addition, the $\mathrm{CO}_{2}$ supply source in the Frank et al. study included $\mathrm{CO}_{2}$ capture from the flue gases of power-plants (17), which may not be an accurate assumption given that there is no current infrastructure for providing flue gas derived $\mathrm{CO}_{2}$ as a commodity. Finally, there are also assumptions about upgrading processes for biocrude that extend beyond catalytic hydrotreating, to produce diesel, such fluid catalytic cracking, which would be used to produce gasoline. 
Most likely the largest shortcoming of the existing algae-to-energy life cycle assessment literature is the lack of real data obtained from measurements in pilot or fullscale facilities $(17,38)$. A number of life cycle analyses have been published to anticipate the environmental implications of large-scale algae-to-energy systems $(8,10,12,37)$. These studies have been widely debated because of the divergent modeling assumptions and system scopes that have resulted in widely disparate results. Efforts to harmonize these studies have produced results that tell a more consistent message - generally that algae-to-energy systems likely have an energy return on investment and greenhouse gas profile that is not unlike those of conventional terrestrial biofuels but that significant bottlenecks exist to make algae technically or economically viable.

The goal of this chapter is to report on a new model of algae-to-energy production processes that are based on HTL and to assess the implications of this pathway on the life cycle energy and GHG emissions of large-scale deployment of this technology. Our model is based on data obtained from a demonstration-scale algae cultivation and conversion facility and so it provides a valuable benchmark for forecasting the future of algae-to-energy systems. The analysis is structured using three scenarios to explicitly capture the temporal dependence of this emerging technology pathway. A lab scenario is used to understand how algae-to-energy production would fare if the growth rates, conversion efficiencies, and other relevant parameters that have been achieved at this scale could be perfectly scaled up. This scenario is a good comparison with the existing literature and it also provides a good theoretical best case for algae-to-energy systems. The second scenario is a field scenario that uses real data from a demonstration-scale 
facility that has been in operation in the Southwestern United States for the past year and a half. This scenario represents the first life cycle model based on field data and it is a useful starting point for discussions about the future of the industry. The third scenario is the aspirational scenario and it is based on model assumptions and parameters that represent an aggregate understanding of where the industry will be in 10 years. This scenario is useful because of the wide variety of research and development that is currently underway and because the algae bioenergy industry has clear ideas about directions and rates at which key technological bottlenecks will be overcome.

\subsection{Literature Review}

\subsubsection{Hydrothermal liquefaction of algae}

Hydrothermal liquefaction (HTL) of biomass has been well studied for a few decades (63). Although the idea of algae as HTL feedstock to produce liquid fuels was raised more than twenty years ago $(51,64)$, it only has been paid considerable attention and investigated in the past five years. Dote et al. (64) examined the recovery of hydrocarbons of thermochemical liquefaction of algae species - Botryococcus braunii at $300^{\circ} \mathrm{C}$ and $10 \mathrm{MPa}$ using a catalyst such as sodium carbonate. They achieved an oil yield as high as $60 \%$. Minowa et al (51) studied the thermochemical liquefaction of another algae species - Dunaliella tertiolecta and examined the compatibility of algal oil and crude oil. Duan and Savage (49) performed experiment to test the conversion efficiencies of algae biomass with various heterogeneous catalysts. The same group also characterized the product fractions from hydrothermal liquefaction of Nannochloropsis 
sp. and the influence of solvents (53). The properties of algal oil derived via hydrothermal liquefaction are studied by Biller and Ross (56). Jena and Das (48) compared the process conditions and algal bio-oil yield via thermochemical liquefaction and pyrolysis. The upgrading of biocrude blended with crude in conventional refinery has also been studied by Sarma and Konwer (54).

\subsubsection{Direct air capture as $\mathrm{CO}_{2}$ supply source}

$\mathrm{CO}_{2}$ supply source is a crucial factor for evaluating the sustainability of algae-toenergy system and can limit the location options for algae cultivation. In this work I have generally assumed that $\mathrm{CO}_{2}$ is sourced for algae cultivation from steam reformed methane plants to make hydrogen or ammonia (8). In recent years, direct air capture (DAC) has emerged as an innovative technology for capturing $\mathrm{CO}_{2}$ from ambient air (65).

\subsection{Methodology}

A stochastic life cycle model was built using Microsoft Excel with the Crystal Ball $^{\circledR}$ plug-in, which enables stochastic analysis using Monte Carlo simulation for complex models by defining statistical distributions for input parameters. The software then automates sampling from the defined input distributions and generates distributions of targeted output parameters (i.e., 'forecasts'). The Monte Carlo simulation was used to conduct 10,000 trials. Increasing the number of trials to 100,000 did not affect the results appreciably. 
The process flow underlying the model is based on data collected at the Sapphire Energy pilot facility in Las Cruces, NM, USA. Sapphire is a leading algae bioenergy company. System boundaries were created to account for all life cycle processes from the cultivation of algae biomass and all upstream burdens to the production of drop-in fuel at the refinery (as shown in Figure 3.1). Cultivation was modeled in open ponds built on non-arable land and growing algae species adapted to grow in brackish growth media (8). $\mathrm{CO}_{2}$ was supplied via one of three pathways: (1) steam reforming of methane, (2) separated flue gas, or (3) direct air capture (66). Make-up nitrogen and phosphorus were delivered to the ponds using commercial fertilizers to supplement the internal nutrient recycle. Algae were assumed to be dewatered using dissolved air floatation and a decanter centrifugation to achieve the water content (10-15\% biomass by weight) that is optimal for conversion. Pre-treatment was performed by heating the biomass to approximately $150^{\circ} \mathrm{C}$ and holding it for $\sim 30$ minutes while the biomass degrades. Hydrothermal liquefaction takes place at $\sim 300^{\circ} \mathrm{C}$ and is held for at least 60 minutes. In both pretreatment and biomass conversion processes, heating is carried out using natural gas combustion. Several separation steps (including liquid-liquid extraction) are carried out on the product streams to enable recycling of the raffinate and upgrading of the nonaqueous phase product. Both solid phase biochar and biogas $\left(\sim 70 \% \mathrm{CO}_{2}\right.$ and $\sim 30 \%$ methane) are burned for heat, where the latter is typically mixed with pure natural gas before combustion. Recycling of carbon emissions from natural gas combustion was modeled in the 'full-scale' scenario and nutrients recycling in the aqueous stream from HTL were modeled in all three scenarios. 
The final step illustrated in Figure 3.1 is the refining process that would take place at a conventional petroleum refinery. Differences between petroleum crude and biocrude could impact this analysis in several meaningful ways. First, biocrude has higher oxygen content than fossil crude oil, which is energetically unfavorable during combustion. This oxygen can, but does not have to be, removed prior to refining. Second, biocrude contains little to no sulfur or heavy metals and it does not require the desalting process (59). Biocrude can be directly blended with crude at various points in the refinery depending on the quality of the biocrude and the desired product. Primary energy consumption and hydrogen demand data were obtained from the US Department of Energy sources (59). Life cycle energy use and GHG emissions were computed using these values and life cycle inventory data.

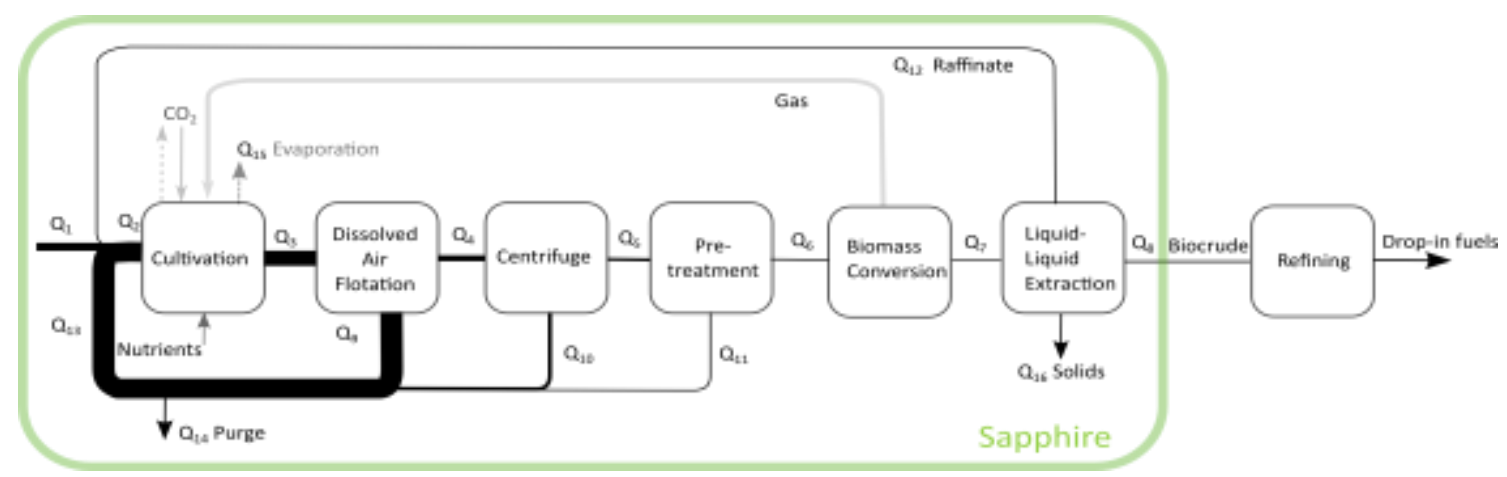

Figure 3.1 System scope of modeled algae-to-energy system and flows

The functional unit (FU) for calculations through all the stages in fuel production is the energy output per hectare in cultivation using open ponds. The functional unit for presenting total impacts is "one barrel biocrude" produced and the results are presented as $\mathrm{MJ} / \mathrm{bbl}$-biocrude and $\mathrm{kgCO}_{2} \mathrm{eq} / \mathrm{bbl}$-biocrude. Following unit conversions and after 
considering refining efficiency and heating values of different fuel products, the results are presented as energy return on investment (Energy output to Energy input) and $\mathrm{gCO}_{2} \mathrm{eq} / \mathrm{MJ}$; this $\mathrm{FU}$ is selected consistently with earlier work by our group.

There are seven worksheets in the Excel spreadsheet model. The results are summarized as tables and figures in the 'Summary' worksheet. The input parameters are stored in the 'Input' worksheet that is linked to the three worksheets where the three individual scenarios - 'lab', 'pilot-scale' and 'full-scale' - are developed. Any updates in input parameters made in the 'Input' worksheet are reflected in the individual scenario worksheets, i.e., users are only required to modify parameters in the 'Input' worksheet and the individual scenario change accordingly. Because of the complexity of the biocrude refining process that requires a variety of materials and energy inputs, the life cycle impacts of the refining stage is computed in a separate worksheet ('Refining'). Sensitivity analysis is conducted using Crystal Ball and tornado plots are presented in the 'Sensitivity analysis' worksheet.

\subsubsection{Data sources}

The 'lab' scenario extrapolates full-scale algae-to-energy process performance using laboratory data such as high algae growth rate and nutrients recycle efficiency. In the 'pilot-scale' scenario, input data are collected from current pilot-scale production facilities in the field; although the prototype data of some unit processes are not fully optimized, they are based on real field data. The 'full-scale' scenario reflects the "achievable goals" of large-scale algae production in the coming decade; most of the 
parameters are based on projections from field data using advancements. The 'full-scale' data were provided and peer-reviewed by Sapphire R\&D team, who believe these parameters to be achievable. However, it is noted here that these parameters may not be achieved over this time horizon therefore these estimates could be considered aspirational. Table 3.1 lists all the input parameters and their ranges for Monte Carlo simulation. All the input parameters are assumed to be in triangular distribution.

Table 3.1 Input parameters of the three scenarios.

\begin{tabular}{|c|c|c|c|c|}
\hline Algae & & $\mathrm{Lab}$ & Field & Aspirational \\
\hline Growth rate $\left(\mathrm{g} / \mathrm{m}^{2} / \mathrm{d}\right)$ & $\begin{array}{l}\text { Mean } \\
\text { Range } \\
\text { References }\end{array}$ & $\begin{array}{c}25 \\
15-35 \\
(8,10-14)\end{array}$ & $\begin{array}{c}12 \\
12-24\end{array}$ & $\begin{array}{c}16 \\
12-25\end{array}$ \\
\hline $\begin{array}{l}\text { Carbon in algae } \\
\text { biomass }\end{array}$ & $\begin{array}{l}\text { Mean } \\
\text { Range } \\
\text { References }\end{array}$ & $\begin{array}{c}51 \% \\
48-53 \% \\
(8,10)\end{array}$ & $\begin{array}{c}47 \% \\
41-50 \% \\
\text { Sapphire }\end{array}$ & $\begin{array}{c}52 \% \\
- \\
\text { Generic } \\
\end{array}$ \\
\hline $\begin{array}{l}\text { Nitrogen in algae } \\
\text { biomass }\end{array}$ & $\begin{array}{l}\text { Mean } \\
\text { Range } \\
\text { References }\end{array}$ & $\begin{array}{c}7 \% \\
5-9 \% \\
(8,10)\end{array}$ & $\begin{array}{c}8 \% \\
7-9 \% \\
\text { Sapphire }\end{array}$ & $\begin{array}{c}9 \% \\
- \\
\text { Generic }\end{array}$ \\
\hline $\begin{array}{l}\text { Phosphorus in algae } \\
\text { biomass }\end{array}$ & $\begin{array}{l}\text { Mean } \\
\text { Range } \\
\text { References }\end{array}$ & $\begin{array}{c}1 \% \\
0.9-1.3 \% \\
(8,10)\end{array}$ & $\begin{array}{c}1.0 \% \\
0.9-1.3 \% \\
\text { Sapphire }\end{array}$ & $\begin{array}{c}1.3 \% \\
- \\
\text { Generic }\end{array}$ \\
\hline $\begin{array}{l}\text { Biocrude } \\
\text { Biocrude yield }\end{array}$ & $\begin{array}{l}\text { Mean } \\
\text { Range } \\
\text { References }\end{array}$ & $\begin{array}{c}\text { Lab } \\
60 \% \\
26-65 \% \\
(48-53,55, \\
56,67,68)\end{array}$ & $\begin{array}{c}\text { Field } \\
20 \% \\
5-20 \%\end{array}$ & $\begin{array}{c}\text { Aspirational } \\
60 \% \\
40-65 \% \\
\\
\text { Sapphire }\end{array}$ \\
\hline Carbon in biocrude & $\begin{array}{l}\text { Mean } \\
\text { Range }\end{array}$ & $\begin{array}{l}73 \% \\
68.1-75.4 \% \\
(48-51,53, \\
55,56,67, \\
68)\end{array}$ & $\begin{array}{c}75 \% \\
65-77 \%\end{array}$ & $\begin{array}{l}78.3 \% \\
65-79\end{array}$ \\
\hline Nitrogen in biocrude & $\begin{array}{l}\text { Mean } \\
\text { Range } \\
\text { References }\end{array}$ & $\begin{array}{c}5.7 \% \\
4-8.1 \% \\
(10,11,48- \\
53,55,56\end{array}$ & $\begin{array}{c}4 \% \\
3-10 \%\end{array}$ & $\begin{array}{c}4.2 \% \\
3-10 \% \\
\text { Sapphire }\end{array}$ \\
\hline
\end{tabular}


$67,68)$

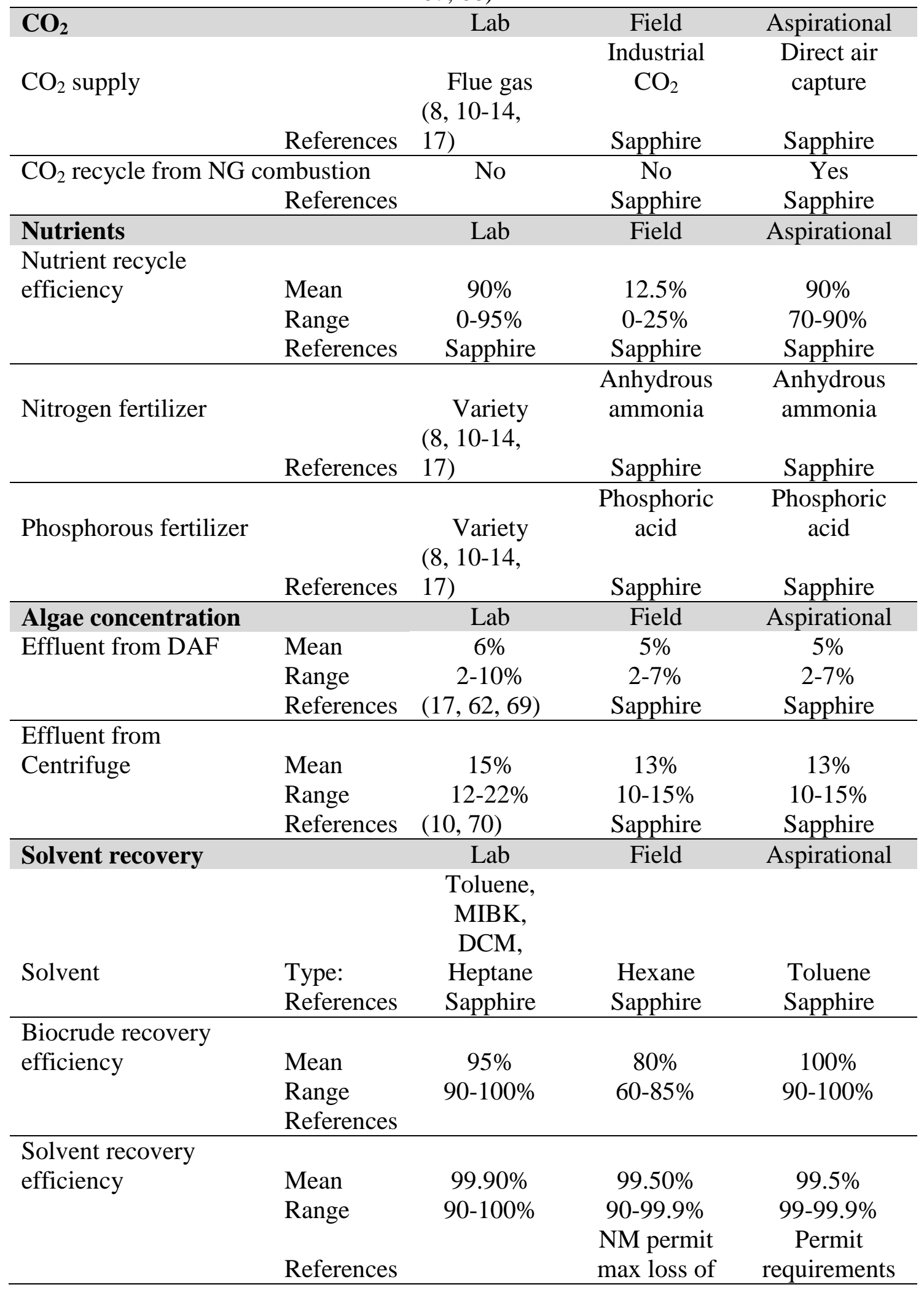


$10 \mathrm{tn} / \mathrm{yr}$

\begin{tabular}{|c|c|c|c|c|}
\hline $\begin{array}{l}\text { Heat exchange } \\
\text { efficiency }\end{array}$ & & $\mathrm{Lab}$ & Field & Aspirational \\
\hline & Mean & $90 \%$ & $90 \%$ & $90 \%$ \\
\hline & Range & $75-95 \%$ & $10-90 \%$ & $80-99 \%$ \\
\hline & References & $(17,71)$ & & 18 \\
\hline Heat recycle & & & & \\
\hline efficiency & & Lab & Field & Aspirational \\
\hline & Mean & $90 \%$ & $90 \%$ & $90 \%$ \\
\hline & Range & & & \\
\hline Biogas production & & $\mathrm{Lab}$ & Field & Aspirational \\
\hline & Mean & $8 \%$ & $3 \%$ & $3 \%$ \\
\hline & Range & $2-35 \%$ & $1-6 \%$ & $1-6 \%$ \\
\hline & & $\begin{array}{l}(48,51,53, \\
55,56,67,\end{array}$ & & \\
\hline & References & 68) & Sapphire & Sapphire \\
\hline
\end{tabular}

The impact factors of energy sources and material inputs are listed in Table 3.2.

They are extracted from the Simapro database and the literature.

Table 3.2 Impact factors of energy and material inputs

\begin{tabular}{|c|c|c|c|c|}
\hline & \multicolumn{2}{|c|}{ Life cycle energy use (MJ) } & \multicolumn{2}{|c|}{$\begin{array}{l}\text { Life cycle GHG emissions } \\
\left(\mathrm{gCO}_{2} \mathrm{e}\right)\end{array}$} \\
\hline & Mean & $\begin{array}{r}\text { Standard } \\
\text { deviation }\end{array}$ & Mean & $\begin{array}{l}\text { Standard } \\
\text { deviation }\end{array}$ \\
\hline Electricity-per kwh & 2.50 & 2.42 & 0.21 & 0.0108 \\
\hline Natural gas - per MJ & 1.18 & 0.115 & 0.0133 & 0.00406 \\
\hline Flue gas - per kg & 1.326 & & 0 & \\
\hline $\begin{array}{l}\text { Anhydrous ammonia - } \\
\text { per } 1 \mathrm{~kg} \mathrm{~N}\end{array}$ & 43.2 & 15.6 & 2.09 & 0.67 \\
\hline $\begin{array}{l}\text { Phosphoric acid - per } 1 \\
\operatorname{kg~}_{2} \mathrm{O}_{5}\end{array}$ & 15.8 & 2.63 & 0.88 & 0.124 \\
\hline $\begin{array}{l}\text { Heating oil - per } 1 \mathrm{MJ} \\
\text { light fuel oil }\end{array}$ & 1.31 & 0.164 & 0.09 & 0.108 \\
\hline Toluene - per kg & 64.7 & 0.00833 & 1.47 & 0.000682 \\
\hline Hexane - per kg & 59.7 & 3.31 & 0.93 & 0.0901 \\
\hline Industrial $\mathrm{CO}_{2}-$ per $\mathrm{kg}$ & 4.15 & 1.95 & 0.412 & 0.137 \\
\hline $\begin{array}{l}\text { Direct air capture - per } \\
\mathrm{kg}\end{array}$ & 3.97 & & 0.127 & \\
\hline Hydrogen - per MJ & 0.753 & & 102.85 & \\
\hline
\end{tabular}




\subsubsection{Cultivation}

\section{Algae biomass growth rates}

The biomass growth rate of $12 \mathrm{~g} / \mathrm{m}^{2} / \mathrm{d}$ as shown in Table 3.1 was measured in the 'field' scenario at the pilot-scale algae cultivation facility in an open pond configuration. Brackish water species are assumed to be cultivated in the open ponds. The 'Lab' scenario collected algae growth rate data at laboratory conditions from a number of publications. It ranges from $15 \mathrm{~g} / \mathrm{m}^{2} / \mathrm{d}$ to $35 \mathrm{~g} / \mathrm{m}^{2} / \mathrm{d}$ and the average value $\left(25 \mathrm{~g} / \mathrm{m}^{2} / \mathrm{d}\right)$ is used as the likeliest value in this scenario.

Given the meteorological data (e.g., insolation, precipitation, temperature, etc.) at the potential location, San Antonio, TX where it is most likely that large-scale algae cultivation systems will be built, the algae growth rate is calculated as $16 \mathrm{~g} / \mathrm{m}^{2} / \mathrm{d}$ using the RUE equation and brackish water species. The calculation is identical to that in the Clarens 2010 (8) model and the equations and its detailed description can be found in the supporting information of Clarens 2010.

\section{Pumping and mixing}

As mentioned previously, this model is based on the cultivation process from Clarens 2010 model (8); similar assumptions are therefore made, such as: 10 paddle wheels are required per hectare (32), each operating at roughly $10 \mathrm{rpm}$ and consuming 
power at a rate given by the following triangular distribution: $\min =10^{-4} \mathrm{~kW}$, likeliest $=10^{-3}$ $\mathrm{kW}$.

Energy demand for pumping operations during cultivation was computed using Equation 3.1. Refer to next section for a generic process flow and details on the overall mass balance. Overall pumping and mixing energy demand for 'pilot-scale', 'lab', and 'full-scale' scenarios were on the order of 34,000 MJ/ha-yr, 67,000 MJ/ha-yr, and 44,000 MJ/ha-yr, respectively.

$$
W_{p}=\frac{g h}{\eta} \text { where } h=\frac{P_{0}-P_{i}}{p g}
$$

The physical meaning of each parameter is: $g$ - force of gravity; $h$ - liquid head; $\eta$ - pumping efficiency; $\mathrm{P}_{\mathrm{i}}$ and $\mathrm{P}_{\mathrm{o}}$ - the inlet and outlet pressure; $\rho$ - the density of water. Pumping volumes are based on the flow rates presented in Table 3.3.

\section{Generic flow and mass balance}

A comprehensive mass balance was performed to obtain flow rates of water, algae biomass mixture and its composition. Figure 3.1 depicts the material flows and corresponding flow names. Given the molecular formula of the algae species and water content of each flow in Figure 3.1, the molecular formula of different algae species are used to compute the composition and ranges of carbon, nitrogen, and phosphorus in the algae biomass, which are presented in Table 3.1 in the 'Algae' section. It is assumed that $1 \%$ ash that is blown to the open ponds and will end in the effluent to harvesting step. Certain assumptions regarding algae concentration were made to perform mass balance and they are listed in Table 3.3; the 'pilot-scale' scenario is presented here as an example. 
Table 3.3 Flow rates, algae concentration and mass balance - 'pilot-scale' scenario

\begin{tabular}{|c|c|c|c|c|c|c|c|c|c|c|}
\hline & $\begin{array}{c}\text { Total flow } \\
(\mathrm{kg})(\mathrm{L})\end{array}$ & $\begin{array}{c}\text { Biomass } \\
(\mathrm{lb})\end{array}$ & $\begin{array}{c}\text { Carbon } \\
(\mathrm{lb})\end{array}$ & $\begin{array}{c}\text { Nitrogen } \\
(\mathrm{lb})\end{array}$ & $\begin{array}{c}\text { Phosp } \\
\text { horus } \\
(\mathrm{lb})\end{array}$ & Water $(\mathrm{lb})$ & $\begin{array}{c}\text { Ash } \\
(\mathrm{lb})\end{array}$ & $\begin{array}{c}\text { Water } \\
(\%)\end{array}$ & $\begin{array}{c}\text { Algae } \\
(\%)\end{array}$ & $\begin{array}{c}\text { Ash/ } \\
\text { salt }\end{array}$ \\
\hline$Q 1$ & $5,448,607$ & - & - & - & - & $11,981,648$ & 966 & $99.7 \%$ & $0.0 \%$ & $0.6 \%$ \\
\hline$Q 2$ & $48,818,073$ & 68,656 & 35,976 & 6,875 & 908 & $107,556,368$ & 966 & $99.94 \%$ & $0.06 \%$ & $0.00 \%$ \\
\hline$Q 3$ & $43,799,719$ & 96,562 & 82,565 & 7,802 & 966 & $96,464,828$ & 966 & $99.90 \%$ & $0.10 \%$ & $0.00 \%$ \\
\hline$Q 4$ & 875,994 & 96,562 & 82,565 & 7,802 & 966 & $1,833,719$ & 966 & $94.95 \%$ & $5 \%$ & $0.05 \%$ \\
\hline$Q 5$ & 336,921 & 96,562 & 82,565 & 7,802 & 966 & 645,259 & 966 & $86.87 \%$ & $13 \%$ & $0.13 \%$ \\
\hline$Q 6$ & 182,499 & 96,562 & 82,565 & 7,725 & 956 & 304,815 & 966 & $75.76 \%$ & $24 \%$ & $0.24 \%$ \\
\hline$Q 7$ & 182,499 & 96,562 & 81,360 & 7,725 & 956 & 304,815 & 966 & $75.76 \%$ & $24 \%$ & $0.24 \%$ \\
\hline$Q 8$ & 8,760 & 19,312 & 45,384 & 772 & - & - & - & & \multicolumn{2}{|c|}{ Biocrude } \\
\hline$Q 9$ & $42,923,725$ & - & - & - & - & $94,631,109$ & - & $100 \%$ & $0 \%$ & $0 \%$ \\
\hline$Q 10$ & 539,073 & - & - & - & - & $1,188,460$ & - & $100 \%$ & $0 \%$ & $0 \%$ \\
\hline$Q 11$ & 154,422 & - & - & 77 & 10 & 340,444 & - & $100 \%$ & $0 \%$ & $0 \%$ \\
\hline$Q 12$ & 159,139 & 68,656 & 35,976 & 6,875 & 908 & 282,187 & - & $80 \%$ & $20 \%$ & $0 \%$ \\
\hline$Q 13$ & $43,210,327$ & - & - & - & - & $95,262,961$ & - & $100 \%$ & $0 \%$ & $0 \%$ \\
\hline$Q 14$ & 406,894 & - & - & 77 & 10 & 896,964 & - & $100 \%$ & $0 \%$ & $0 \%$ \\
\hline$Q 15$ & $5,018,353$ & - & - & - & - & $11,063,633$ & - & $100 \%$ & $0 \%$ & $0 \%$ \\
\hline$Q 16$ & 14,600 & - & 108 & 77 & 48 & 21,051 & 966 & $65 \%$ & $32 \%$ & $3 \%$ \\
\hline Gas & 1,314 & 2,897 & $3 \%$ & & & & & & & 0 \\
\hline flow & & - & & & & & & 0 \\
\hline
\end{tabular}

\section{$\mathrm{CO}_{2}$ and nutrients supply}

\section{$\mathrm{CO}_{2}$ supply}

Stoichiometric formulas are used to perform mass balance at the elemental level. As described in Tables 3.3 and Table 3.4, the carbon flow in the system indicates that the carbon input into the system is identical to the carbon in biocrude. Approximately $10 \%$ of the $\mathrm{CO}_{2}$ is lost to the atmosphere through evaporation, $9 \%$ is lost as algae return and $0.6 \%$ ends in solid waste $\left(\mathrm{Q}_{16}\right)$. Table 3.3 also indicates that in 'full-scale' scenario, the carbon released from combustion of natural gas that provides heat to hydrothermal 
liquefaction will be captured and recycled to cultivation ponds. Thus, the carbon balance is as follows ('pilot-scale' scenario as an example):

Table 3.4 Carbon balance (lb) in 'pilot-scale' scenario

\begin{tabular}{|c|r|}
\hline Total input per hectare & $\mathbf{1 8 , 0 3 8}$ \\
\hline Evaporation & 1,840 \\
\hline Algae return & 1,605 \\
\hline Biocrude & 14,484 \\
\hline Waste & 108 \\
\hline
\end{tabular}

As mentioned in Table 3.1, $\mathrm{CO}_{2}$ supplies in different scenarios are different. At current production facilities ('pilot-scale' scenario), industrial $\mathrm{CO}_{2}$ from steam-reformed methane plants is delivered to algae ponds with $99.9 \%$ concentration, whereas in most literature, it is assumed that flue gas would be captured from coal-fired power plants and delivered to algae open ponds. Direct air capture (DAC) is an emerging technology that can be a potentially significant source of $\mathrm{CO}_{2}$ supply for algae growth. It is advantageous for the algae farm to be location-independent with respect to $\mathrm{CO}_{2}$ supply. The impact factors of industrial $\mathrm{CO}_{2}$ production and flue gas capture are the same as MABEL (38) and are presented in Table 3.2. Sapphire Energy LLC has considered incorporating $\mathrm{CO}_{2}$ delivered via DAC technology developed by Kilimanjaro LLC in large-scale production in the near future. The preliminary estimates of environmental impacts of DAC are presented in the last row of Table 3.2 and these data are from the Lackner study (66).

Nitrogen and phosphorus fertilizers

The demands of nitrogen and phosphorus fertilizers are computed using the stoichiometric formula and nutrients recycle efficiency from raffinate $\left(Q_{12}\right)$ - an aqueous 
stream that flows out of extraction and contains significant amount of nutrients to be recycled back to open ponds. Nutrient recycling efficiencies of the three scenarios are listed in Table 3.1 (under 'Nutrients' category). Tables 3.5 and 3.6 provide mass balances of nitrogen and phosphorus in the system with the 'pilot-scale' scenario as an example. The total input of nitrogen is the sum of nitrogen in biocrude, solids and purge. Phosphorus mass balance was computed similarly. Anhydrous ammonia and phosphoric acid are the fertilizers used. The impacts of the production of these fertilizers are extracted from the Simapro database and presented in Table 3.2.

Table 3.5 Nitrogen balance (lb) in the 'pilot-scale' scenario

\begin{tabular}{|l|r|}
\hline Total input per hectare & $\mathbf{6 , 9 4 3}$ \\
\hline Total in the system & 7,725 \\
\hline Biocrude & 772 \\
\hline Recycled in raffinate & 6,875 \\
\hline Solids & 77 \\
\hline Purge & 77 \\
\hline
\end{tabular}

Table 3.6 Phosphorus balance (lb) in 'pilot-scale' scenario

\begin{tabular}{|l|r|}
\hline Total Input per hectare & $\mathbf{5 8}$ \\
\hline Total in the system & 966 \\
\hline Recycled in raffinate & 908 \\
\hline Solids & 48 \\
\hline Purge & 10 \\
\hline
\end{tabular}

\section{Makeup water supply}

Makeup water (obtained from well water) is required to supply water losses from evaporation. Precipitation and temperature data at a given location were downloaded from the National Solar Radiation Database (NSRDB). Temperature and insolation data 
were used to compute evaporation. The amount of makeup water is the absolute value obtained by subtracting precipitation from evaporation. Details of calculations of precipitation and evaporation are described in the supporting information of Clarens 2010 (8).

\subsubsection{Harvesting and dewatering}

Algae biomass is harvested in a dissolved air flotation unit and concentrated to $10-15 \%$ in a centrifuge unit in order to enable reaction in the pretreatment unit.

\section{Primary harvest - dissolved air flotation (DAF)}

DAF is a commonly used unit process to remove algae from wastewater and it has been well established to achieve maximum efficiency with minimum electricity and polymer input. Thus, it is used as an effective algae harvesting process following cultivation ponds. The algae concentration of influent to DAF is $\sim 0.1 \%$ and that of the effluent from DAF is $2-7 \%$. The electricity consumption per liter mixture processed is $0.0001267 \mathrm{kWh}$ and DAF pressure is $45 \mathrm{psi}$ (69). Direct electricity consumption is computed as the multiplication of flow rate $\left(\mathrm{Q}_{3}\right)$ and 0.0001267 . The life cycle energy use is the sum of direct electricity use and its upstream impacts that are computed as the multiplication of direct electricity use and its impact factors listed in Table 3.2. Large quantity of water $\left(\mathrm{Q}_{9}\right)$ is recycled back to algae open ponds and it is assumed that there was negligible algae biomass in $\mathrm{Q}_{9}$. 


\section{Secondary harvest - decanter centrifuge}

Decanter centrifuge is applied to further concentrate the algae mixture from DAF. In order to be consistent with the LCA studies in our group, the electricity use for the decanter centrifuge is $28.8 \mathrm{MJ} / \mathrm{m}^{3}$ of algal slurry entering the centrifuge. The algae concentration in the effluent of the centrifuge is $\sim 15 \%$. The total electricity use is

computed as the multiplication of $28.8 \mathrm{MJ} / \mathrm{m}^{3}$ by the flow rate $\mathrm{Q}_{4}$. It is assumed that certain amount of water is recycled back to the algae open ponds $\left(\mathrm{Q}_{10}\right)$.

\subsubsection{Hydrothermal liquefaction}

As described in the beginning of this section and in the publication (16), hydrothermal liquefaction (HTL) of algae biomass consists of two steps: pretreatment and biomass conversion. The energy consumption of each sub-process is computed using engineering first principles. Because of its low price, current HTL units use natural gas (NG) as the energy source. The life cycle burdens of natural gas production are described in Table 3.2. The total GHG emissions of the HTL process are the sum of life cycle GHG emissions of natural gas production and the direct emissions from NG combustion. The natural gas combustion efficiency is described in Table 3.1. The HTL unit is a mature process in the Chemical Engineering industry and heat can be recycled efficiently.

\section{Engineering first principle}

The following equation describes the total energy use of heating water by certain degrees. 


$$
Q=c_{p} * \Delta t * m
$$

Equation 3.2

$Q$ - total energy requirement (MJ)

$C_{p}$ - heat capacity of water at certain temperature $\left(\mathrm{MJ} / \mathrm{kg}^{*} \mathrm{~K}\right)$

$\Delta t$ - temperature change $\left({ }^{\circ} \mathrm{C}\right)$

$m-$ unit mass $(\mathrm{kg})$

\section{Pretreatment}

In the pretreatment unit the temperature of algae flow increases from room temperature $\left(25{ }^{\circ} \mathrm{C}\right)$ to $\sim 150{ }^{\circ} \mathrm{C}$. The heat capacity of water is $4.2 \mathrm{MJ} / \mathrm{kg}^{*} \mathrm{~K}$ within this temperature range. Heat is provided from natural gas combustion. Thus, the energy use of heating $1 \mathrm{~kg}$ of water is $0.53 \mathrm{MJ} / \mathrm{kg}$. The direct energy use in pretreatment is the multiplication of $0.53 \mathrm{MJ} / \mathrm{kg}$ and $\mathrm{Q}_{5}$. The total energy use is sum of the direct energy use and the associated upstream energy use of natural gas production. Algae mixture is concentrated to $18-30 \%$ and a small amount of water $\left(Q_{11}\right)$ is evaporated, captured and recycled to algae ponds.

\section{Biomass conversion}

In biomass conversion unit, the temperature of algae mixture increases from $\sim 150$ ${ }^{\circ} \mathrm{C}$ to $\sim 300{ }^{\circ} \mathrm{C}$. The heat capacity of water is $4.8 \mathrm{MJ} / \mathrm{kg} / \mathrm{K}$ within this temperature range. The calculation of energy use at this step is similar as pretreatment unit, which is 0.72 $\mathrm{MJ} / \mathrm{kg}$. The direct energy use in pretreatment is the multiplication of $0.72 \mathrm{MJ} / \mathrm{kg}$ and $\mathrm{Q}_{6}$. The total energy use is sum of the direct energy use and their associated upstream energy use of natural gas production. Algae mixture is concentrated to $18-30 \%$ and $~ 3 \%$ of the biomass is converted to biogas that is produced, captured and combusted to be used as energy source within the system. Biocrude yield varies among different scenarios and the 
values can be found in Table 3.1. The effluent $\left(\mathrm{Q}_{7}\right)$ out of $\mathrm{HTL}$ is a mixture of biocrude (oil), aqueous phase that contains large amount of nitrogen, phosphorus and other organic matter. Approximately 3-8 wt $\%$ biomass becomes solids that mainly consist of silicon.

\subsubsection{Extraction}

Following the HTL step, liquid-liquid extraction separates biocrude $\left(\mathrm{Q}_{8}\right)$ from aqueous phase using solvent and discharge solids $\left(\mathrm{Q}_{16}\right)$. The organic solvents used for 'lab', 'field' and 'aspirational' scenarios are toluene, hexane and toluene, respectively. Solvent input ratio was $0.75 \mathrm{~L}$ solvent (both hexane and toluene) per $1 \mathrm{~L}$ biocrude. The densities of toluene and hexane are $0.87 \mathrm{~kg} / \mathrm{L}$ and $0.7 \mathrm{~kg} / \mathrm{L}$, respectively. Thus, by multiplying the biocrude feed with lipid extraction unit $\left(\mathrm{Q}_{7}\right)$, the ratio and the density of the solvent, the solvent demand can be obtained. The electricity use for liquid extraction is $0.02 \mathrm{MJ} / \mathrm{L}$ feed, therefore the total electricity use can be computed by multiplying 0.02 $\mathrm{MJ} / \mathrm{L}$ and $\mathrm{Q}_{7}$.

After extracting biocrude from the mixture of oil and aqueous phase using solvent, the solvent is recovered via separation in a stripper column. It was assumed to consume heat at a rate of $2.1 \mathrm{MJ} /$ tonne biocrude based on the first principles calculations by Stephenson et al. (10) and empirical data from rapeseed separations (10). As described in Table 3.1, in all three scenarios, solvents are recovered at a very high efficiency (99.5\%-99.9\%). The $0.1-0.5 \%$ loss is the annual consumption of solvents, which is on the

order of $35,724 \mathrm{~kg} / \mathrm{ha}-\mathrm{yr}$. The upstream burdens of solvents production presented in Table 3.2 are accounted into the total life cycle impacts of the 'extraction' step. 
At this step, the raffinate stream $\left(\mathrm{Q}_{12}\right)$ is also separated and conducted back to algae open ponds to recycle considerable amount of nutrients. As mentioned in Table 3.4, approximately $10 \%$ of the algae biomass (algae return) is lost in this process.

\subsubsection{Refining}

Biocrude is upgraded to drop-in fuels in traditional petroleum refineries. As described in the paper, based on the conversation with a professional in Sapphire Energy LLC., biocrude contains negligible sulfur and chlorine components; thus, the desalting process and atmospheric distillation can be avoided. Hydrotreating is the unit process that upgrades biocrude to diesel. Fluid catalytic cracking is the unit process that upgrades biocrude to gasoline. In fluid catalytic cracking, approximately $19 \%$ of the biocrude is converted to biochar that is assumed to be combusted to provide heat and $81 \%$ of the energy use within fluid catalytic cracking is allocated to gasoline.

The material and energy inputs are well documented in 'Energy and Environmental Profile of the U.S. Petroleum Refining Industry' (59). Tables 3.7 and 3.8 list the raw material and energy inputs for hydrotreating and fluid catalytic cracking. The data in Table 3.2 are from Eco-invent and policy life cycle inventory. Life cycle burdens from the production of these raw materials and energy uses are computed in the following two tables by multiplying their quantity and corresponding lifecycle upstream burdens in Table 3.2. In hydrotreating, approximately $7 \%$ of the biocrude is converted to biochar that is assumed to be combusted to provide heat thus $93 \%$ of the energy use within hydrotreating is allocated to diesel. 
Table 3.7 Energy inputs to the fluid catalytic cracking unit (per bbl feed)

\begin{tabular}{|l|r|r|r|}
\hline Energy source & $\begin{array}{l}\text { Specific Energy } \\
\text { Use (MJ/bbl) }\end{array}$ & $\begin{array}{l}\text { Life cycle } \\
\text { energy use } \\
\text { (MJ/bbl) }\end{array}$ & $\begin{array}{l}\text { Lifecycle } \\
\text { GHG } \\
\text { emissions } \\
\left(\mathrm{gCO}_{2} \mathrm{e} / \mathrm{bbl}\right)\end{array}$ \\
\hline Electricity & 13.19 & 22.35 & 0.78 \\
\hline \multicolumn{2}{|c|}{ Energy for Steam/Process Heat } \\
\hline Natural gas & 17.94 & 39.10 & 0.24 \\
\hline Refinery gas & 32.18 & 35.12 & 177.71 \\
\hline Coke & 11.82 & 12.05 & 1174.36 \\
\hline Oils & 2.22 & 2.38 & 1.11 \\
\hline Net process energy & 78.60 & 112.26 & 27.32 \\
\hline Electricity losses & 27.32 & -103.07 & 1.61 \\
\hline Energy export & -103.07 & 217.33 & $\mathbf{1 , 0 9 4}$ \\
\hline Combustion of coke & 217.33 & 253.85 & 1355.81 \\
\hline Total process energy use & 220.18 & $\mathbf{2 0 5}$ & \\
\hline \multicolumn{1}{|c|}{ Allocation to gasoline } & & & \\
\hline
\end{tabular}

Table 3.8 Energy inputs to fluid catalytic cracking unit (per bbl feed)

\begin{tabular}{|l|r|r|r|}
\hline Energy source & $\begin{array}{l}\text { Specific Energy } \\
\text { Use (MJ/bbl) }\end{array}$ & $\begin{array}{l}\text { Life cycle } \\
\text { energy use } \\
(\mathrm{MJ} / \mathrm{bbl})\end{array}$ & $\begin{array}{l}\text { Lifecycle } \\
\text { GHG } \\
\text { emissions } \\
\left(\mathrm{gCO}_{2} \mathrm{e} / \mathrm{bbl}\right)\end{array}$ \\
\hline Electricity & 19.62 & 33.25 & 1.16 \\
$\begin{array}{l}\text { Energy for Steam/Process } \\
\text { Heat }\end{array}$ & & & \\
\hline Natural gas & 17.94 & 39.10 & 0.24 \\
\hline Refinery gas & 32.28 & 35.24 & 178.30 \\
\hline Coke & 11.92 & 12.16 & 1184.85 \\
\hline Oils & 2.22 & 2.38 & 1.11 \\
\hline Net process energy & 85.24 & 123.39 & 2.40 \\
\hline Electricity losses & 40.83 & 69.18 & 24197.01 \\
\hline Hydrogen consumed & 235.27 & 409.20 & 28,406 \\
\hline Net steam exported & -32.81 & -32.81 & $\mathbf{2 5 , 5 6 5}$ \\
\hline Total process energy & 328.53 & 632 & \\
\hline \multicolumn{1}{|c|}{ Allocate to diesel } & & $\mathbf{5 6 9}$ & \\
\hline
\end{tabular}




\subsubsection{Benchmark calculations}

The ratios of EROI and values of GHG emissions per MJ algal biodiesel produced via transesterification, corn ethanol, cellulosic ethanol, soybean biodiesel, petroleum derived ultra low sulfur diesel and gasoline are computed and used as benchmarks. Data are extracted from various sources in literature and fuel policy life cycle models.

\section{Ethanol}

The calculation of EROI ratios and GHG emissions from corn ethanol and cellulosic ethanol production are derived from literature and two predominant life cycle models implemented in policy frameworks, i.e., CA-GREET model and Argonne GREET model. Error bars are 95\% confidence intervals.

\section{Corn ethanol}

EROI ratio and GHG emissions of corn ethanol are computed from three sources: EBAMM, a widely cited life cycle meta-analysis of corn ethanol; CA-GREET life cycle model adopted by LCFS; Argonne GREET model.

The GHG emission of "Ethanol Today" scenario is found in the "GHGs" worksheet in EBAMM model, $77.25 \mathrm{gCO}_{2}$-eq/MJ. The total energy output from corn derived ethanol is $25.3 \mathrm{MJ} / \mathrm{L}$ and total energy input is $21 \mathrm{MJ} / \mathrm{L}$. Thus the NER is:

$$
25.3^{M J} / L \div 21^{M J} / L=1.20
$$


In the corn ethanol pathway document of LCFS program (72), the GHG emissions per $\mathrm{MJ}$ is $69.4 \mathrm{gCO}_{2} \mathrm{e} / \mathrm{MJ}$ and the energy use per mmBtu is $1,657,651 \mathrm{Btu}$ thus the energy ratio is:

$$
1000,000 B T U \div 1,657,651 B T U=0.6
$$

In the Argonne GREET sample results, the energy use of corn ethanol per gallon gasoline is $150,450 \mathrm{BTU}$ and low heating value of gasoline is $113,602 \mathrm{BTU} / \mathrm{gal}$. Thus the energy ratio is:

$$
113,602 B T U \div 150,450 B T U=0.77
$$

And the GHG emissions per gallon gasoline are 7,614 $\mathrm{gCO}_{2} \mathrm{e}$. Thus the $\mathrm{GHG}$ emissions per MJ are:

$$
7,614 \mathrm{gCO}_{2} e \div 150,450 \mathrm{BTU}=94.55 \mathrm{gCO}_{2} e / \mathrm{MJ}
$$

Therefore the average EROI based on these values is 0.85 and the average GHG emissions per $\mathrm{MJ}$ are $80.4 \mathrm{gCO}_{2} \mathrm{e} / \mathrm{MJ}$.

\section{Cellulosic ethanol}

In the Argonne GREET sample results, the energy use of cellulosic ethanol per gallon gasoline is $96,783 \mathrm{BTU}$ and low heating value of gasoline is 113,602 BTU/gal. Thus the energy ratio is:

$$
113,602 B T U \div 96,783 B T U=1.20
$$

And the GHG emissions per gallon gasoline are 1,808 $\mathrm{gCO}_{2} \mathrm{e}$. Thus the $\mathrm{GHG}$ emissions per MJ are: 


$$
1,808 \mathrm{gCO}_{2} e \div 116,090 \mathrm{BTU}=22.45 \mathrm{gCO}_{2} e / \mathrm{MJ}
$$

In LCFS' cellulosic ethanol pathway, GHG emissions per $\mathrm{MJ}$ are $21.40 \mathrm{gCO}_{2} \mathrm{e} / \mathrm{MJ}$ and energy use per mmBTU is $1,163,490 \mathrm{MJ}$. Thus the EROI ratio is:

$$
1,000,000 B T U \div 1,163,490 B T U=0.86
$$

Therefore the average EROI based on these values is 1.03 and the average GHG emissions per $\mathrm{MJ}$ are $21.83 \mathrm{gCO}_{2} \mathrm{e} / \mathrm{MJ}$.

\section{Biodiesel}

\section{Algal biodiesel produced via dry extraction and transesterification}

The meta-analysis - MABEL, developed by our group reports life cycle energy use and GHG emissions from algal biodiesel produced via dry extraction and transesterification and data are from six previously published algae life cycle studies. 'Base case' scenario in MABEL - industrial $\mathrm{CO}_{2}$ with bioelectricity as coproduct derived from residual biomass via anaerobic digestion is used as the algal biodiesel benchmark. Results show that EROI is 1.39 and GHG emissions are $0.17 \mathrm{~kg}$ per vehicle kilometer traveled. As described in MABEL supporting information, the efficiency of internal combustion vehicle $\left(\eta_{I C V}\right)$ using biodiesel is $0.39 \mathrm{~km} / \mathrm{MJ}$. Equation 3.3 shows the calculation of GHG emissions per MJ algal biodiesel:

$$
0.17 \frac{\mathrm{kgCO}_{2} e}{V K T} \times \frac{1000 \mathrm{~g}}{\mathrm{~kg}} \times \frac{0.39 \mathrm{VKT}}{\mathrm{MJ}}=66.3 \mathrm{gCO}_{2} / \mathrm{MJ} \text { Eq } 3.3
$$

Soybean biodiesel 
In the soybean biodiesel pathway document of LCFS program, GHG emissions per $\mathrm{MJ}$ are $21.25 \mathrm{gCO}_{2} \mathrm{e} / \mathrm{MJ}$ and energy consumption per mmBTU produced is 301,413 BTU. Thus the energy ratio is computed as:

$$
1000,000 B T U \div 301,413 B T U=3.32
$$

In Argonne GREET model results, soy-derived biodiesel emits $2762 \mathrm{gCO}_{2} \mathrm{e}$ and consumes 94,837 BTU per gallon gasoline. Thus the GHG emissions per MJ are:

$$
\frac{2,762 \mathrm{gCO}_{2} e}{\frac{0.001055 \mathrm{MJ}}{B T U} * 113,602 \mathrm{BTU}}=21.9 \mathrm{gCO}_{2} e
$$

\section{Petroleum fuels - diesel and gasoline}

\section{Low sulfur diesel (LSD)}

In the petroleum derived low sulfur diesel pathway document of LCFS' program, the $\mathrm{GHG}$ emissions per $\mathrm{MJ}$ are $96.20 \mathrm{gCO}_{2} \mathrm{e} / \mathrm{MJ}$ and the energy consumption per million BTU produced is 327,869 BTU. Thus the EROI ratio is 3.05 .

In Argonne GREET model, the energy use and GHG emissions per gallon gasoline equivalent produced are 27,475 $\mathrm{BTU}$ and $11,056 \mathrm{gCO}_{2} \mathrm{e}$. Thus the EROI is computed as 4.13 and $\mathrm{GHG}$ emissions per $\mathrm{MJ}$ is $90.27 \mathrm{gCO}_{2} \mathrm{e} / \mathrm{MJ}$ using the same principle as previous ones.

\section{Gasoline}


In the petroleum derived gasoline pathway document of LCFS program, the GHG emissions per $\mathrm{MJ}$ are $94.38 \mathrm{gCO}_{2} \mathrm{e} / \mathrm{MJ}$ and the energy consumption per million $\mathrm{BTU}$ produced is 327,869 BTU. Thus the EROI ratio is 3.71 .

In Argonne GREET model, the energy use and GHG emissions per gallon gasoline equivalent produced are 27,475 $\mathrm{BTU}$ and $11,056 \mathrm{gCO}_{2} \mathrm{e}$. Thus the EROI is computed as 4.75 and $\mathrm{GHG}$ emissions per $\mathrm{MJ}$ is $94.38 \mathrm{gCO}_{2} \mathrm{e} / \mathrm{MJ}$ using the same principle as the other benchmarks.

\subsubsection{Sensitivity analyses}

A sensitivity analysis was performed in Crystal Ball to identify components of this algal HTL pathway that contribute most directly to overall energy use and GHG emissions. The sensitivity analysis results are presented for the three scenarios. The results of this analysis are presented in Figure 3.2. Each error bar represents a variation of $\pm 10 \%$ in each input parameter and its effect on the model outputs. These results reveal interesting differences in the immediate priorities and future priorities for the algae industry that will be discussed in section 3.4.

\subsection{Results and discussion}

The energy return on investment (EROI) and GHG emissions for producing diesel and gasoline from algae using HTL are presented in Figures 3.2a and 3.2b, respectively. The results show that currently deployed algae-to-energy production processes using HTL have energy burdens and GHG emission profiles that are similar to conventional 
biofuels, cellulosic ethanol and soybean biodiesel. The GHG emissions are slightly lower than other existing algae-to-energy processes based on transesterification as captured in the MABEL (38). The results are benchmarked against both biofuels (conventional ethanol, cellulosic ethanol, and biodiesel) and to petroleum-derived fuels (gasoline and low sulfur diesel). The data for the biofuels was obtained from a variety of published meta-analyses and the estimate for petroleum-derived fuels was obtained from GREET. These results are generally consistent with the findings of others (17) and suggest that even though algae biofuels present considerable benefits relative to conventional biofuels, many of those benefits have yet to be realized.

EROI is an attractive metric for evaluating proposed bioenergy pathways because it can distill complex and integrated energy production systems into one measure of the thermodynamic feasibility of an energy production process. Any EROI value greater than one suggests that the process will generate more energy than is invested. Petroleumderived fuels once exhibited EROI values on the order of 50-100, but as petroleum reserves have become depleted and reservoirs are exploited in more remote locations, EROI has dropped from $\sim 100$ to roughly 4-5 for both gasoline and diesel (3). The results of this modeling effort show that the EROI of current HTL processes is approximately 1. However, over time, EROI could increase to $2.5-3.0$. EROI has a few important limitations, primarily in that it does not prioritize useful energy and it ignores market factors that would make some energy outputs (e.g., liquid fuels) more desirable than others (e.g., $\left.\mathrm{CH}_{4}\right)$. Nevertheless, it represents a valuable first estimate of the viability of different fuel production pathways relative to conventional benchmarks. 
For all fuels, lower life cycle greenhouse gas emissions are desirable and the values closest to zero would represent the most carbon neutral fuel sources. The lowsulfur petroleum diesel appears quite attractive from an EROI perspective but it emits considerably more GHGs $\left(94.3 \mathrm{gCO}_{2} \mathrm{e} / \mathrm{MJ}\right)$ than all of the algae scenarios modeled here. This has important implications for developing climate policy objectives via low carbon fuel standards. Notably, the soybean biodiesel estimate here, which was adapted from Hill et al. 2006 (9), does not incorporate indirect land use effects, which have recently emerged as important factors influencing the carbon accounting of conventional biofuels. These effects were also not considered for algae because its cultivation has not been carried out long enough to produce representative agricultural economic data. It is expected that algae's indirect land use carbon impacts will be much smaller than those of other crops because algae can be cultivated on marginal land. 
a.
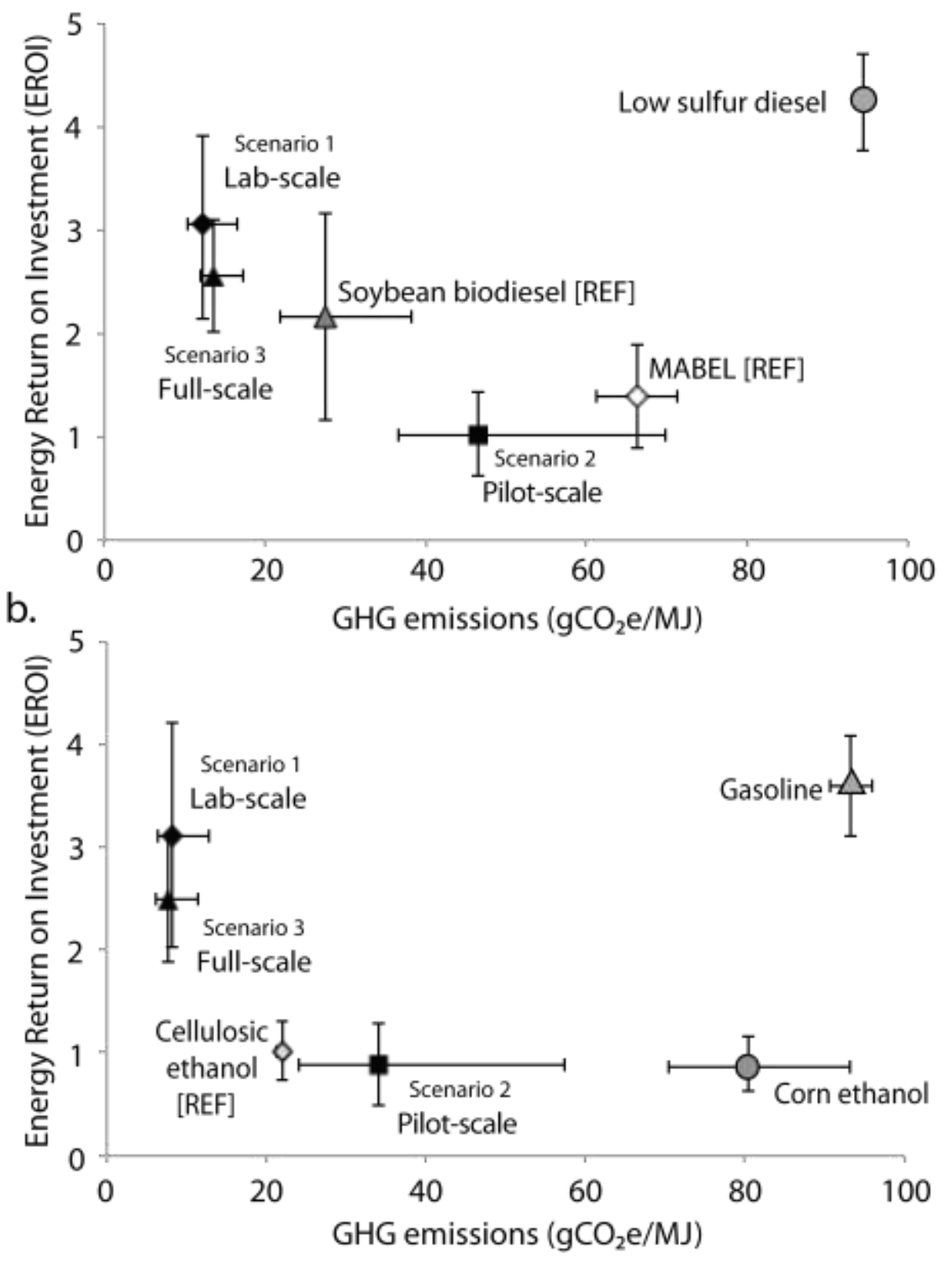
Figure 3.2 The EROI ratio and GHG emissions/MJ of (a) algae-derived diesel and (b) algae-derived gasoline produced using HTL. The results are benchmarked against commercialized biodiesel or bioethanol as well as and petroleum-derived versions of the drop-in fuels. Better outcomes are in the upper left hand corner of the plots (i.e., high EROI, low GHG emissions). Error bars correspond to $90 \%$ confidence intervals from the Monte Carlo simulations carried out here. Soybean biodiesel data source: (9); cellulosic ethanol data sources: $(73,74)$; corn ethanol data sources: $(6,62,74)$; MABEL data source: (38).

The lab and full-scale scenarios both have EROI ratios that are somewhat greater than one (3.1 and 2.6, respectively) and lower GHG emissions than all other biofuels (12.3 and $13.6 \mathrm{gCO}_{2} \mathrm{e} / \mathrm{MJ}$ respectively). This is expected since well-controlled laboratory conditions cannot typically be scaled up to field conditions without some loss in efficiency. These results underscore the difficulty of extrapolating future full-scale life cycle burdens from current bench-scale or pilot-scale parameter values. More notably, the full-scale scenario suggests that the improvements in efficiency that the industry foresees in the coming years would go a long way toward closing the gap between the maximally efficient processing (as captured in the laboratory scenario) and the current state-of-theart in the field.

Interestingly, using HTL to make gasoline from algae has a considerably lower GHG footprint and a comparable EROI relative to conventional ethanol made from corn on a per MJ basis. This is important because corn-based ethanol is widely deployed in the United States and these data suggest that a shift to algae-derived gasoline could have immediate climate benefits even using existing technologies. In addition, given the technological improvements that the industry anticipates will occur, the benefits of algaederived gasoline will likely improve. This is in contrast to the corn-ethanol industry, which relies almost entirely on proven technologies. 
The breakdown of energy use and GHG emissions by step within the supply chain is presented in Figure 3.3. As shown in Figure 3.2, the highest impacts are observed consistently for the 'pilot-scale' scenario. Within the supply chain production chain for all three processes, the HTL conversion process is a significant driver of energy use and there are certainly opportunities to improve heat recapture and efficiency in this step that will have important impacts on the overall energy balance for the production process. The burdens of extracting the biocrude from the raffinate stream are relatively minor though these are sensitive to the choice of solvent (e.g., toluene or hexane). Also integral to the process supply chain are efforts to improve the efficiency of pumping and mixing as well as the biomass dewatering step. These are being explored actively by the industry though it is likely that significant improvements in these areas will be limited, and even in fullscale systems, these will represent an important source of the burdens in the supply chain.

Much of the life cycle burden comes from the upstream production of nutrients. Nutrients are a perennial challenge to large-scale algae bioenergy deployment, and this result puts into context the underlying physical and chemical bottlenecks associated with deploying algae biofuels (15). Current efforts to recycle nutrients are not efficient $(12.5 \% \pm 3 \%)$, and this has an important impact on the overall burdens of the HTL value chain. As it has been discussed in Frank et al 2013 (17), the nitrogen and phosphorus ratio in raffinate stream out of HTL unit is not suitable for efficient anaerobic digestion thus gasification is a technical option to recycle nutrients. However, gasification requires large amount of hydrogen the production of which bears dramatic environmental burdens. 
Extensive research has been rigorously on-going in the lab to solve this nutrients recycle issue from both the sustainable and economic perspective.

$\mathrm{CO}_{2}$ supply also represents an important possible area of improvement. The potential to implement innovative $\mathrm{CO}_{2}$ capture technologies (e.g., direct air capture and capture from the flue gas of coal fired power-plants) versus industrial $\mathrm{CO}_{2}$ production (from steam methane reforming) will have very important impacts on the environmental profile of algae-to-energy production. As there is increasing demands for $\mathrm{CO}_{2}$ to achieve environmental goals, $\mathrm{CO}_{2}$ is becoming a commodity that also drives such technology development, especially in Europe. For example, OCAP in Netherlands collects large amount of high quality $\mathrm{CO}_{2}$ that is emitted by Shell and Abengoa and transports $\mathrm{CO}_{2}$ via pipelines and an extensive distribution network to bio-ethanol producers and potentially algae biomass producers. This design both reduces $\mathrm{CO}_{2}$ emissions significantly by replacing natural gas combustion for $\mathrm{CO}_{2}$ supply purposes and recycle $\mathrm{CO}_{2}$ emissions from emitters (e.g., Shell and Abengoa).

Downstream processing of the algae biocrude could also have important impacts on the overall energy and GHG profiles of algae derived biofuels produced via HTL. Processing in a conventional refinery represents the second largest source of burdens besides upstream nutrients and $\mathrm{CO}_{2}$. Again here, algae bioenergy producers will have limited influence in terms of process improvement, but when compared to petroleumderived fuels, algal biocrude can offer several advantages due to its elemental composition, and low sulfur content, and relative lack of heavy metals. Consequently, atmospheric distillation, desulfurization and heteroatom removal processes can be 
avoided when upgrading algae biocrude from HTL. Efforts to pre-treat or otherwise upgrade the fuel and integrate it into the refinery while simultaneously preserving the energy content of the fuel should be a top priority for refineries incorporating biocrude for the first time.

a.

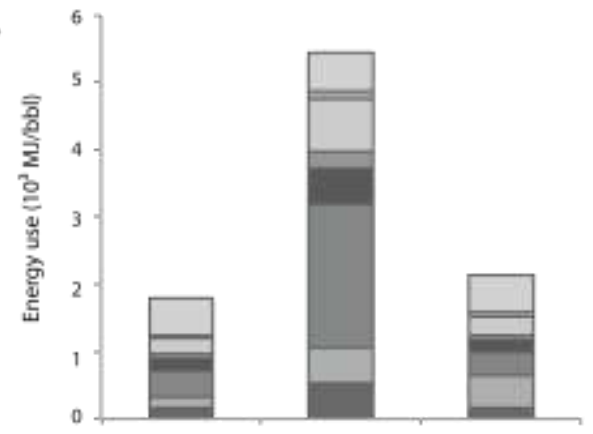

b.

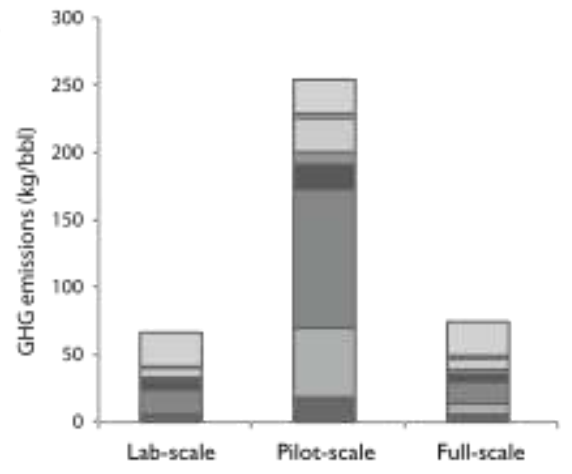

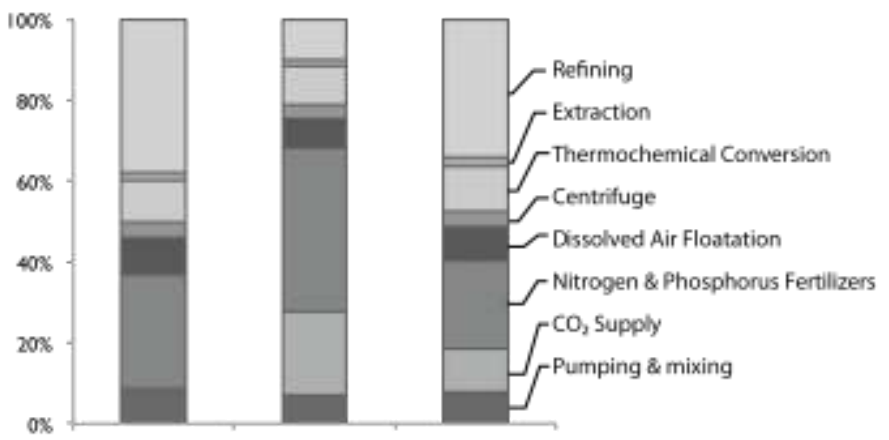

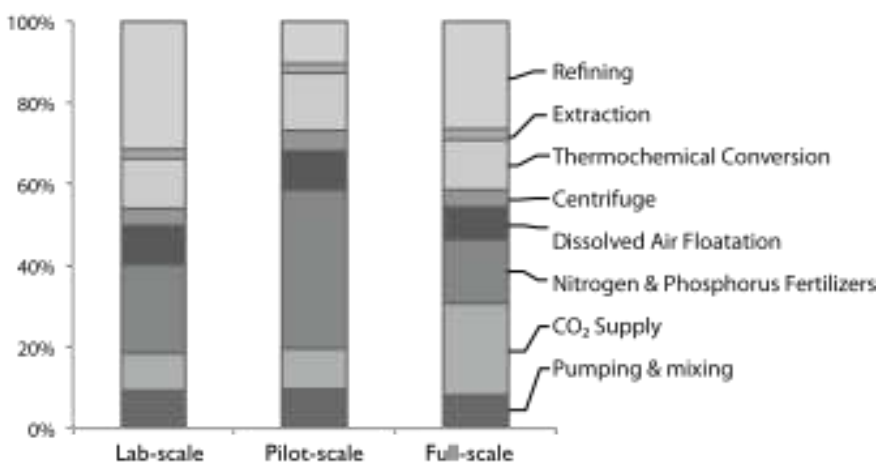

Figure 3.3 Energy use and GHG emissions per barrel biocrude. Energy use is the left plot of row a. and percentages of energy use are on the right plot of row a. GHG emissions per barrel and the percentages of each step are presented in row $b$. HTL conversion process is depicted for the three scenarios: lab-, pilot-, and full-scale. Algal biocrude is upgraded to diesel and gasoline in petroleum refinery. These results are for production of diesel (the results for gasoline are the same except that the proportion in refining changes slightly).

\section{Model Sensitivity}

A sensitivity analysis was performed to identify components of this algal HTL pathway that contribute most directly to overall energy use and GHG emissions. The sensitivity analysis results are presented here for the pilot-scale and full-scale scenarios. 
The lab-scale scenario is not representative of a realistic fuel production case but it is presented in the supporting information of (16). The results of this analysis are presented in Figure 3.4. Each bar represents a variation of $\pm 10 \%$ in each input parameter and its effect on the model outputs. These results reveal interesting differences in the immediate priorities and future priorities for the algae industry.

For the pilot-scale scenario, the LCA results are most sensitive to changes in nitrogen fertilizer production impacts, biocrude yield, heat recycling efficiency, industrial $\mathrm{CO}_{2}$ production, and nutrients recycling efficiency. Because the nutrient recycling efficiency is extremely low in the pilot facility and a certain amount of nitrogen ends up in biocrude, large amount of fertilizers are required to maintain the current level of production. Similarly, heat recycling efficiency becomes a driving factor when the value is low. Thus the production of nitrogen fertilizer and natural gas influence the performance dramatically. Biocrude yield also impacts the results by altering the energy output significantly. The production of industrial $\mathrm{CO}_{2}$ from steam reformed methane plant is very burdensome and the amount of $\mathrm{CO}_{2}$ supplied to the algae cultivation can be very large therefore it is also a top driving factor.

In the 'full-scale' scenario, however, a minor difference lies in $\mathrm{CO}_{2}$ supply, which no longer plays a key role on the impacts. This is because the full-scale scenario assumes that a new technology (direct air capture) will make it possible to avoid the use of heavily-burdensome industrial $\mathrm{CO}_{2}$ produced from steam methane reforming. Improvements in the upgrading process, (e.g., diesel yield from hydrotreating unit), are also expected to contribute to reduced burdens in future. Finally, it is interesting to 
consider what impactful parameters are within or outside the control of algae bioenergy companies. Factors pertaining to biocrude yield, as arising from biomass composition and catalyst selection, and also heat recycling efficiency are HTL parameters that can and should be improved through research and development at algae bioenergy companies. These parameters were found to have significant impacts on energy use and GHG emissions for both the pilot-scale and the full-scale scenarios. In contrast, factors pertaining to fertilizer production and electricity delivery also offer significant opportunities for improvement; however, these parameters are presumably outside of the domain of algae bioenergy companies.

Algae growth rate is one of many input parameters that separate the three scenarios. This parameter relies on several factors, including algae species selection and local insolation. As shown in Table 3.1, the full-scale growth rate is $16 \mathrm{~g} / \mathrm{m}^{2} / \mathrm{d}$, based on theoretical radiation use efficiency and meteorological data at a prospective location that is suitable for commercial-scale algae farming at commercial size. Biocrude yield in HTL unit also impacts the results significantly. In the 'pilot-scale' scenario, the energy use and GHG emissions of biomass conversion using HTL are higher than refining because of the low biocrude yield in HTL $(20 \% \pm 2 \%)$; whereas in the 'lab-scale' and 'full-scale' scenarios, conversion efficiencies as high as $60 \%$ can be achieved. 
a.

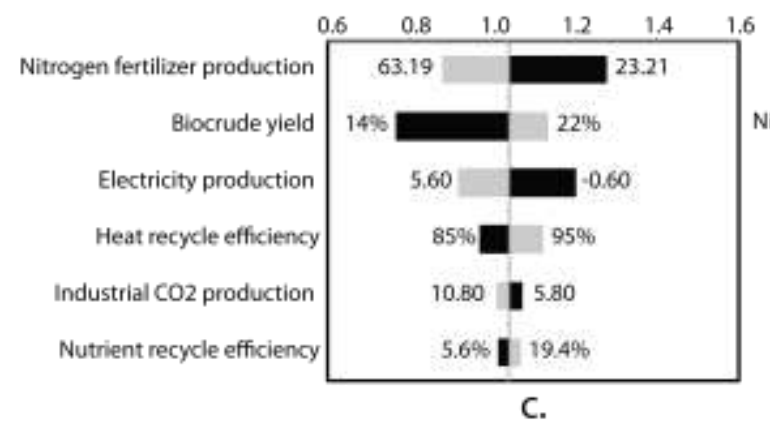

b.

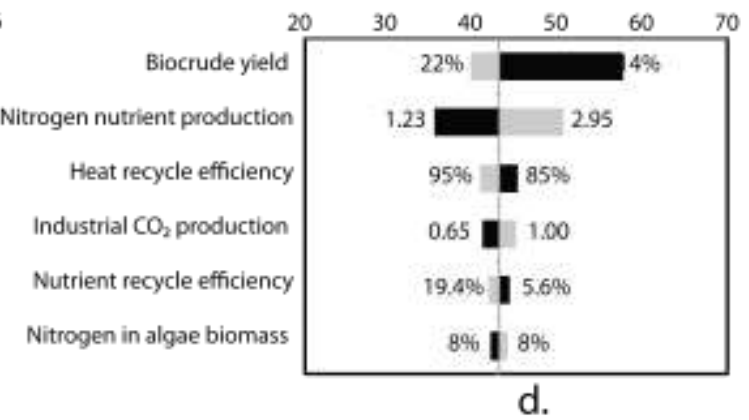

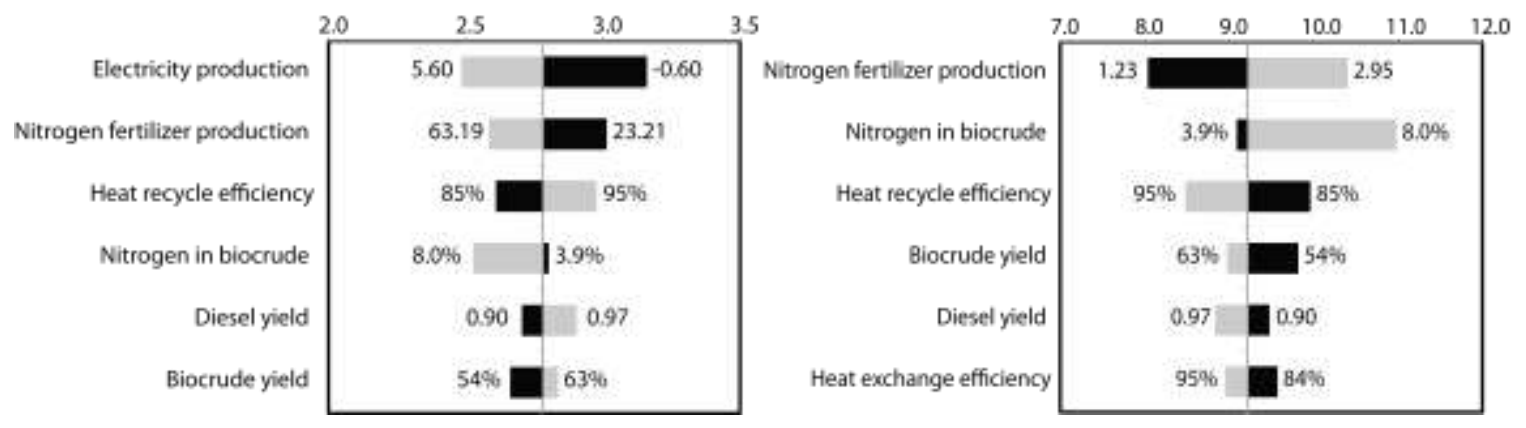

Figure 3.4 Tornado plots from sensitivity analyses show the extent to which (a) EROI, pilot-scale; (b) GHG emissions, pilot-scale; (c) EROI, full-scale; (d) GHG emissions, full-scale are sensitive to a $\pm 10 \%$ change in the input parameters. The centerline represents the baseline value of EROI or GHG emissions in each scenario. The black and gray shaded bars indicate direct and inverse relationships, respectively. For example, a $10 \%$ increase in the biocrude yield increases EROI from 1.01 to 1.14. More detailed sensitivity analysis information, including tornado plots for the 'lab-scale' scenario, are provided in the Supporting Information.

\subsection{Conclusions}

The model developed here is the first to characterize the life cycle energy and greenhouse gas emissions associated with algae-to-energy processing using field data collected at a pilot-scale facility. The model is also used to explore how anticipated technological improvements could impact the nascent algae bioenergy industry in the coming years. For example, biocrude yield from HTL is expected to increase as process optimizations and improvements are implemented is applied. Similarly, the identification 
of algae species with biomass compositions that are most suitable for HTL will also improve the process profile. Improvements in the heat recycle efficiency of the HTL unit can also reduce the energy burden and carbon emissions of the conversion process. Even without many of these advancements, the results indicate that HTL produces more favorable life cycle burdens as an algae conversion process than conventional lipid extraction followed by transesterification.

The results of this work show that even using existing technology, significant GHG emission reductions can be achieved using algae-derived biofuels when compared to the petroleum benchmarks and existing bio-ethanol pathways. Even though the EROI ratios of algae-to-energy production are not as favorable as petroleum fuels in the short term, displacing petroleum equivalents with algal liquid fuels that are much less carbon intensive will contribute to substantial carbon mitigation in the transportation sector. The environmental burdens of this algal biofuel production system (under current field conditions) are comparable to crop-based biofuels such as corn ethanol and soybean biodiesel. An important element of this work is that it extrapolates forward and the data suggest that algae-based biofuels will ultimately surpass advanced biofuels (such as cellulosic ethanol) in terms of both EROI and GHG emissions. 


\section{Chapter 4}

\section{Historical Land Use Change: Implications for Biofuels Carbon Accounting}

\subsection{Introduction}

Biofuels have been widely recognized as important means to reduce carbon emissions and offer potential energy security and rural economic development (75). However, researchers and stakeholders have concerns that the feedstock for conventional biofuels production can displace agricultural production (76). This displacement could drive expansion of cropland to replace the crops that had been used for biofuels. This impact could result in direct and indirect land conversion for agriculture and high carbon stocks being released $(25,28)$. Significant GHG emissions from such land conversion 
could potentially negate the carbon credits from using biofuels in the first place (77). Therefore policy makers have been making efforts to identify the potential effects of land use change (LUC) in biofuels policy to avoid negative impacts. For example, the U.S. Renewable Fuel Standard (RFS2), as amended in 2007, requires (i) that biofuels produced from crops or crop residues only qualify as "renewable" if their feedstock is produced on cropland cleared before the date of the regulation, and (ii) LCA to determine biofuel GHG emissions must account for ILUC (78).

Appropriate methods for accounting of these LUC emissions are subject to ongoing debate $(26,27)$ because the quantification of LUC is highly complex due to underlying socio-economic, biophysical, cultural, and political factors $(79,80)$. Current modeling efforts by LCA practitioners and policy makers have focused largely on indirect land use change (ILUC) using consequential life cycle analysis (CLCA) (25). ILUC, which cannot be directly observed or measured, occurs as an unintended consequence of land decisions elsewhere, e.g., switching cropland from food production to biofuel feedstock production (25). The globally integrated nature of agricultural commodity markets ensures that price signals from crop switching to biofuel feedstock are transmitted globally and are therefore capable of triggering land use change in essentially any agricultural region of the world (81). A variety of agro-economic and geological models have been developed and implemented to estimate ILUC. For example, the US Environment Protection Agency (EPA) estimated ILUC using an integrated framework centered on two partial equilibrium economic models (FASOM and CARD-FAPRI) (78); GTAP, a computable general equilibrium model, was used by 
California Air Resource Board (CARB) to calculate ILUC emissions (73); in the European Union, different methodologies were also applied such as AGLINK-COSMO and MIRAGE(82). Although the economic models are different, the mechanisms of the LCA methods that form the basis for these analyses are inherently consequential.

Consequential LCA (CLCA) provides information about how a system responds to a marginal change in the output of a functional unit of a product both inside and outside of the life cycle of the specified product $(83,84)$. It is applicable for informing policy makers on the change in total emissions from policy decision taking into account both direct and indirect effects (85). Despite the fact that CLCA is well suited for estimating environmental impacts, the practical application of this methodology faces challenges in terms of both economic modeling and applications to policy. For example, Searchinger et al. illustrates the potential magnitudes of CLCA from biofuel feedstock cultivation on global commodity prices and land markets (25). As demonstrated in this study, economic mechanism in a CLCA model could include numerous interactions and debatable assumptions. And different CLCA policy scenarios and technology scenarios are neither comparable nor consistent with each other, e.g., ILUC estimate of corn ethanol pathway cannot be compared with that of soybean diesel. Also, because these two estimates both considered the indirect market effects, double counting of total emissions will occur if ILUC estimates of two individual fuel pathways are aggregated in a certain scenario.

Attributional LCA (ALCA) is an alternative but not a direct substitute to CLCA. It is used to compute the absolute material flows and impacts associated with a functional 
unit of activity (86). This method provides information of the direct impacts associated with the life cycle of a product and describes the stoichiometric relationships between the inputs and outputs, consequently model results have a known level of accuracy and low uncertainty. In the context of LUC accounting, a number of recent studies suggest that there can be great value in considering ALCA perspectives on this problem $(87,88)$. Unlike CLCA, market effects and non-market indirect effects are not included in ALCA. Emissions are allocated based on energy content, economic value, or mass and no double counting of emissions exists in ALCA models and different ALCA policy scenarios and fuel pathways can be aggregated. Although ALCA is not suitable for quantifying the total emissions change, the above characteristics of ALCA decide it is a more appropriate carbon accounting method for an individual supply chain. Some fuel policies have required ALCA approach for reporting life cycle impacts. For example, Renewable Energy Directive (RED) carbon reporting guidelines apply ALCA methodologies to identify opportunities for reducing direct impacts in different stages of the life cycle (89).

Currently, the attributional life cycle approach for quantifying LUC emissions has been limited to measuring direct land use change (DLUC) - emissions originating from the land where biofuel feedstock is actually produced(28). Analyses of these emissions generally focus on the special case of land cleared specifically to supply biofuel feedstock. In practice, very few sites used for biofuel feedstock cultivation are cleared exclusively for this purpose. For example, the European Fuel Quality Directive ("FQD") limits DLUC emissions in part by restricting land used for biofuel feedstock production according to the land cover in 2008 (90). The general convention in biofuel lifecycle 
analyses (LCA) is to assume zero DLUC emissions where cropland was originally cleared for another purpose, generally the production of food, feed, or fiber, and is subsequently diverted for biofuel feedstock production (28). This convention ignores the substantial DLUC emissions embodied in agricultural landscapes from their original conversion to agricultural production. This results in strong path dependence in LCA results (e.g., bias according to the "purpose" and timing of land conversion), which is particularly irrational given the substitutability of agricultural land and the potential reversibility of land use change.

In this study, I propose an innovative attributional approach of accounting for carbon emissions from land use change: historical land use change (HLUC). HLUC is computed as historical direct land use change emissions for a parcel of land used in biofuel feedstock production and an allocation of those emissions across all associated agricultural production - both before and after conversion to producing biofuel feedstock. It can be calculated conveniently and transparently for any site in the world using publically available historical cropland data and land cover data. Location-dependent HLUC estimates can be applied directly or aggregated in a variety of ways to report carbon accounting for a region, feedstock, or fuel type.

HLUC, as an ALCA framework for understanding LUC emissions, is efficient, fair, methodologically sound, transparent, and can be evaluated in parallel with existing DLUC/ILUC frameworks to inform policy and carbon reporting. It could have a number of important benefits. First, HLUC estimates of different policy scenarios and technology options are consistent and directly comparable. It could provide carbon accounting 
information that can be applied directly or aggregated in a variety of ways to support climate motivated biofuel and land use policies for a region, feedstock, or product type (e.g., fuel type). Second, HLUC eliminates path-dependence in carbon calculations, which creates irrational asymmetries and equity issues between developed nations, where the benefits of decades (or centuries) of land cultivation are not considered in existing ALCAs, and developing countries where land conversion is proceeding rapidly (91). Third, HLUC can be calculated conveniently for any site in the world using publically available historical cropland data, a few assumptions about associated LUC emissions, and a decision regarding the appropriate allocation methodology (92).

Although I propose an ALCA method in this study, it is not meant to replace existing CLCA frameworks entirely. Life cycle analysis models should be used based on their functionalities. A combination of these two frameworks and interdisciplinary research will improve our understanding of biofuels LUC issue more comprehensively.

\subsection{Literature Review}

Land use change accounting may involve agricultural, economic, biophysical, geological and political factors. Policy makers and LCA practitioners have conducted considerable interdisciplinary research in the above fields to develop appropriate LUC modeling frameworks. The major components of the existing LUC accounting frameworks are: carbon stocks of various geological regions, temporal profiles of carbon emissions from different land types, agro-economic models implemented in biofuel 
policies across the world, and two distinct LCA approaches. The current studies on these aspects are discussed briefly in this section.

\subsubsection{Carbon stocks of ecosystems and time profiles of carbon release}

Land use change (LUC) emissions are generated from carbon stocks being released from both vegetation and topsoil of the undisturbed ecosystems that are cleared. The LUC carbon emissions of a certain fuel type largely depend on the feedstock and the original land cover at the location where land is cleared. For example, in the U.S., corn ethanol is the major biofuel product in the Midwest where large areas of savanna have been converted to corn farms. In contrast, Southeast Asia has large areas of peatland, which contains significantly higher amount of carbon than other land covers, and this is being drained to build oil palm plantations for the production of biodiesel $(87,93)$.

A number of research studies have explored the carbon stocks associated with different vegetation types and the soils of major ecosystems. Houghton et al. study (9496) the carbon contents of terrestrial biota and soils of five types of forest, two types of woodland, grassland and pasture. These data form the basis of numerous subsequent land use change studies. The carbon contents of vegetation and soils in forests are generally much higher than that of woodland and grassland. For example, the carbon in vegetation of tropical forest is approximately 200 tonne/ha, which is nearly 10 times as that of tropical grassland, 18 tonne/ha (94). Peatland in southeast Asia has drawn increasing attention from both academia and policy sector due to the conversion of these lands to oil palm plantation and the significant amount of carbon released $(28,87,93,97)$. Though 
the total area of peatland in the world is relatively insignificant compared with other ecosystems, the carbon debt of land conversion from peatland can be as high as 750 tonne/ha(28).

Net carbon fluxes from various terrestrial ecosystems to the atmosphere result from land conversion to agricultural purposes. These fluxes comply with certain time profiles due to the gradual soil carbon release over time that results from tillage $(94,98)$. For example, it was assumed in Houghton et al. that $20 \%$ of the soil carbon is lost during the first 5 years and another 5\% is lost during the following 20 years. Davidson and Ackerman (98) support this notion with results suggesting that most of the soil carbon losses occur within the first few years following cultivation.

\subsubsection{Time-dependent effects on biofuel's GHG emissions and $\mathrm{CO}_{2}$ decay in the atmosphere}

Although $\mathrm{CO}_{2}$ is the most important anthropogenic greenhouse gas emissions, only around half of the anthropogenic $\mathrm{CO}_{2}$ currently remains in the atmosphere. The terrestrial biosphere and the ocean are the two carbon sinks that take in the rest of the

anthropogenic $\mathrm{CO}_{2}(99)$. Nonetheless, the capacities of these two natural $\mathrm{CO}_{2}$ sinks could be reduced as a result of global climate change due to increasing GHG concentrations $(100,101)$. The Intergovernmental Panel of Climate Change (IPCC) has investigated the feedbacks between climate change and the terrestrial system and developed new emission scenarios projecting the future changes (102). The feedbacks involve atmospheric $\mathrm{CO}_{2}$, non- $\mathrm{CO}_{2}$ radiative forcing agents, surface temperature change, the carbon cycle and the 
hydrological cycle. Joos et al. 2001 developed the Bern Carbon Cycle model that couples physical-biogeochemical models that includes a dynamic global vegetation model and atmosphere-ocean general circulation model by IPCC (99). Bern Carbon Cycle model is widely used for anticipate the atmospheric $\mathrm{CO}_{2}$ resulting from carbon emissions by fossil fuels, land use change and the carbon uptake (or release) by terrestrial sphere and the ocean $(103,104)$. Here in this study, Bern $2.5 \mathrm{CC}$ model is implemented as estimating $\mathrm{CO} 2$ residue from land use change in the atmosphere.

For LUC emissions from biofuel's life cycle, it has been argued that the potential carbon mitigation from biofuels deployment will change significantly by taking into consideration of the cumulative radiative forcing of amortizing the carbon emissions over a few decades of biofuel production life span $(103,105)$. The time profile of biofuel production process is very different from direct emissions from fossil fuels and current market-mediated LUC emissions have separated the LUC emissions from the actual biofuel production process by a number of economic links and physical distance. To properly account for the timing of LUC emissions in the biofuel life cycle, O'Hare et al. developed BTIME model, which includes Bern CC model and economic discounting, to capture such timing effect (103). In another study, Kendall 2009 advocated for a time correction factor, which is a ratio of emissions occurred at the outset of biofuel feedstock cultivation versus emissions amortized over a time horizon. 


\subsubsection{Current ILUC modeling approaches in biofuel policies and uncertainty of such estimates}

The basic concept of ILUC is to assume that diverting certain agricultural commodities to biofuel feedstocks places additional demand on top of the existing uses for these commodities (e.g., food, animal feed or fibre) (25). To meet this additional demand, production of commodity crops may be displaced onto areas of land not currently available for arable crop production, thus causing a change of land use. The displacement effects of ILUC may cross national borders and different feedstock crops. For example, demand for corn for US ethanol could trigger expansion of corn production in developing countries in order to maintain the supply of corn in the US. Equally, ILUC effects can occur within the same feedstock crop. For example, increased demand for corn for ethanol could result in converting land from other uses to agricultural production so that existing non-biofuel demands for corn can be met.

In the Renewable Fuel Standard (RFS2) final rule by U.S. Environmental Protection Agency (EPA)(78), research teams established an integrated framework centered on two partial equilibrium agricultural-economic models to quantify total ILUC emissions (i.e., FASOM for domestic LUC and FAPRI-CARD for international LUC). California Air Resources Board (CARB) used GTAP, a computable general equilibrium (CGE) model developed by Purdue University, to estimate ILUC emissions for Low Carbon Fuel Standard (LCFS) rule making (73). On the European Union side, multiple methodologies have been applied in the biofuel policy making (106). Two biofuel 
policies had been legislated since December 2008, Renewable Energy Directive (RED) and Fuel Quality Directive (FQD), to define sustainability criteria and target GHG emissions from transportation fuels (90). The European Commission has launched a number of pieces of work in order to better understand the ILUC associated with biofuels. In the first stage, International Food Policy Research Institute (IFPRI) established a framework including an extended version of GTAP and MIRAGE model that integrated land use maps, energy, land use module and detailed treatment of biofuel feedstocks to calculate GHG emissions (107). On the second stage, a partial equilibrium model (i.e. AGLINK-COSIMO/OECD) and a CGE model with MIRAGE-BioF are used to resolve additional questions related to ILUC emissions (106).

The ILUC estimates using agricultural and economic models are highly uncertaint owing to the parameters and system modeling assumptions (i.e., assumption of perfect elasticity, linear substitution, etc.). Plevin et al.(27)developed a reduced-form model to evaluate the broad bounding range for emissions from ILUC for US corn ethanol, which is from 10 to $340 \mathrm{gCO}_{2} / \mathrm{MJ}$.

Only recently, historical approach of land use change from biofuels has been considered as an alternative LUC accounting methodology by Joint Research Center at the Workshop on Sustainable Biofuels: addressing Indirect Land Use Change in 2013. 


\subsection{Data sources}

\subsubsection{Historical cropland dataset and global vegetation land cover} dataset

Open-source historical cropland data were obtained at a resolution of 0.5 degree $(\sim 3000 \mathrm{~km} 2)(92)$. It is in NC format and is opened in Matlab. It can be downloaded here (108). At a resolution of 0.5 degree, the world is divided in to $720 \times 360$ grids and four decimal percentage of cropland is reported in each grid for every year from 1700 to 2007 . Even though the size of the cells is large (i.e., $55 \mathrm{~km}$ on one side), cropland percentages with four decimals in this data set still provide a relatively more accurate approximation of land cover within a region.

Native land cover types were also obtained from this source. Their data are also stored in a file in NC format with resolution of both $5 \mathrm{~min}$ and 0.5 degree. It can be downloaded free of charge (109). For a given parcel of land, specified by its longitude and latitude, relevant data were extracted from this dataset using Matlab software (a copy of the code for performing this data manipulation is included in the appendix to this dissertation). For the analysis presented here data with a resolution of 0.5 degrees is used to maintain consistency with other datasets for which higher resolution data are not available. The data resolution issues are described in more detail in the sensitivity analysis section. There are 15 land types in this dataset and these are listed in Table 4.1 (the code for water or undefined area is 9999). Peatland in South Asia is too small to be defined as one of the land types here in this dataset, but it has been shown to be important 
in terms of indirect land use impacts from these regions therefore I applied the percentage of peatland covering the two selected regions in this study from other sources (93).

Table 4.1 Land types in natural vegetation dataset

\begin{tabular}{|l|l|l|}
\hline $\begin{array}{l}\text { Code in } \\
\text { dataset }\end{array}$ & Represented land cover type & Acronym in HLUC model \\
\hline 1 & Tropical evergreen forest & TEF \\
\hline 2 & Tropical deciduous forest & TDF \\
\hline 3 & Temperate broadleaf evergreen forest & TempEF \\
\hline 4 & Temperate needleleaf evergreen forest & TempEF \\
\hline 5 & Temperate deciduous forest & TempDF \\
\hline 6 & Boreal evergreen forest & Not used in this study \\
\hline 7 & Boreal deciduous forest & Not used in this study \\
\hline 8 & Evergreen/Deciduous mixed forest & EDMix \\
\hline 9 & Savanna & SV \\
\hline 10 & Grassland & TG \\
\hline 11 & Densed shrubland & Not used in this study \\
\hline 12 & Open shrubland & Not used in this study \\
\hline 13 & Tundra & Not used in this study \\
\hline 14 & Desert & Not used in this study \\
\hline 15 & Polar desert/rock/ice & Not used in this study \\
\hline
\end{tabular}

\subsubsection{Carbon stocks in various ecosystems}

The carbon stocks of the land cover ecosystems studied here have been well characterized over the years. A detailed literature review was carried out and mean values of carbon stocks were derived for the land uses of interest here. The lower bound and upper bound were also extracted to enable uncertainty analysis. Plevin et al. carried out a detailed analysis of uncertainty in land use change and their ranges are used in this study if primary data was unavailable in the literature (27). Table 4.2 provides carbon stock 
data of vegetation and Table 4.3 provides carbon stock data for soils. In peatland, the carbon sequestration in oil palm plantation and carbon loss from soil were studied by Germer et al. (97).

Table 4.2 Carbon stocks in vegetation of different land types in HLUC model

\begin{tabular}{|l|l|l|l|l|l|}
\hline \multirow{2}{*}{ Land type } & \multicolumn{3}{|l|}{ Value of carbon stock in } \\
vegetation (ton C/ha) & Country & Source \\
\cline { 2 - 5 } & Choice & Low & High & & \\
\hline SV & 30 & 16 & 43 & US & $(110)$ \\
\hline TDF & 140 & 126 & 154 & Brazil & $(25)$ \\
\hline TEF & 200 & 180 & 220 & $\begin{array}{l}\text { Indonesia, } \\
\text { Brazil (high } \\
\text { resolution) }\end{array}$ & $(25)$ \\
\hline TempDF & 160 & 144 & 176 & $\begin{array}{l}\text { France, } \\
\text { Germany }\end{array}$ & $(94)$ \\
\hline TempEF & 120 & 108 & 132 & Germany & $(94)$ \\
\hline EDMix & 140 & 126 & 154 & $\begin{array}{l}\text { France, } \\
\text { Germany } \\
\text { (high } \\
\text { resolution) }\end{array}$ & $\begin{array}{l}\text { Mean of } \\
\text { TempDF and } \\
\text { TempEF }\end{array}$ \\
\hline TG & 10 & 9 & 11 & $\begin{array}{l}\text { Brazil (high } \\
\text { resolution) }\end{array}$ & $(94)$ \\
\hline Peatland & 160 & 131 & 160 & $\begin{array}{l}\text { Indonesia, } \\
\text { Malaysia }\end{array}$ & $(28)$ \\
\hline
\end{tabular}

Table 4.3 Carbon stocks in topsoil of different land types in HLUC model

\begin{tabular}{|l|l|l|l|l|}
\hline \multirow{2}{*}{ Land type } & \multicolumn{3}{|l|}{$\begin{array}{l}\text { Value of carbon stock in } \\
\text { topsoil (ton C/ha) }\end{array}$} & \multirow{2}{*}{ Source } \\
\cline { 2 - 4 } & Choice & Low & High & \\
\hline SV & 65 & 35 & 94 & $(111)$ \\
\hline TDF & 98 & 53 & 141 & $(25)$ \\
\hline TEF & 97 & 53 & 141 & $(94)$ \\
\hline TempDF & 134 & 72 & 194 & $(25)$ \\
\hline TempEF & 134 & 72 & 194 & $(94)$ \\
\hline EDMix & 133 & 72 & 193 & $\begin{array}{l}\text { Average value of } \\
\text { TempDF and TempEF }\end{array}$ \\
\hline TG & 42 & 23 & 61 & $(94)$ \\
\hline
\end{tabular}




\subsubsection{Selected regions \& energy yield}

\section{Corn ethanol}

In the US, ethanol derived from corn is the most widely consumed and most widely produced biofuel. Most corn is grown and processed into ethanol in the midwestern region. Bureau County in Illinois was selected for this analysis because it is one of the top producing counties in one of the top producing states (112).

\section{Sugar cane ethanol}

Brazil is the world's leading producer of sugarcane-based ethanol. Sao Paulo state is one of the two leading production regions in the state and was consequently chosen for this analysis.

\section{Rapeseed biodiesel}

The European Union produces large volumes of liquid biofuels, much of it derived from rapeseeds for the production of biodiesel. The top two biofuel producing nations are Germany and France (107) and the top two rapeseed producing regions are Hamburg and Leer/Niedersachsen (113). For France the Bourgogne region produces the most rapeseed for biodiesel (114).

\section{Palm oil biodiesel}

In South Asia, much of the biofuels is produced from palm oil, much of which is planted on peatlands that are drained to plant the palm (28). In Indonesia, most of the 
palm oil is produced in the province of Riau in central Sumatra (115). In Malaysia, the Sarawak region is the leading palm oil producing region (93).

\section{Energy yield}

To compute energy yield of each type of biofuels, crop yield data and fuel production data were used and the values incorporated into this analysis are summarized in Table 4.4.

Table 4.4 Energy yield of different biofuels

\begin{tabular}{|l|l|l|l|l|}
\hline Fuel type & Corn ethanol & $\begin{array}{l}\text { Sugar cane } \\
\text { ethanol }\end{array}$ & $\begin{array}{l}\text { Rapeseed } \\
\text { biodiesel }\end{array}$ & $\begin{array}{l}\text { Palm oil } \\
\text { biodiesel }\end{array}$ \\
\hline $\begin{array}{l}\text { Production } \\
\text { country }\end{array}$ & USA & $\begin{array}{l}\text { Brazil } \\
(116)\end{array}$ & $\begin{array}{l}\text { Germany } \\
\text { France } \\
(107) .\end{array}$ & $\begin{array}{l}\text { Indonesia } \\
\text { Malaysia } \\
(93) .\end{array}$ \\
\hline Crop yield & $\begin{array}{l}372 \mathrm{bushel} \\
\text { corn/ha/yr } \\
(117)\end{array}$ & $\begin{array}{l}77.6 \mathrm{tonne} \\
\text { cane/ha/yr } \\
(117,118)\end{array}$ & $\begin{array}{l}3437 \mathrm{~kg} / \mathrm{ha} / \mathrm{yr} \\
(117,118)\end{array}$ & \\
\hline Fuel yield & $\begin{array}{l}1008 \mathrm{gal} \\
\text { ethanol } / \mathrm{ha} / \mathrm{yr} \\
(73)\end{array}$ & $\begin{array}{l}1863 \mathrm{gal} \\
\text { ethanol/ha/yr } \\
(73)\end{array}$ & $\begin{array}{l}1334 \mathrm{~kg} \\
\text { biodiesel/ha/yr } \\
(119)\end{array}$ & $\begin{array}{l}4.3 \mathrm{tonne} \mathrm{palm} \\
\text { oil } / \mathrm{ha} / \mathrm{yr} \\
(115)\end{array}$ \\
\hline HHV & $84530 \mathrm{Btu} / \mathrm{gal}$ & $84530 \mathrm{Btu} / \mathrm{gal}$ & $38072 \mathrm{Btu} / \mathrm{kg}$ & $35980 \mathrm{Btu} / \mathrm{kg}$ \\
\hline Energy yield & $\begin{array}{l}\mathbf{8 9 8 5 0} \\
\mathbf{M J} / \mathbf{h a} / \mathbf{y r}\end{array}$ & $\begin{array}{l}\mathbf{1 6 6 1 5 3} \\
\mathbf{M J} / \mathbf{h a} / \mathbf{y r}\end{array}$ & $\begin{array}{l}\mathbf{5 3 6 0 7} \\
\mathbf{M J} / \mathbf{h a} / \mathbf{y r}\end{array}$ & $\begin{array}{l}\mathbf{1 6 3 2 3 2} \\
\mathbf{M J} / \mathbf{h a} / \mathbf{y r}\end{array}$ \\
\hline
\end{tabular}

\subsection{Methodology}

\subsubsection{Annual cropland increase}

For US, Brazil, Indonesia and Malaysia, historical cropland data from 1850 to 2007 were compiled. The uncertainty associated with data before 1850 was high but these data were crucial for understanding agricultural development in Germany and France, 
where considerable agricultural development occurred before 1850. For these countries, data from 1700 to 2007 are used. For all countries, the annual cropland increase can be obtained by subtracting the previous year's cropland value from current year's value. Negative value correspond to years in which cropland was abandoned or allowed to lay fallow that year. Annual historical cropland data were extracted using Matlab. The code is provided in Appendix.

\subsubsection{Annual carbon fluxes from land}

When land is cleared for agriculture, $\mathrm{CO}_{2}$ is emitted from vegetation and from soil. The emissions from vegetation occur primarily in the first year while the emissions from soil occur over longer time horizons. The carbon loss profile from the soils is a function of the type of ecosystem that existed on a land prior to agricultural development. When cropland is abandoned or in fallow, vegetation begins to recover and certain amount of $\mathrm{CO}_{2}$ in the atmosphere will be sequestered. The time profiles of land recovery are also different among between land types. This section describes these processes.

\section{Carbon flux from vegetation}

When land is cleared for agriculture purposes the carbon in vegetation is readily lost. In contrast, when cropland is allowed to lay fallow or abandoned, carbon sequestration occurs in the soils gradually. For all the non-forest systems, vegetation was assumed to recover to $100 \%$ of its original level. For forest land types, the carbon in vegetation was assumed to recover only to $75 \%$ of its original level (94). It was assumed that the time required for savanna or temperate grassland to reach steady state with regard 
to carbon cycling is 10 years; for tropical grassland it takes 5 years; and for all forest types, it takes 50 years to recover to $75 \%$ of original level. In the HLUC model, if carbon loss is positive in a given year, this indicates that carbon is emitted to the environment. If carbon loss is negative, this means that carbon is sequestered in soils, predominantly when cropland is abandoned or laid fallow. In the case of palm oil harvesting, only oil seeds are collected to process oil while the biomass in the plantation is maintained on the land. It is estimated that carbon is sequestered in oil palm plantations for the first 25-year cycle of oil palm growth. These results in a sequestration rate of $50 \sim 100 \mathrm{Mg} \mathrm{C} / \mathrm{ha}$. In the HLUC model, this sequestration rate is assumed to occur linearly over the 25 -year time span.

\section{Carbon cycling from soils}

Unlike carbon losses from above ground biomass, emissions from soil occur over longer periods of time. Published studies of carbon loss from soils following land use changes suggest that approximately $25 \%$ of the carbon stored in the soil will be lost in the first 25-years that the soil is in production (98). Most of that loss occurs early on with $20 \%$ lost in the first 5 years following clearing. In contrast, it is assumed that the recovery of soil carbon is linear. In savanna and temperate grassland, it takes 45 years for the soil to regain its original carbon stock. In tropical grassland, it takes 15 years for soil to regain its original carbon stock. For all types of tropical forest, it takes 15 years for soil carbon to recover $75 \%$ of their original level. For temperate forests, it takes 40 years for soils to reach $75 \%$ of their original carbon level. For oil palm grown on peatland, the emissions rate for peatland forest is applied $(8.6 \pm 3.8 \mathrm{Mg} \mathrm{C} / \mathrm{ha})(97)$. 


\section{CO2 emissions from regions containing different land types}

The Matlab code developed in this study extracts both historical cropland data and original natural vegetation data. The area of each land type is calculated and exported to an excel file. For those regions with more than one land types converted into cropland, the percentage of each land type in original land cover is calculated. Then the total HLUC of each land type is computed as weighted individual HLUC of different land types, which is the product of individual HLUC by its corresponding percentage. Here, France, Germany and Indonesia all have more than one land type in the studied region.

\section{Annul carbon fluxes}

Carbon fluxes between the land and the atmosphere were calculated using standard LUC accounting methods, including standard estimates of the carbon stock in vegetation and topsoil $(25,27,28)$. Vegetation carbon was assumed to be emitted in the year when the land was cleared. Temporal profiles of soil carbon emission are assumed to vary by land cover type, and in some cases fallow cropland is assumed to recover soil carbon (120). The temporal dynamics of carbon emissions from LUC, including clearing for agriculture, land fallowing, and abandonment, are modeled using published methods (94, 98). Crop yield data are primarily from National Agricultural Statistics Service Database of USDA (117).

The results presented in this methods section are for Bureau County, Illinois, one of the top corn producing counties in one of the leading biofuels producing states in the United States (117). To calculate HLUC for this region, the historical cropland use is first 
abstracted from land records and quantified for the period from 1850 to 2007 (Figure 4.1a). Accurate land use data are available after 1850 but this also coincides approximately when large-scale agricultural development of this region occurred. Next, annual emissions that result from these land use changes are quantified using established carbon flux models (Figure 4.1b)(25, 94, 97). Finally, three alternate schemes are used to allocate LUC between historical production of conventional crops and prospective bioenergy feedstock.

These calulations are summarized in Figure 4.1 where $a_{t}=$ cropland area in year $\mathrm{t}$ (ha); $e=\mathrm{CO}_{2}$ emissions from LUC in year $t$ (tonnes).
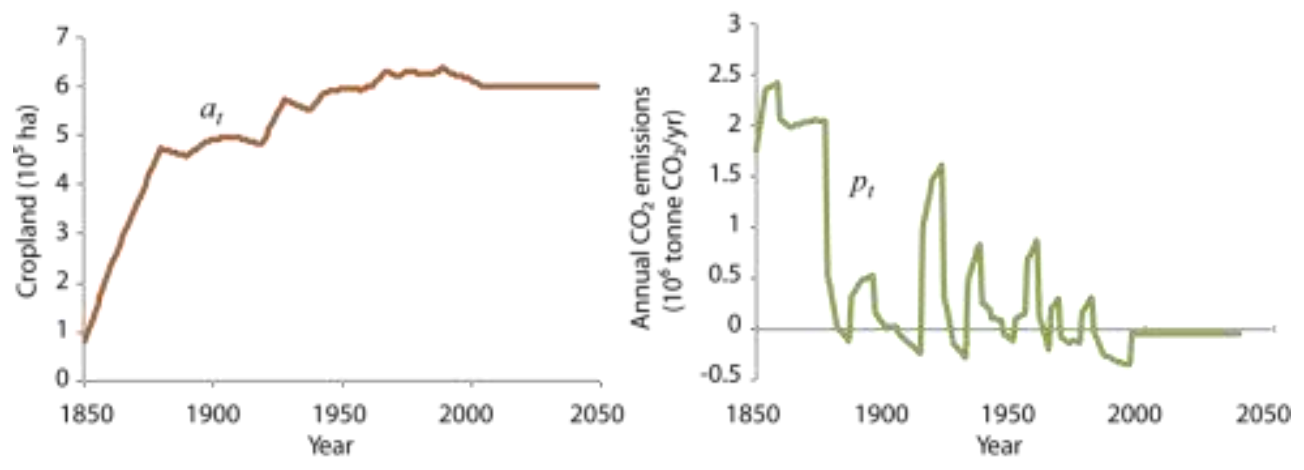

Figure 4.1 Historical cropland and annual emissions estimates for this activity based on carbon intensity. Historical direct land use change (HLUC) emissions can be readily calculated using historical cropland (left) and annual emissions estimates for this activity based on carbon intensity of different land use types (right). Here the data is for the top corn-producing county in Illinois, USA.

To understand spatial differences in the HLUC estimates, biofuels from different parts of the world were considered including corn ethanol (USA), rapeseed biodiesel (Germany and France), sugar cane ethanol (Brazil), and palm oil biodiesel (Malaysia and 
Indonesia). These regions have very different histories of agricultural expansion. Malaysia and Indonesia, for example, have seen relatively recent expansion, while the European cropland has been in active cultivation for centuries. France and Germany had substantial agricultural production before 1700, when the data record begins. To overcome this data constraint, I assume that early agricultural expansion varied linearly with population.

\subsubsection{Bern Carbon Cycle Model}

In order to track how much $\mathrm{CO}_{2}$ emissions remain in the atmosphere and compute the cumulative radiative forcing, I use revised version of Bern carbon cycle model by Joos et al. (99) and assume a background $\mathrm{CO}_{2}$ concentration of $378 \mathrm{ppm}$ (104). The unitless decay parameter of a pulse of $\mathrm{CO}_{2}$ at time $\mathrm{t}$ is given as:

$$
Q_{t}=a_{0}+\sum_{k=1}^{3} a_{k} e^{\left(\frac{-t}{\tau_{k}}\right)}
$$

where $a_{0}=0.217, a_{1}=0.259, a_{3}=0.338, \tau_{1}=172.9$ years, $\tau_{2}=18.51$ years, $\tau_{3}=1.186$ years.

The annual atmospheric $\mathrm{CO}_{2}$ at year $t$ is calculated as the carbon emissions times $Q_{t}$; the cumulative radiative forcing is calculated as the sum of annual atmospheric $\mathrm{CO}_{2}$.

\subsubsection{Allocation}

Four scenarios for allocating historical carbon emissions were explored and the results of Illinois, USA are summarized and described in Figure 4.2. Here $P_{1 A}=$ sum of annual $\mathrm{CO}_{2}$ emissions (tonnes); $e=$ energy yield of corn ethanol $(\mathrm{MJ} / \mathrm{ha} / \mathrm{yr}) ; p_{t}=$ 
cumulative $\mathrm{CO}_{2}$ in the atmosphere in year $\mathrm{t} ; B_{2 A}=$ cumulative $\mathrm{CO}_{2}$ in the atmosphere using Bern carbon model (tonnes); GWP100 = radiative forcing created by 1 tonne $\mathrm{CO}_{2}$ in 100 years (1/year).
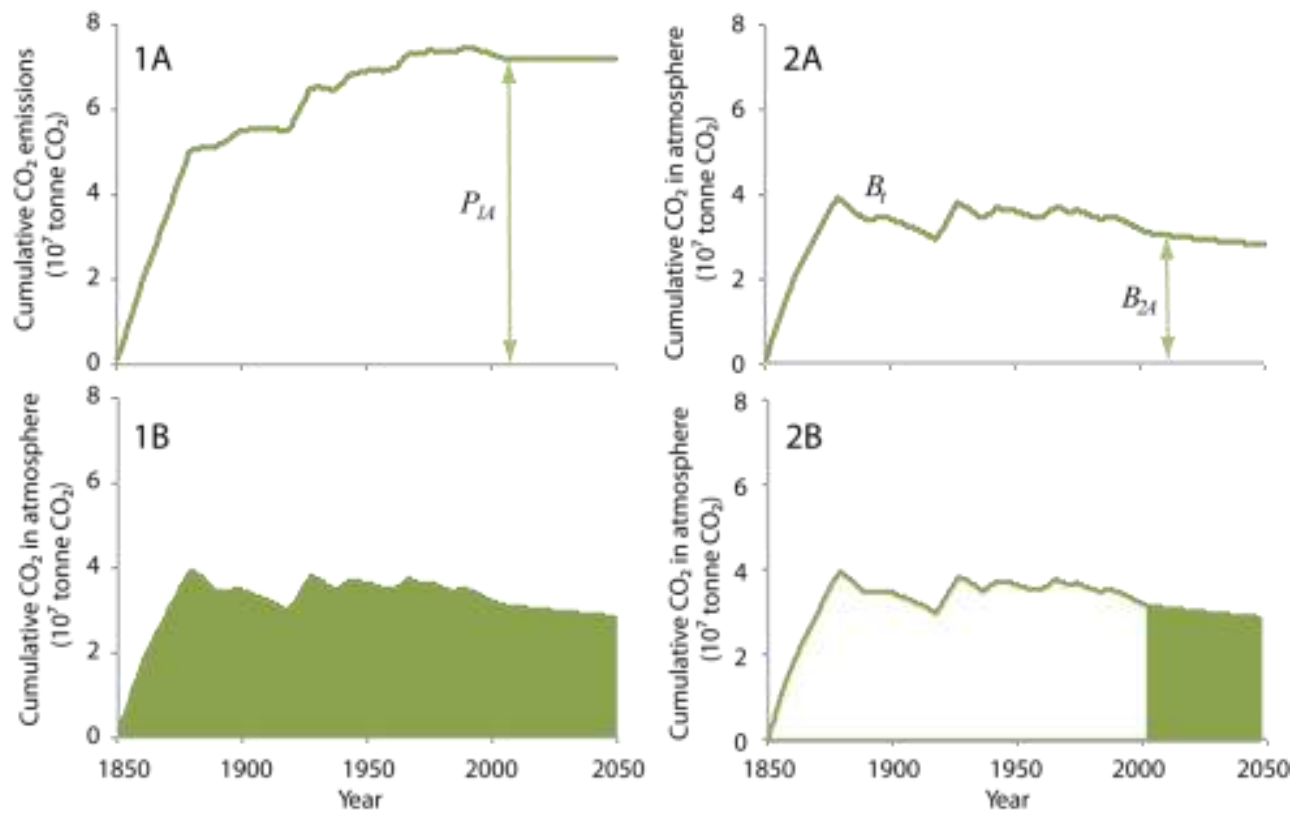

Figure 4.2 Methods for allocating burdens between current biofuels production and historical agricultural activity: $1 \mathrm{~A}$ - using the total $\mathrm{CO}_{2}$ emissions allocated equally to each year of historical production; $2 \mathrm{~A}$ - using the residual $\mathrm{CO}_{2}$ in the atmosphere considering decay and allocating over the years the land is used for biofuel production; $1 \mathrm{~B}$ - using the cumulative radiative forcing of the carbon emissions in the atmosphere and allocating equally to each year of historical and prospective production; and $2 \mathrm{~B}-$ using the cumulative radiative forcing of residual pulse of carbon emissions in the atmosphere and only allocating over the years the land is used for biofuel production. Here at $=$ cropland area in year $\mathrm{t}(\mathrm{ha}) ; \mathrm{p}_{\mathrm{t}}=\mathrm{CO}_{2}$ emissions from LUC in year $\mathrm{t}$ (tonnes/yr); $\mathrm{P}_{1 \mathrm{~A}}=$ sum of annual $\mathrm{CO}_{2}$ emissions (tonnes); $\mathrm{B}_{\mathrm{t}}=$ cumulative $\mathrm{CO}_{2}$ in the atmosphere in year $\mathrm{t} ; \mathrm{B}_{2 \mathrm{~A}}=$ residual cumulative $\mathrm{CO}_{2}$ in the atmosphere using Bern carbon model (tonnes)

In Scenario 1A, historical emissions burdens are allocated using the sum of $\mathrm{CO}_{2}$ emissions from land use change averaged over the period since the land was first brought 
into production. $\mathrm{CO}_{2}$ decay in the atmosphere is not considered. The total emissions pulse is allocated across the 177 years of agricultural production. This period extends from the beginning of agricultural expansion in 1850 through the assumed twenty-year economic life of a biofuel project, which is assumed to commence production in 2027. Using these historical data, it is possible to estimate the tonnes of $\mathrm{CO}_{2}$ equivalent emitted using the following equation:

$$
h L U C=\frac{P_{1 A}}{\frac{\sum_{t=1850}^{2027} a_{t}}{177 y r s} \cdot e \cdot 177 y r s}
$$

where $P_{1 A}=$ sum of annual $\mathrm{CO}_{2}$ emissions (tonnes), $a_{t}=$ cropland area in year $\mathrm{t}(\mathrm{ha}) ; e=$ energy yield of corn ethanol (MJ/ha/yr). The term is defined as:

$$
P_{1 A}=\sum_{t=1850}^{2027} p_{t}
$$

where $p_{t}=\mathrm{CO}_{2}$ emissions from LUC in year $t$ (tonnes).

Scenario $2 \mathrm{~A}$ is similar to $1 \mathrm{~A}$ except that $\mathrm{CO}_{2}$ decay in the atmosphere is considered. The portion of $\mathrm{CO}_{2}$ emissions remaining in the atmosphere when biofuel production begins are allocated across the $20 \sim 45$ year economic life assumed for biofuel production. This approach is similar in some respects to the more conventional computations of DLUC, except the residual pulse of emissions from historical LUC is allocated to biofuel rather than the total pulse of prospective land clearing. Scenario $2 \mathrm{~A}$ 
increases the importance of more recent LUC emissions. The residual pulse of $\mathrm{CO}_{2}$ equivalent remaining in the atmosphere is calculated using the following ratio:

$$
h L U C=\frac{B_{2 A}}{\frac{\sum_{t=2007}^{2027} a_{t}}{20 y r s} \cdot e \cdot 20 y r s}
$$

Eq. 4.

Where $B_{2 A}=$ residual $\mathrm{CO}_{2}$ in the atmosphere using Bern carbon model (tonnes).

Scenario 1B quantifies the climate forcing resulting from historical land use change and allocates this forcing equally to each year of historical and prospective biofuel feedstock production. Computation of climate forcing from LUC emissions is computed by a method analogous to those used to compute 100-year global warming potentials for non- $\mathrm{CO}_{2}$ GHGs (e.g., using residence time of gases in the atmosphere, etc.). The sum of annual atmospheric $\mathrm{CO}_{2}$ accumulation from historical land use change is divided by the sum of annual atmospheric $\mathrm{CO}_{2}$ accumulation from a one-tonne pulse of $\mathrm{CO}_{2}$ over a 100 -year period. The resulting estimate of atmospheric $\mathrm{CO}_{2}$ accumulation since the beginning of the land use change record is allocated equally to each hectareyear of production over the same time period. Like scenario $2 \mathrm{~A}$, the units are expressed as tonnes of $\mathrm{CO}_{2}$ equivalent remaining in the atmosphere. The formulation for HLUC in scenario 1B is:

$$
h L U C=\frac{\sum_{i=1850}^{2027} B_{t} \cdot \sum_{i=1850}^{2027} a_{t}}{e \cdot G W P_{100}}
$$

Eq. 5. 
where $B_{t}=$ cumulative $\mathrm{CO}_{2}$ in the atmosphere in year $t$ and $G W P_{100}=$ radiative forcing created by 1 tonne $\mathrm{CO}_{2}$ in 100 years (1/year).

Scenario 2B computes the climate forcing of historical emissions for the prospective years of biofuel production and allocates that forcing equally to each year of biofuel production. It is similar to $1 \mathrm{~B}$ in calculating climate forcing, but is similar to $2 \mathrm{~A}$ in computing only the residual effect and allocating that residual to the period of biofuel production. The units are the same as $1 \mathrm{~B}$ and $2 \mathrm{~A}$, i.e., tonnes of $\mathrm{CO}_{2}$ equivalent. The equation is:

$$
h L U C=\frac{\sum_{i=2007}^{2027} B_{t} \cdot \sum_{i=2007}^{2027} a_{t}}{e \cdot G W P_{100}}
$$

Eq. 6.

\subsubsection{Data benchmarks}

The US Environment Protection Agency (USEPA)'s Renewable Fuel Standard program (RFS2) reports corn ethanol related iLUC estimates (4). The mean value, high end, and low end of $95 \%$ confidence interval are $32.67 \mathrm{gCO}_{2} / \mathrm{MJ}, 41.89 \mathrm{gCO}_{2} / \mathrm{MJ}$ and $23.45 \mathrm{CO}_{2} / \mathrm{MJ}$ respectively. Assuming the ILUC estimates in RFS2 follow normal distribution, the standard deviation was obtained from statistical tables(121). For some estimates, the distributions were assumed to follow lognormal distributions. The parameters for these lognormal distributions can be calculated using mean value and standard deviation. Estimates of European rapeseed biodiesel iLUC, were obtained from the European Union International for Food Policy Research Institute (EU-IFPRI), and have a mean value of $54 \mathrm{gCO}_{2} / \mathrm{MJ}$, high and low end of $95 \%$ confidence interval of 80.7 
$\mathrm{gCO}_{2} / \mathrm{MJ}$ and $28.2 \mathrm{gCO}_{2} / \mathrm{MJ}(107)$. The reduced form model of Plevin et al. is implemented and run using the Crystal Ball plug-in for MS Excel (27). The mean value, high and low end of Plevin's iLUC 95\% confidence interval are $59 \mathrm{gCO}_{2} / \mathrm{MJ}, 17$ $\mathrm{gCO}_{2} / \mathrm{MJ}$ and $165 \mathrm{gCO}_{2} / \mathrm{MJ}$ respectively. The California Air Resources Board Low Carbon Fuel Standard (LCFS) have a mean value of $30 \mathrm{gCO}_{2} / \mathrm{MJ}$, high and low end of $95 \%$ confidence interval of $93 \mathrm{gCO}_{2} / \mathrm{MJ}$ and $34 \mathrm{gCO}_{2} / \mathrm{MJ}$ for corn ethanol, while Brazilian sugarcane has a mean value of $46 \mathrm{gCO}_{2} / \mathrm{MJ}$, high and low end of $95 \%$ confidence interval of $81 \mathrm{gCO}_{2} / \mathrm{MJ}$ and $11 \mathrm{gCO}_{2} / \mathrm{MJ}(73)$.

\subsubsection{Uncertainty analysis}

\section{Sources of uncertainty}

The factors contributing to uncertainty in HLUC are: carbon stocks in vegetation and soils, fuel yield, and historical cropland data. The range of carbon stock values is described above. Yield data is listed in Table 4.4 (fuel yield varies $\pm 10 \%$ ). The authors of historical cropland dataset estimate that their data are reliable to within $\pm 10 \%$. These three uncertainty sources are included in the HLUC model when it is compiled using Monte Carlo analysis using Crystal Ball.

\section{Monte Carlo simulation in Crystal Ball}

The model was then compiled in a spreadsheet using the Crystal Ball plugin to enable stochastic analysis of the results. For those values were full statistical distributions are not available, triangle distribution were used. The estimates of HLUC typically fit 
lognormal distributions and these were extracted from Crystal Ball along with the supporting statistical parameters.

\subsection{Results and discussion}

\subsubsection{HLUC estimates - base case (US corn ethanol at IL)}

As shown in Figures 4.1 and 4.2, HLUC emissions can be readily computed for agricultural land using using publically available datasets. The results in these figures are from Illinois, USA and are further quantified in Table 4.5. Here the four scenarios are characterized in terms of the average emissions factor for fuel ethanol, the time horizon over which emissions impacts are allocated, and the standard error of the emissions factor distribution. This characterization of the data enables several key observations. First, the error on these HLUC estimates is relatively small. This reflects several key factors, including particularly the fact that reasonably accurate historical land use data are available, at least on a regional basis, and that both LUC emissions mechanisms and the fate of atmospheric GHG emissions are relatively well understood.

Second, with the exception of scenario 2A, the HLUC estimates are very consistent across allocation scenarios. $2 \mathrm{~A}$ is uniquely biased against future biofuel deployment since it allocates the historical residual pulse associated with a given plot of land onto only future biofuels production. The relative consistency of the other three scenario results suggests that they are relatively robust with respect to the inherently subjective decision of allocation method. While allocation scenario 2A appears to be an outlier, it may still be deemed appropriate in certain policy contexts, as it implicitly 
questions whether current land uses provide sufficient value to justify allowing GHG from land conversion to remain in the atmosphere (as opposed to converting the land back to a more natural state).

Table 4.5 HLUC estimates for Bureau County, Illinois, USA show that the magnitude of these emissions is appreciable in the context of the ongoing debate about biofuels and carbon emissions.

\begin{tabular}{|c|c|c|c|c|}
\hline Scenario & Emission & Time horizon & $\begin{array}{l}\text { HLUC } \\
\left(\mathrm{gCO}_{2} / \mathrm{MJ}\right) \\
\end{array}$ & $\begin{array}{l}\text { Standard } \\
\text { deviation }\end{array}$ \\
\hline $1 \mathrm{~A}$ & $\begin{array}{l}\text { Total GHG } \\
\text { emissions }\end{array}$ & $\begin{array}{l}\text { All production } \\
\text { years }\end{array}$ & 11 & 2 \\
\hline $2 \mathrm{~A}$ & $\begin{array}{l}\text { Residual GHG } \\
\text { emissions }\end{array}$ & $\begin{array}{l}\text { Years land } \\
\text { produces biofuel } \\
\text { feedstock }\end{array}$ & 29 & 4 \\
\hline $1 B$ & $\begin{array}{l}\text { Cumulative } \\
\text { radiative forcing of } \\
\text { carbon emissions }\end{array}$ & $\begin{array}{l}\text { All production } \\
\text { years }\end{array}$ & 15 & 2 \\
\hline $2 \mathrm{~B}$ & $\begin{array}{l}\text { Cumulative } \\
\text { radiative forcing of } \\
\text { carbon emissions }\end{array}$ & $\begin{array}{l}\text { Years land } \\
\text { produces biofuel } \\
\text { feedstock }\end{array}$ & 13 & 2 \\
\hline
\end{tabular}

The key conceptual challenges in interpreting HLUC results presented in Table 4.5 are determining (1) the appropriate metric for emissions burdens (e.g., emissions or 
climate forcing) and (2) the appropriate time horizon for quantifying and allocating emissions burdens (e.g., historical and prospective periods or only prospective periods).

Allocating a fraction of historical LUC emissions to current production within LCA treats agricultural production as a unit process with two co-products: historical agricultural products and biofuel feedstock. Attributional LCA methods generally provide for allocation across co-products on the basis of mass, energy content, or economic value (15). While such allocation methods could theoretically be directly applied to HLUC emissions allocation, the additional data requirements (e.g., historical yields) and assumptions (e.g., inflation) pose certain practical challenges and introduce more complex subjective judgments. Further, agricultural yield growth would likely shift allocation of the environmental burdens toward more recent production using mass or energy based allocation methods, which may not be justified in light of the historical value of agricultural products that motivated land clearing when it occurred. For these reasons, the two options developed for each key allocation question (e.g., emissions impact metric and time horizon) for quantifying and allocating impacts are combined to make the four scenarios described above in the methods section.

\subsubsection{Location impacts}

HLUC can be readily computed for most geographic areas in the world. Estimates for six of the world's leading biofuel producing regions are presented in Figure 4.3. The results reveal that HLUC emissions are relatively low in regions where agricultural expansion occurred a long time ago, such as in the US and Europe. Estimates for 
Indonesia and Malaysia are substantially higher in part because emissions are allocated across fewer years of historical (pre-biofuel) production and in part because of the relatively higher carbon content of native land cover. For example, cropland used to produce corn in the US was converted from grassland, whereas Indonesian and Malaysian palm oil plantations were converted from tropical forest, including some peat land, which contain higher vegetative and soil carbon, respectively.

The comparison between countries presented in Figure 4.3 also reveals several important differences between the allocation scenarios. First, the magnitude of HLUC results varies by region, reflecting the relative carbon content of natural land cover. HLUC values are relatively higher in Europe and South Asia due to the carbon content of native temperate forests, relative to North American grassland, for example. Differences in allocation scenario results also vary regionally. In Europe, for example, relatively large differences between scenarios reflects the impact of substantially longer histories of agricultural production and associated long time horizons for computing and allocating emissions burdens.

I make no value judgment about which one of the allocation scenarios is most appropriate. The results in Figure 4.3 suggest that scenario $2 \mathrm{~A}$ is consistently the highest of all those quantified here while the other scenarios vary by country. These differences reflect certain tradeoffs regarding how emissions burdens should be measured, each of which may be appropriate for advancing certain policy objectives. Indeed, comparing between scenarios is difficult since the A scenarios report a fundamentally different metric than the B scenarios. It is instructive to consider both the relative magnitudes of 
the scenarios across regions and their relative consistency, which has important implications for both equity and compatibility with existing policy frameworks (e.g., trade policies).

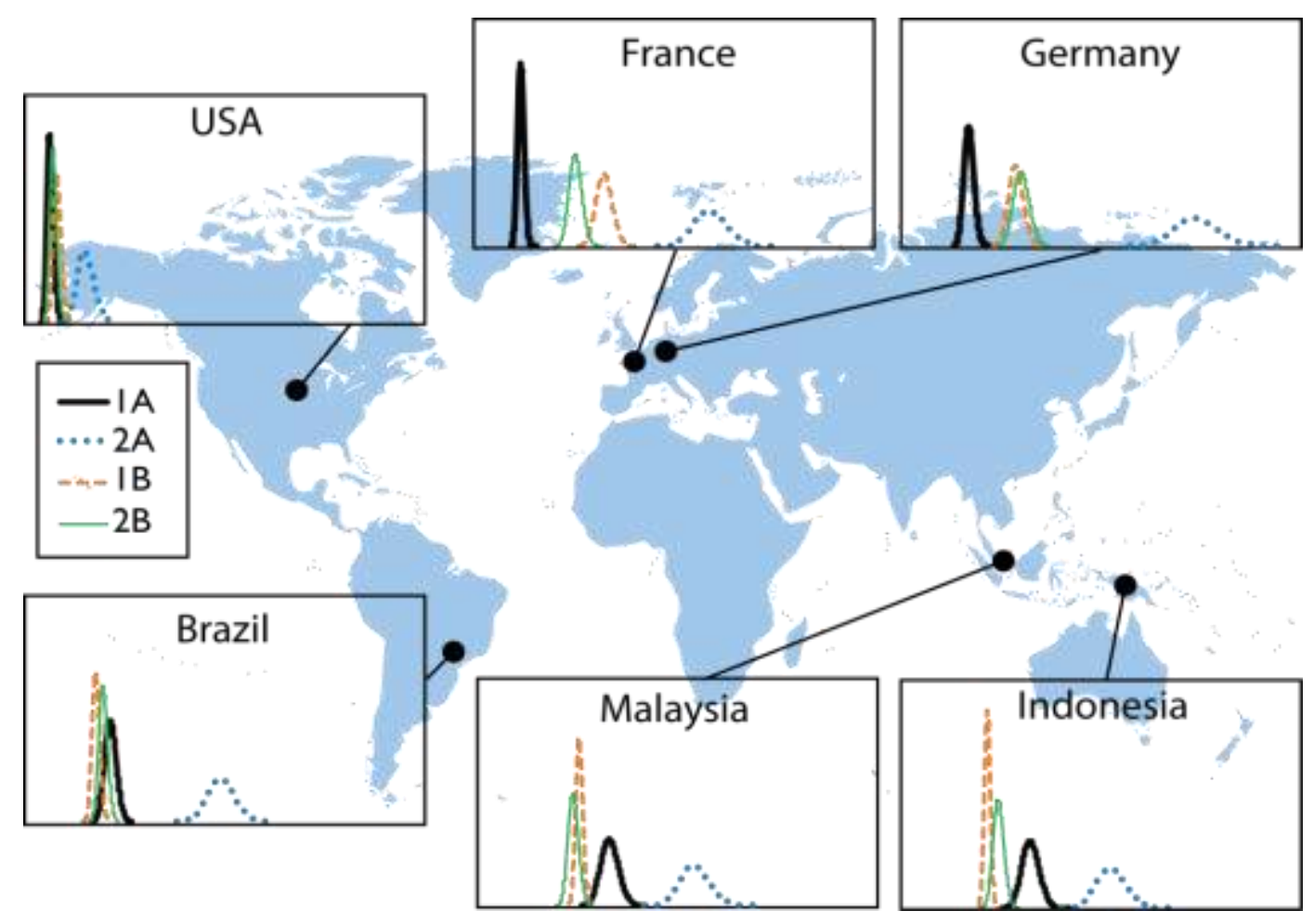

Figure 4.3 HLUC distributions for six biofuel-producing regions around the world for different fuel types reveal important differences between regions in terms of the magnitude of the estimate and the importance of the allocation scenario. The $\mathrm{x}$-axes in these plots all range from a carbon intensity of 0 to $200 \mathrm{~g} \mathrm{CO}_{2} / \mathrm{MJ}$, and the $\mathrm{y}$-axes range from a probability of 0 to 0.3 .

Regional variability in LUC emissions raises challenging policy questions, to which there are no simple answers. On the one hand, regionally specific LUC values could motivate more efficient land use decisions (e.g., prioritizing production in areas with lower LUC emissions). On the other hand, discriminating between products according to where they are produced raises complex issues of ethics, equity, and trade 
policy. These issues exist across all LUC accounting methodologies. One policy approach would be to adopt regional or global average values that aggregate LUC emissions by biofuel type. While this approach abstracts away from decisions at the level of individual producers, HLUC values would remain fundamentally tied to physical processes on the land used for biofuel production, which is distinct from the marketbased abstraction inherent to iLUC accounting.

The six biofuel production regions represented in Figure 4.3 produce two types of biofuels-i.e., ethanol and biodiesel-from four feedstocks, i.e., corn, sugarcane, rapeseed, and palm. ILUC values for all of these biofuels have been calculated by various groups and these published values are presented with HLUC emission estimates in Figure 4.4. The top row represents HLUC estimates (Scenario 1A) and the bottom row are published iLUC estimates where A: ethanol, B: rapeseed biodiesel, and C: palm oil biodiesel. The results suggest that the magnitudes of the estimates are generally consistent in magnitude. In some cases HLUC is higher, e.g., Brazil, while in others HLUC is a bit lower, but for most of the countries, the estimates are highly consistent. Of course, iLUC and HLUC measure different things but ultimately both values reveal something about the connection between land use and carbon emissions. 
A. Corn ethanol (US)
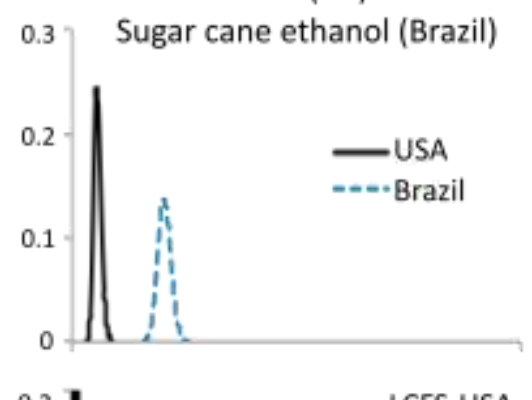

0.2

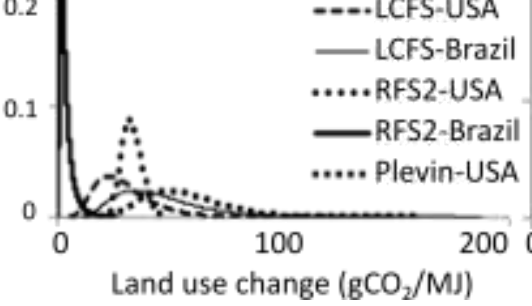

B. Rapeseed biodiesel

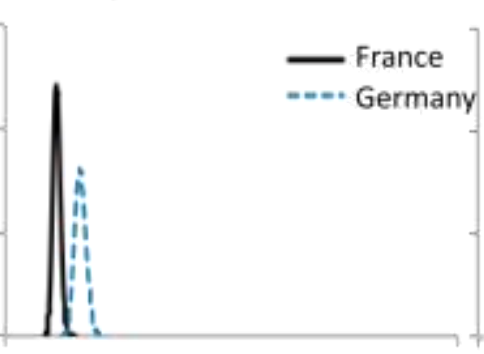

C. palm oil biodiesel

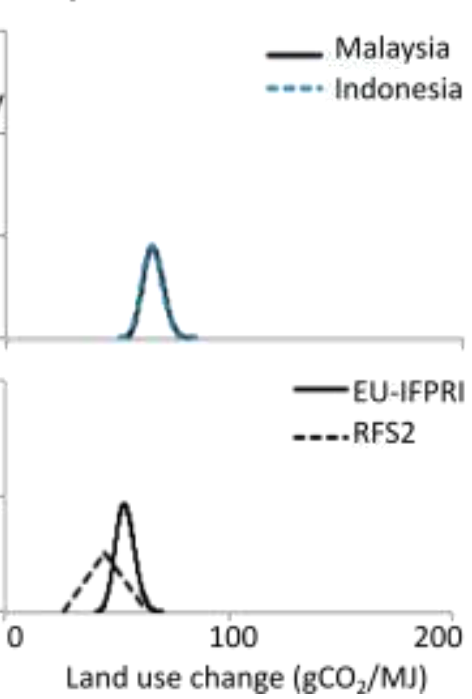

Figure 4.4 HLUC probability distributions for ethanol, biodiesel from rapeseed and biodiesel from palm oil and their corresponding benchmarks. Top row represents the three biofuel types studied here A. ethanol, B. biodiesel (from rapeseed), C. biodiesel (from palm oil). The bottom row presents published iLUC estimates for the same fuels. Though iLUC and HLUC measure fundamentally different things, broad similarity in the magnitude of results suggests that comparisons may be useful in validating results across methodologies and in understanding the emissions implications of biofuel production. Differences in results for similar fuels (e.g., ethanol produced in the US and Brazil) suggests parallel analyses using HLUC and iLUC methods may yield additional insights to inform ongoing policy discussions and decision making. The iLUC data in this figure are: US EPA Renewable Fuel Standard 2 model (RFS2)(78), CARB Low Carbon Fuel Standard (LCFS)(73), Plevin et al.(27) and the EU-IFPRI (107).

\subsubsection{Cropland estimates pre-1700}

The agricultural activities in Europe have been developed for centuries before cropland data started to be collected and it is assumed that the area cropland was proportional to the population before industrialization. Therefore, population data before 1700 were used to derive historical land data assuming that the relationship between these two is linear. Given the population data and cropland data from 1700 until 2007, the linear relationship between them can be found. Then cropland before 1700 can be derived 
using the relationship equation and population data. The results are shown in Table 4.6. The above assumption can be invalid if cropland was brought into agriculture production starting from when population data were first collected. In order to find the upper bound of this population to cropland approach, I also assume that land was converted from natural vegetation to cropland instantly at 1700. It is different from base case in which there was already cropland in 1700 .

Table 4.6 HLUC results of population derived historical cropland data

\begin{tabular}{|lc|}
\hline \multicolumn{2}{|l|}{ Land converted from the year cropland data was available } \\
\hline France (1700) & 22 \\
Germany (1700) & 33 \\
\hline Land was converted given the population data of that year \\
France (0BC) \\
Germany (1200) \\
\hline Land was converted from the very beginning \\
\hline France \\
Germany \\
\hline
\end{tabular}

\subsubsection{Reversibility}

An important characteristic of HLUC accounting is that it enables farmers to explore different uses for their land based on decisions made today. For example, farmers often make choices related to planting crops or allowing their land to revert to its natural 
land cover (e.g., by enrolling in the CRP program), effectively sequestering $\mathrm{CO}_{2}$ in soil and native vegetation cover. This inherent reversibility makes LUC emissions fundamentally different from fossil fuel combustion emissions; for example, because they can generally be reversed if and when current land uses do not justify the associated emissions burden under potential future climate policies. HLUC emissions results characterizing the impacts of allowing cropland to revert to native grasslands in Bureau County, Illinois are presented in Figure 4.5 and Table 4.7. In scenario 1A the emissions over both time horizons are negative because the baseline for our allocation (i.e., 1850) occurred when cropland in this region was already under cultivation. For scenarios $2 \mathrm{~A}$ the emissions are mixed (i.e., positive over 20 years and negative over 45 years) because based on previous studies, soil carbon will recover continuously during a longer period of time. For scenarios $1 \mathrm{~B}$ and $2 \mathrm{~B}$, the HLUC estimates are positive over both time horizons because the cumulative radiative forcing from land conversion has been greater than that of reversing cropland. As a consequence, all land uses constitute a positive residual flux to the atmosphere, but the differences between planting biofuels feedstocks and not as significant. Conceptually, the carbon effects of reverting the land to its native land cover are presented in Figure 4.5. The top graph shows the annual carbon flux from the region. The graphs below show how the different allocation scenarios impact HLUC estimates. Farmers' decisions on historical land conversion and crop selection have been embedded in historical cropland data. 

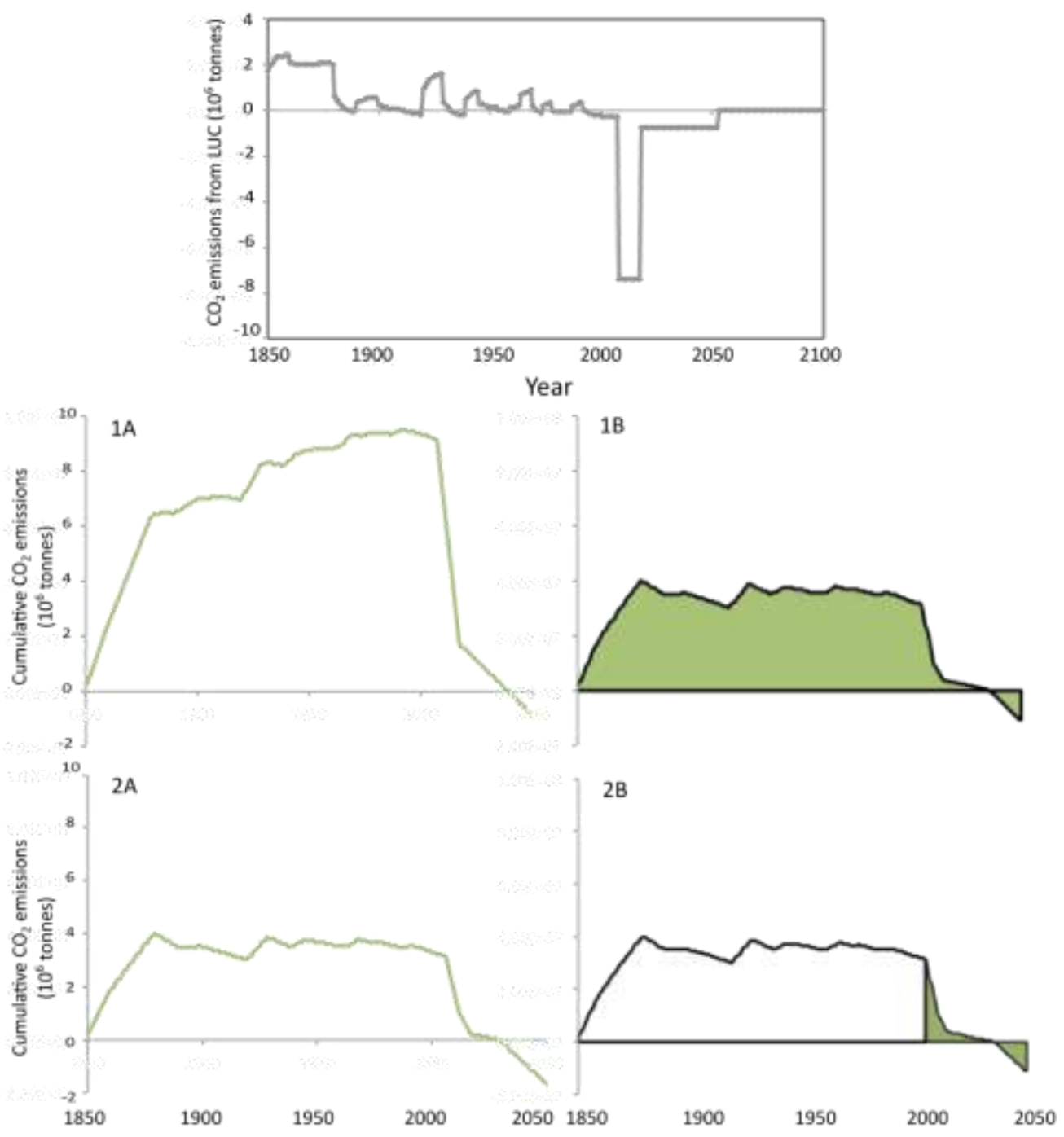

Figure 4.5 Four allocation scenarios in HLUC methodology. These HLUC allocation schemes would allow farmers to calculate the carbon implications of allowing land to revert to its natural vegetation state. The top graph shows annual carbon emissions over a 200-year time horizon with a net negative carbon flux of carbon when the land is allowed to revert starting in 2012. These negative emissions would only be temporary as the carbon stock of the soil and biomass would eventually be balanced by biomass decay. Depending on the allocation scenario, the effects on the net carbon flux would vary as shown in Table 4.7.

For each of the allocation scenarios proposed here, the difference is on the order of 10 s of tonnes $\mathrm{CO}_{2}$ /hectare. In a carbon constrained marketplace, these differences 
could translate to economic signals on par with the price of difference commodity biofuels crops. For example, if letting the land revert to native vegetation represents a 30 tonne $\mathrm{CO}_{2}$ /ha improvement over biofuels and $\mathrm{CO}_{2}$ is $\$ 30 /$ tonne, which constitutes $\$ 900$ per hectare in emissions reductions. Naturally, this simple analysis example ignores many of the accounting details that would be inherent in any carbon trading scheme but it does illustrate the potential for HLUC accounting to provide significant incentives for farmlevel decision making. The emission estimates are inherently sensitive to the time horizon over which the estimate is calculated. In Table 4.7, the results are presented for a 20 -year and a 45-year time horizon.

Table 4.7 HLUC estimates of land reversion. Using HLUC, it is possible to calculate the carbon emissions, over twenty or forty-five year time horizons, associated with planting corn for ethanol or allowing the land to revert to its natural state.

\begin{tabular}{|l|l|l|l|}
\hline & \multicolumn{3}{|c|}{$\mathrm{CO}_{2}$ emissions (tonne $\mathrm{CO}_{2} /$ ha) } \\
\hline Scenario & Biofuels LUC & $\begin{array}{l}\text { Revert to natural } \\
\text { vegetation } \\
20 \text {-year time horizon }\end{array}$ & $\begin{array}{l}\text { Revert to natural vegetation } \\
\text { 45-year time horizon }\end{array}$ \\
\hline 1A & 179 & -17 & -17 \\
\hline 2A & 52 & 2 & -30 \\
\hline 1B & 63 & 52 & 49 \\
\hline 2B & 54 & 16 & 7 \\
\hline
\end{tabular}

\subsubsection{Sensitivity to resolution}

The modeling results of data resolution on HLUC estimates reported here were compiled using historical cropland estimates and a natural vegetation dataset with a resolution of 0.5 degree. The natural vegetation dataset is also available at $5 \mathrm{~min}$ 
resolution. These data were used to evaluate whether using this higher resolution data would impact the HLUC estimates appreciably.

Sensitivity analysis suggests that HLUC estimates are generally robust with respect to the geographical resolution of land use and land cover data and to the temporal trajectory of agricultural expansion. In terms of data resolution, the land cover data is available at a resolution of 0.5 degree but calculation of HLUC estimates using lower and higher resolution datasets produced results with a variance less than $8 \%$. In terms of temporal availability of data, the time horizon from 1850-2007 is appropriate for many regions of the world but for some (i.e., in Europe) this time horizon excludes substantial agricultural expansion. Extrapolating agricultural activities to infer earlier LUC had only small effects on HLUC estimates.

\section{Higher resolution}

5-min resolution is six times finer than 0.5 degree meaning that each grid in the latter is 36 bigger than the former (shown in Figure 4.6). In this first analysis, the historical cropland dataset was used with its resolution of 0.5 degree while the higher resolution natural vegetation dataset $(5 \mathrm{~min})$ was used. Because the historical cropland dataset only has resolution of 0.5 degree, in order to create a 5 min resolution dataset, I assume the 0.5 degree grid is divided into 36 grids equally and each has the same cropland percentage as the original value. Then a similar Matlab code was developed to combine the historical cropland data and natural vegetation data. 


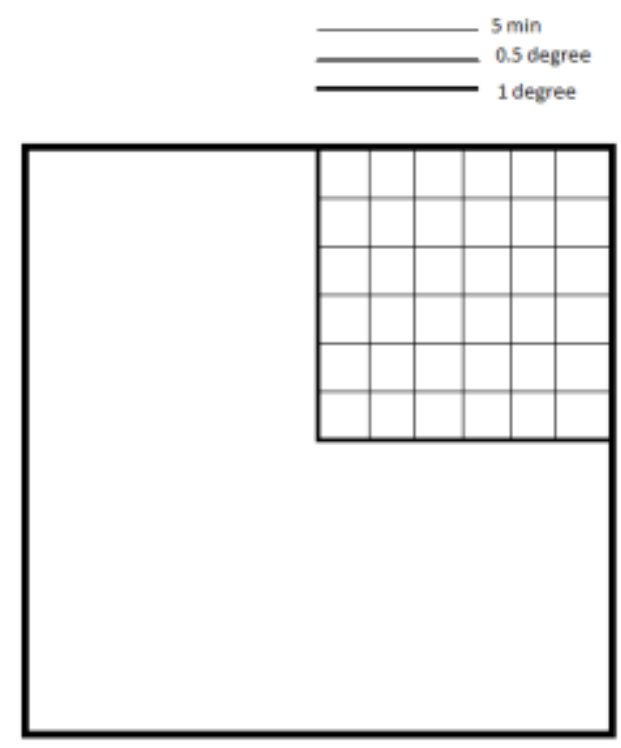

Figure 4.6 Resolution - 5 min, 0.5 degree, 1 degree.

\section{Lower resolution}

Using datasets with a resolution of 0.5 degree, I integrated them to 1 degree resolution in Matlab. For the historical cropland dataset, the four values of cropland percentage is averaged to obtain that of the aggregate grid. For the natural vegetation data, the four numbers of land types were compared. If two or more of them are the same, that land type will represent the big grid. If none of them are the same, the land type on the up left corner of the four medium-sized grid will be the land type of the larger grid. The comparison of HLUC estimates using the three resolution values is shown in Figure 4.7 . 


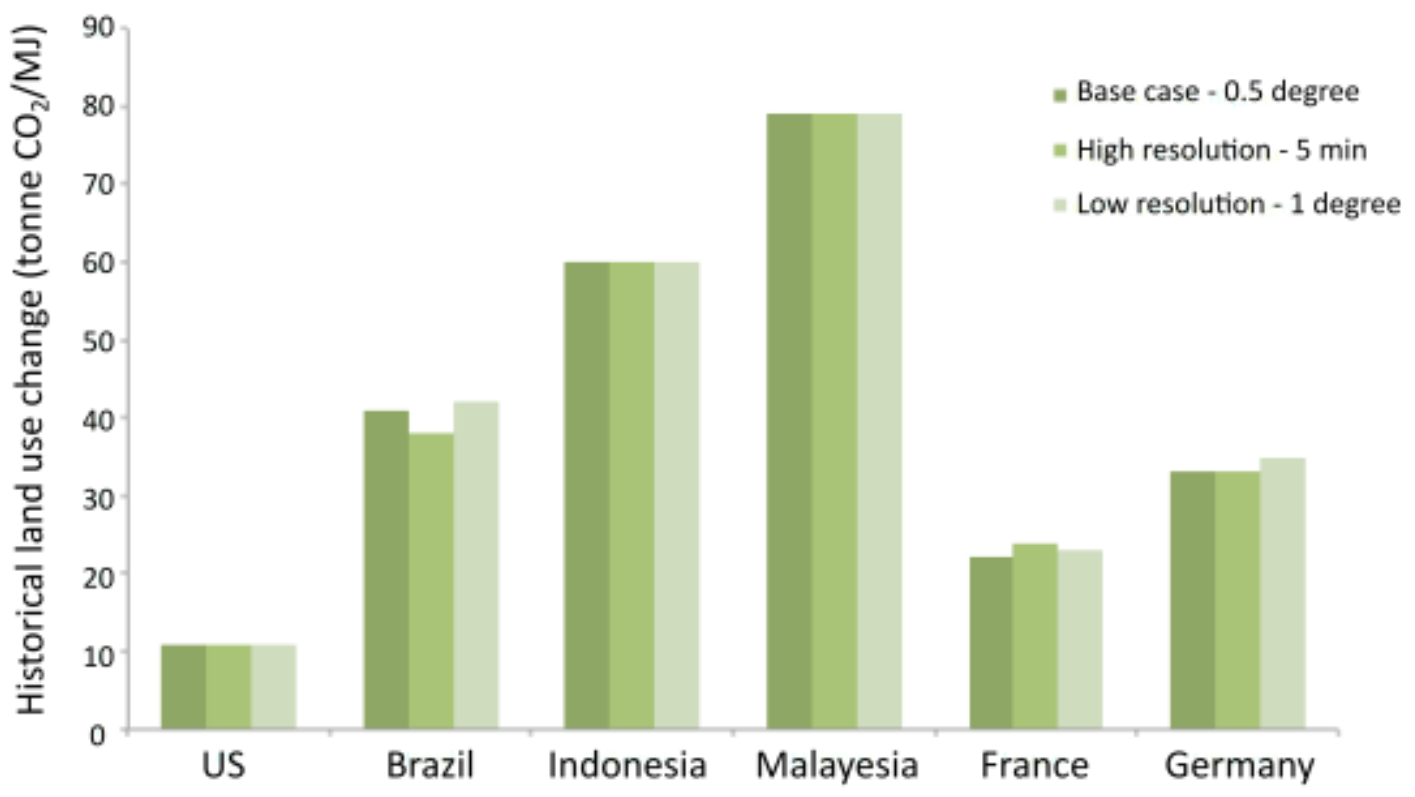

Figure 4.7 Comparison of HLUC model results with different resolutions.

\subsubsection{Carbon accounting across scales}

The attributional nature of HLUC could make it a valuable complement to existing CLCA-based LUC modeling techniques. As governments, regions, industrial sectors, companies and individual farmers seek ways to adjust to shifting regulatory frameworks, HLUC could provide an efficient means to quantify the burdens of decisions associated with a specific supply chain. The HLUC results are easily understood and robust to a variety of different conditions. HLUC also provides transparent and locationspecific LUC estimates for any type of cropland, recognizing that some lands have been in agricultural production for extended periods of time. HLUC estimates are independent of existing policy frameworks and can be compared across locations or aggregated in a variety of ways to report carbon accounting for a given region, feedstock, or fuel type. 


\section{Chapter 5}

\section{Life Cycle Burdens of $\mathrm{CO}_{2}$ Supply Sources}

\subsection{Introduction}

GHG emissions and radiative forcers from anthropogenic activities are altering the global climate system. The energy and transportation sector in the United States emits significant amount of $\mathrm{CO}_{2}$. Tremendous efforts have been taken to mitigate such emissions and several technological options are available to manage such emissions including algae bioenergy production (16), etc. The deployment of any carbon capture and storage technologies depends on the availability and proximity of $\mathrm{CO}_{2}$ supply sources to these facilities. Algae biomass is generally cultivated in open ponds as feedstock for biofuel production. Lipid portion of algae cells is easily converted to fuels and the nonlipid portion can be processed to usable co-product to offset the burdens (38). Such 
process can potentially reduce significant amount of lifecycle $\mathrm{CO}_{2}$ emissions due to the rapid growth rate of aquatic species compared with terrestrial plants. Most of the algae LCA papers assume that $\mathrm{CO}_{2}$, which is essential to algae cultivation, can be supplied by nearby coal-fired power plants although very few power plants in the United States actually sell small quantities of $\mathrm{CO}_{2}$. Life cycle analyses (LCA) of algae biofuel deployment have indicated that $\mathrm{CO}_{2}$ supply can be a constraint to achieving the goal of reducing the GHG emissions across the entire biofuel production life cycle (38).

Under current technological and market conditions, the sources that supply $\mathrm{CO}_{2}$ to carbon mitigation facilities are mainly natural $\mathrm{CO}_{2}$ deposits, acid gas removal unit in natural gas processing, ethanol plants, ammonia plants and hydrogen plants (29). Most of the $\mathrm{CO}_{2}$ comes from a few dedicated wells, which are drilled to extract large quantities of high purity $\mathrm{CO}_{2}$. Acid gas removal plants are the second largest source of $\mathrm{CO}_{2}$. In this case, $\mathrm{CO}_{2}$ is a byproduct from natural gas streams and can be captured and sold. Both hydrogen and ammonia production generate $\mathrm{CO}_{2}$ from steam reforming methane reaction where natural gas is reformed to produce a hydrogen stream and a pure $\mathrm{CO}_{2}$ stream. On one hand, the lifecycle burdens of these five $\mathrm{CO}_{2}$ sources vary significantly and thus can alter the environmental profile of algae biofuels. On the other hand, the geospatial locations of $\mathrm{CO}_{2}$ suppliers can influence the strategies of carbon management options such as algae biofuels. Therefore, the optimization of $\mathrm{CO}_{2}$ sources and $\mathrm{CO}_{2}$ sinks to minimize environmental burdens requires better understanding of the $\mathrm{CO}_{2}$ supply chains.

In this chapter, I compiled the locations and quantities of $\mathrm{CO}_{2}$ to depict a picture of supply capacity for $\mathrm{CO}_{2}$ in the United States with the purpose of improving our 
understanding of where these facilities could be located. In addition, the lifecycle impacts of the five different $\mathrm{CO}_{2}$ sources are characterized to identify cleaner source of $\mathrm{CO}_{2}$ that would be suitable for algae biofuel feedstock cultivation. Spatial analysis and $\mathrm{CO}_{2}$ intensities of supplying $\mathrm{CO}_{2}$ from different industrial sectors are conducted to provide insights in algae biofuel deployment.

\subsection{Methodology}

\subsubsection{Data Sources}

A high level summary of $\mathrm{CO}_{2}$ suppliers in the US has been provided to the EPA for over a decade as part of their GHG Inventory process though facility-scale data has only recently become available (31). In 2012, the U.S. Environmental Protection Agency (EPA) issued GHG reporting requirements for all facilities generating over 25 kilotonnes of $\mathrm{CO}_{2}$ annually. This statute requires facilities to disclose their emissions and these data are consolidated by the EPA and provided to the public through their website (31). The most recent data that is available is for 2012. Even with these data available, the relevant $\mathrm{CO}_{2}$ supply numbers were not readily available for the five sectors described here from a single data source because of methodological differences in reporting requirements between industries. For example, natural gas processing had to be obtained from the EPA enviro facts database to be able to filter only those facilities that use an acid gas removal unit. We developed tools for processing the data, which are fully described in the supporting information, to produce a list of 597 sources for the continental United States. This list is the most comprehensive source evaluation for $\mathrm{CO}_{2}$ reported to date. A 
complete spreadsheet of facilities representing all the sources after being processed is available in the supporting information. It is important to note that these data are selfreported by the various industries and so focusing on facility-scale numbers can occasionally be misleading. Every effort was made to ensure that the data quality was high and cross referenced.

All the facilities that produce data as reported to the EPA are presented in Figure 5.1. The facilities that capture their $\mathrm{CO}_{2}$ and sell it downstream are plotted as filled circles while those facilities that emit the $\mathrm{CO}_{2}$ are plotted as hollow circles. The size of the circles is proportional to the amount of $\mathrm{CO}_{2}$ produced. The decision to capture $\mathrm{CO}_{2}$, and the size of the facility, appear correlated to facility type. There also appear to be large sections of the country where no $\mathrm{CO}_{2}$ source is readily available. These observations of the raw data, among others, provided the impetus for this work. 


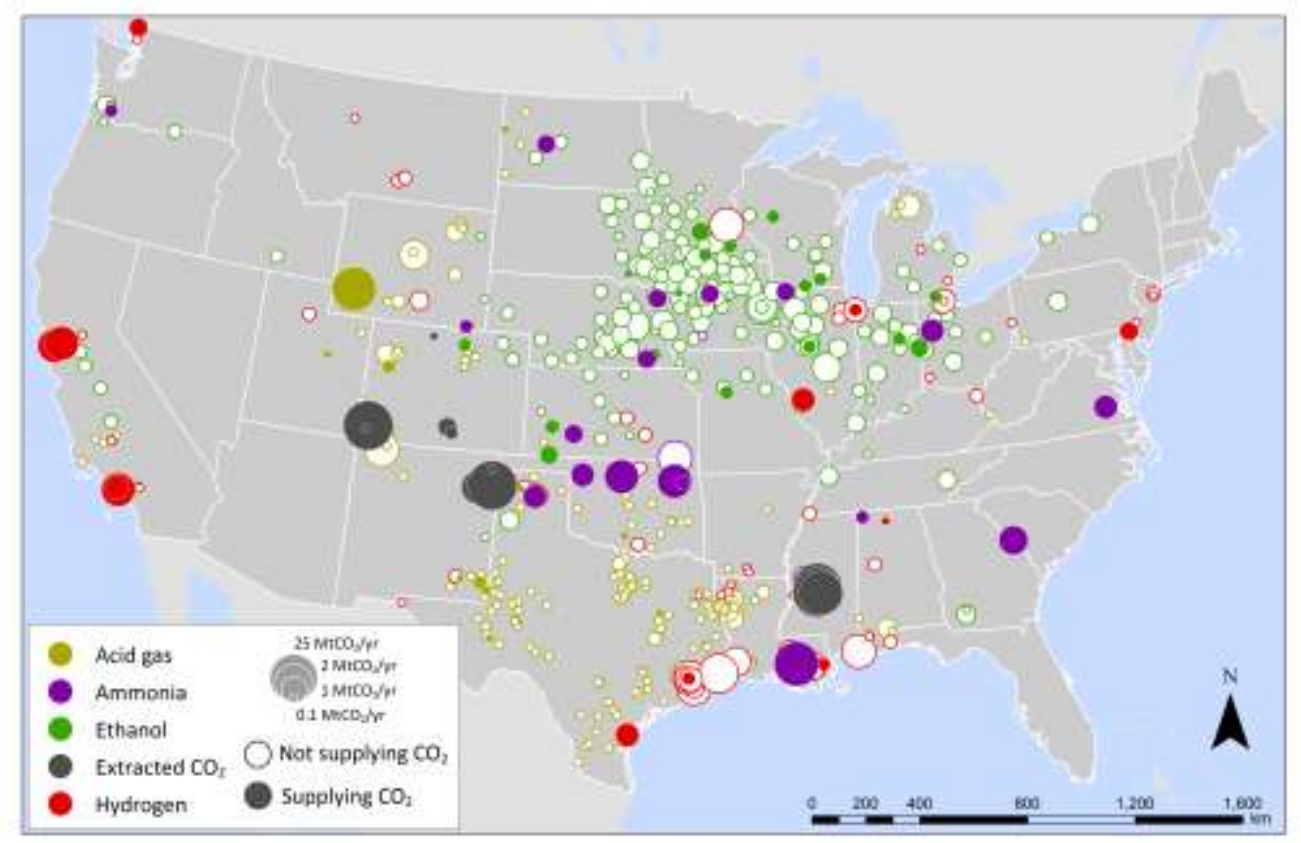

Figure 5.1 Sources of high-purity $\mathrm{CO}_{2}$ in the United States (U.S. EPA 2014). Solid circles indicate that the source is presently supplying its $\mathrm{CO}_{2}$ to other industries, such as algae cultivation and food industry. Hollow circles indicate that the source is either not providing its $\mathrm{CO}_{2}$ or that the disposition of the $\mathrm{CO}_{2}$ is unknown. The size of the circles is proportional to the supply mass flow rate.

Many of the source facilities are producing $\mathrm{CO}_{2}$ at the small or intermediate scale. Even though the EPA data did not require producers generating less than 25 kilotonnes of $\mathrm{CO}_{2}$, this analysis suggests that there were very few facilities producing and capturing their $\mathrm{CO}_{2}$ at such small scales presumably because it is rarely economical to do so. The number of facilities and their sizes provide some insights into the structure of the $\mathrm{CO}_{2}$ supply chain. Figure 5.2 presents the maximum $\mathrm{CO}_{2}$ production at the facility level as a function of the number of facilities. Extracted $\mathrm{CO}_{2}$ operations are the least numerous, but produce the most $\mathrm{CO}_{2}$. In contrast, ethanol facilities are the most numerous and also the most consistently sized. Acid gas and hydrogen facilities have wide variability in facility 
size. Note that the data are plotted on a log scale on the y-axis suggesting that the supply chain is dominated by a small number of large suppliers.

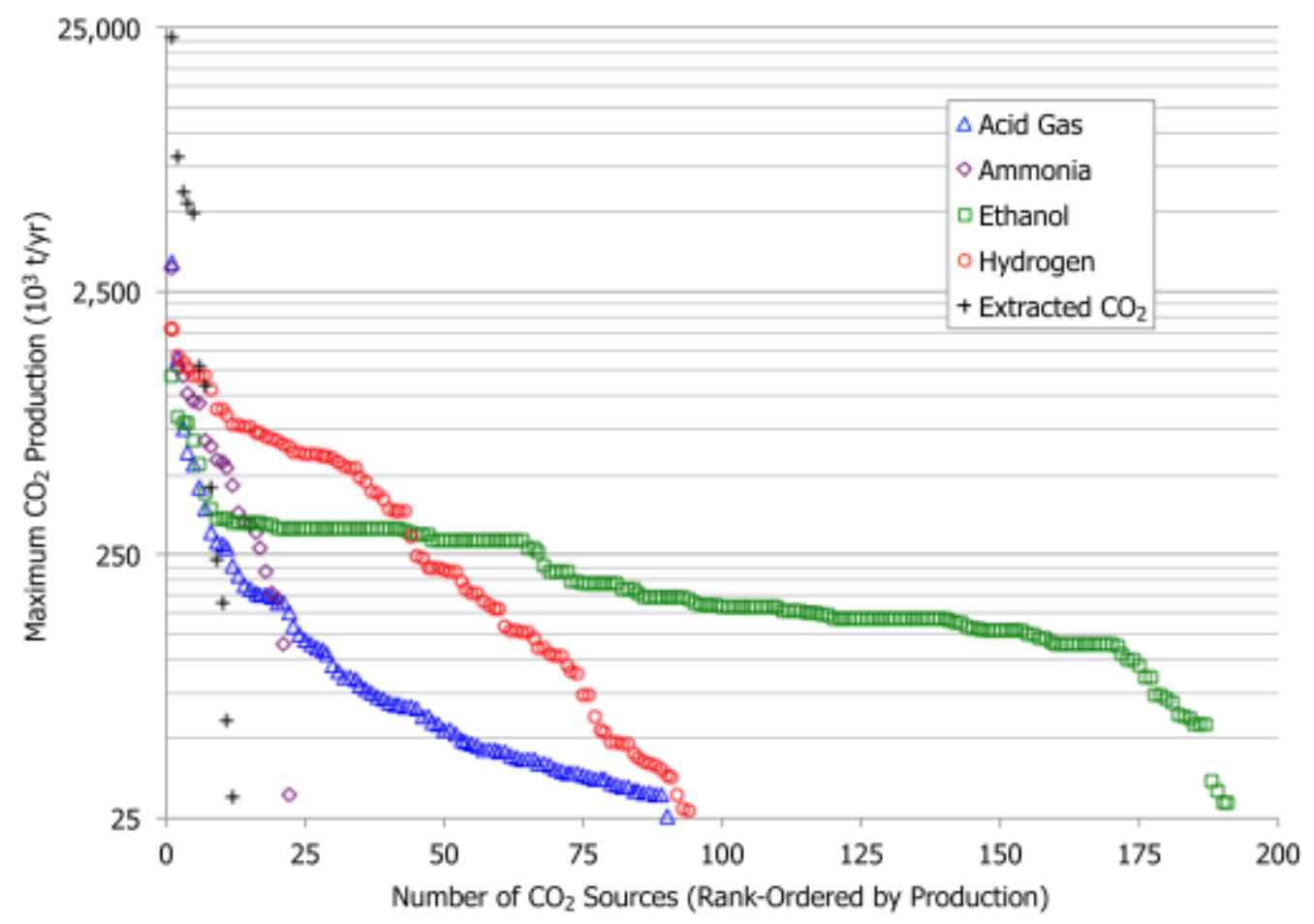

Figure 5.2 Individual $\mathrm{CO}_{2}$ source in the United States plotted in terms of $\mathrm{CO}_{2}$ production potential relative to the number of facilities with this capacity.

\section{Geospatial analysis}

The amount and GHG intensity of $\mathrm{CO}_{2}$ supply varies spatially across the United States, though this is difficult to comprehend using the individual facility information in Figure 5.1. Consequently, an algorithm is developed to aggregate the $\mathrm{EPA} \mathrm{CO}_{2}$ emissions data into regular 50 by $50 \mathrm{~km}$ blocks or grid cells (Figure 5.4). In addition to the total $\mathrm{CO}_{2}$ supply within each block, we also kept track of the $\mathrm{CO}_{2}$ intensity weighted by the 
total $\mathrm{CO}_{2}$. The individual facilities are represented as black dots; each dot is elevated to the height of its containing $50 \mathrm{~km}$ grid for visualization purposes. A single point in the United States is considered to be in a $5 \mathrm{MtCO}_{2} 500 \mathrm{~km}$ carbon desert if that point does not have 5 million tonnes of $\mathrm{CO}_{2}$ supply within a $500 \mathrm{~km}$ radius. This concept is visualized on Figure 5.5 and Figure 5.6 in the 5.3 Results and Discussion section. These figures were generated by discretizing the United States into 5 by $5 \mathrm{~km}$ grid cells and then, for each cell, calculating the radial distance required in order to encapsulate $1,2,5$, 10, 25, and $50 \mathrm{MtCO}_{2} / \mathrm{yr}$ supply. The final distance information was then converted into five distance categories ranging from 100 to $500 \mathrm{~km}$ for visualization purposes only.

\subsubsection{Life cycle model - marginal burdens of capturing $\mathrm{CO}_{2}$}

For each source, a life cycle model was developed in order to quantify the environmental burdens associated with the capture of $\mathrm{CO}_{2}$. This work reported the marginal burdens of capturing the $\mathrm{CO}_{2}$, i.e., the life cycle energy and $\mathrm{GHG}$ emissions that arise from the specific activity of capturing $\mathrm{CO}_{2}$ from these processes and preparing it for sale into the market. This is unlike previous studies which have sought to perform an allocation between a primary product (e.g., ammonia) and a coproduct (e.g., $\mathrm{CO}_{2}$ ) (30). Using allocation, the burdens need to be split using some economic or material balance rationale with little physical or policy basis. Here it is assumed that without a $\mathrm{CO}_{2}$ market, the $\mathrm{CO}_{2}$ stream would be vented to the atmosphere and so the burdens of capturing $\mathrm{CO}_{2}$ should be the marginal impacts of capturing the gas versus not capturing 
it. The EPA data indirectly supports this assumption since many plants that could theoretically capture their $\mathrm{CO}_{2}$ do not.

For most processes, the lifecycle (LC) burdens of capturing $\mathrm{CO}_{2}$ amounted to dehydration and compression to pipeline pressures. In addition, a credit was assigned to those processes that generate the $\mathrm{CO}_{2}$ as a byproduct because capturing the $\mathrm{CO}_{2}$ amounts to an avoidance of emissions. The only process that would not be eligible for such a credit is the natural $\mathrm{CO}_{2}$ wells. These wells represent a novel source of $\mathrm{CO}_{2}$ into the atmosphere and should receive no credit if they are associated with a carbon management project. Consequently, the burdens of the five different sources are: Natural wells -3.0 $\mathrm{MJ}$ and $0.15 \mathrm{~kg} \mathrm{CO} 2^{-} \mathrm{eq} / \mathrm{kg} \mathrm{CO} \mathrm{CO}_{2}$; Natural gas processing - $0.12 \mathrm{MJ}$ and $-0.98 \mathrm{~kg} \mathrm{CO}_{2^{-}}$ eq/kg $\mathrm{CO}_{2}$; Ethanol plants - 0.24 MJ and $-0.98 \mathrm{~kg} \mathrm{CO}$-eq/kg $\mathrm{CO}_{2} ;$ Ammonia/Hydrogen plants $-0.24 \mathrm{MJ}$ and $-0.98 \mathrm{~kg} \mathrm{CO}$-eq/ $/ \mathrm{kg} \mathrm{CO}_{2}$. The LC data fall into two bins: (1) those processes that can claim no credit for carbon emissions avoided (i.e., natural wells) and those that can (i.e., all other sources). Even though small differences in pressure and temperature exist in these streams, the differences in marginal LC burdens are small except for natural wells. The specific emissions factors used here are described in the following subsections in details.

\section{Natural $\mathrm{CO}_{2}$ formations}

The sole purpose of natural $\mathrm{CO}_{2}$ wells is to produce $\mathrm{CO}_{2}$ as the main product while the other industrial processes generate and capture $\mathrm{CO}_{2}$ as a by-product. The life cycle burdens of delivering compressed $\mathrm{CO}_{2}$ from natural deposits are $3.024 \mathrm{MJ} / \mathrm{kg} \mathrm{CO} 2$ 
and $0.148 \mathrm{~kg} \mathrm{CO}$ e/kg $\mathrm{CO}_{2}$, respectively (30). The Overcash paper provides a detailed model of the steps associated with mining $\mathrm{CO}_{2}$ from dedicated wells and delivering it to the market. It is worth noting that the burdens of this activity are low relative to most natural gas extraction operations $\left(3.997 \mathrm{kgCO}_{2} \mathrm{e} / \mathrm{kgCH}_{4}(122)\right)$ in large part because only the highest pressure and most pure $\mathrm{CO}_{2}$ formations are currently being mined.

\section{Other facilities}

The marginal life cycle burdens of capturing $\mathrm{CO}_{2}$ from the other four sources generally involve some combination of compression and dehydration. The final pressure of $\mathrm{CO}_{2}$ from all sources is $10.3 \mathrm{MPa}$, which is suitable for transporting $\mathrm{CO}_{2}$ in pipelines. The stream must be dehydrated to limit corrosion and prevent the formation of hydrates. The water solubility limit for transporting high-pressure $\mathrm{CO}_{2}$ at $30^{\circ} \mathrm{C}$ is $2000 \mathrm{ppm}(123)$. This solubility can be sensitive to the presence of trace gas contaminants in the $\mathrm{CO}_{2}$ such as $\mathrm{CH}_{4}, \mathrm{H}_{2} \mathrm{~S}, \mathrm{O}_{2}$ and $\mathrm{N}_{2}$.

The four pathways are summarized in Figure 5.3. 
Natural gas processing

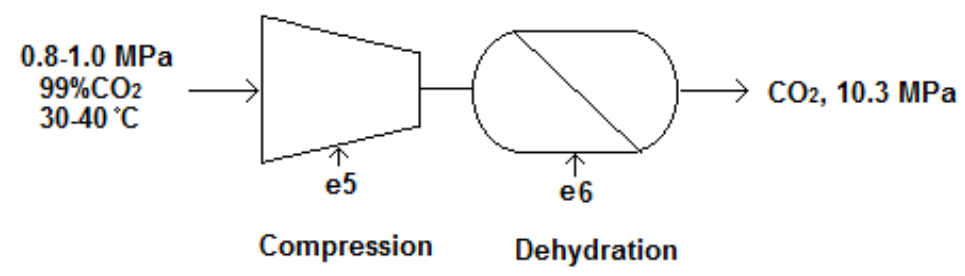

\section{Ammonia plant / Hydrogen plant}

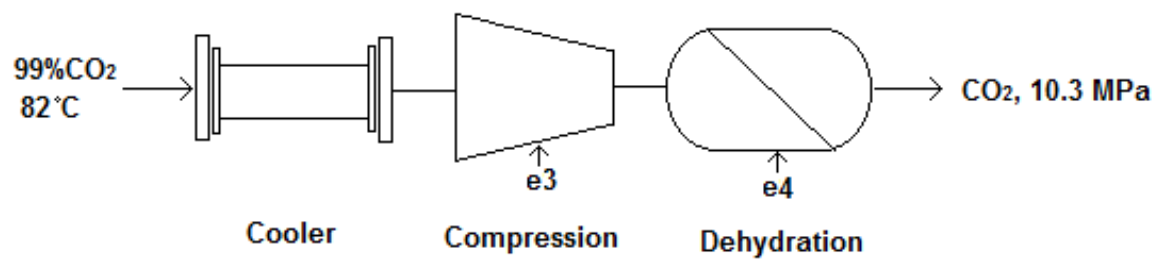

Ethanol plant

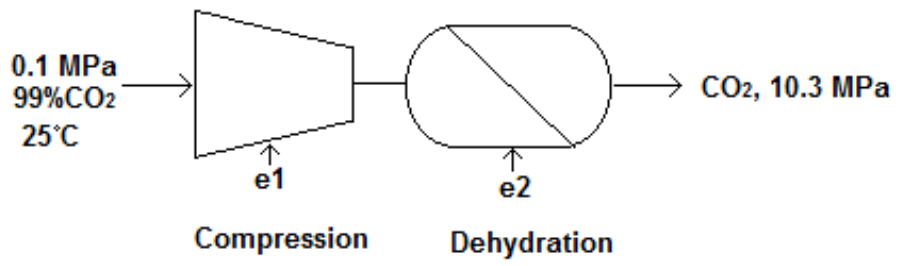

Figure 5.3 Processes of pre-treating $\mathrm{CO}_{2}$ to be transported in pipelines.

- In acid gas removal unit, $\mathrm{CO}_{2}$ streams are at approximately 8 to 10 atm with insignificant traces of $\mathrm{H}_{2} \mathrm{~S}, \mathrm{CH}_{4}$ and $\mathrm{N}_{2}$ as impurities (124). A monoethanolamine (MEA) separation process is used because it is the most commonly used method to separate $\mathrm{CO}_{2}$ from mixed gas streams. The temperature of the acid gas streams is $30-$ $40^{\circ} \mathrm{C}$.

- In hydrogen production and ammonia plants, $\mathrm{CO}_{2}$ removed from scrubbers that are used to recover the $\mathrm{NH}_{3}$ have a temperature of $\sim 82^{\circ} \mathrm{C}$. Therefore a cooling step is necessary prior to compression and dehydration (30). 
- In ethanol plants, $\mathrm{CO}_{2}$ streams $\left(\sim 0.987 \mathrm{~atm}, 27^{\circ} \mathrm{C}\right)$ are very pure and can be easily captured from fermentation unit with little traces of impurities (e.g., ethanol, $\mathrm{CH}_{4}$ and sulfur compounds) (125). Only compression and dehydration steps are necessary for this stream.

- Details about how the burdens of compression and dehydration were calculated are provided below.

\section{Compression}

In "IPCC Special Report on Carbon dioxide Capture and Storage" (123), the pressure for $\mathrm{CO}_{2}$ transport in pipelines ranges from 90 bars to 140 bars. Knoope and Faaij's (126) report that the medium pressure in $\mathrm{CO}_{2}$ pipelines in the US is $10.3 \mathrm{MPa}$. Here, the desired final pressure for pumping $\mathrm{CO}_{2}$ to the pipeline is assumed to be 10.3 $\mathrm{MPa}$. Electricity demand for $\mathrm{CO}_{2}$ compression was computed using McCollum"s model developed by David L. McCollum and Joan M. Ogden from University of California, Davis (127). They estimate that the $\mathrm{CO}_{2}$ transport in pipelines requires a five-stage compression to raise $\mathrm{CO}_{2}$ pressure from $0.1 \mathrm{MPa}$ to $7.3 \mathrm{MPa}$ (i.e., cut-off pressure for gas phase). Then a pumping process further increases the pressure from $7.3 \mathrm{MPa}$ to $10.3 \mathrm{MPa}$ (i.e., $\mathrm{CO}_{2}$ liquid/dense phase). The computed electricity uses of compressing and pumping $\mathrm{CO}_{2}$ from $0.1 \mathrm{MPa}$ to $10.3 \mathrm{MPa}$ are $337.8 \mathrm{~kJ} / \mathrm{kgCO}_{2}$ and $6.1799 \mathrm{~kJ} / \mathrm{kg}$ respectively. After unit conversion, the total electricity use for compressing and pumping $1 \mathrm{t} \mathrm{CO}_{2}$ from ethanol plants and ammonia plants is $95.5 \mathrm{kWh} / \mathrm{tCO}_{2}$. For $\mathrm{CO}_{2}$ from acid gas removal unit in natural gas process, the pressure of $\mathrm{CO} 2$ varies from 0.8 to $1.0 \mathrm{MPa}$. 
After applying this initial pressure using the same computing approach, the electricity use of $34.2 \mathrm{kWh} / \mathrm{tCO}_{2}$ is required for compressing $\mathrm{CO}_{2}$ from acid gas removal unit.

The life cycle impact data for electricity are obtained from the ecoinvent database (128). Life cycle energy use and GHG emissions for producing $1 \mathrm{kWh}$ electricity are 0.21 $\mathrm{kgCO}_{2} \mathrm{e}$ and $2.5 \mathrm{MJ}$, respectively. The impact factors for compression are the multiplication of $95.5 \mathrm{kWh}$ electricity and the aforementioned two impact factors of electricity. Therefore the life cycle GHG emissions for $\mathrm{CO}_{2}$ compression are 0.02 tonne $\mathrm{CO}_{2} \mathrm{e} /$ tonne $\mathrm{CO}_{2}$ delivered. The life cycle energy use for $\mathrm{CO} 2$ compression is 239 $\mathrm{MJ} / \mathrm{tCO}_{2}$ delivered. Similarly, the life cycle GHG emissions and life cycle energy use for $\mathrm{CO}_{2}$ compression from acid gas removal unit are $0.01 \mathrm{tCO}_{2} \mathrm{e} / \mathrm{tCO}_{2}$ and $85 \mathrm{MJ} / \mathrm{tCO}_{2}$, respectively.

\section{Dehydration}

Water vapor is typically removed from $\mathrm{CO}_{2}$ to prevent corrosion in pipelines. The energy use of absorption units using triethylene glycol, which is the most common dehydration method in natural gas processing, is provided in its Figure 5 of (129). The electricity use for dehydrating $105 \mathrm{Nm}^{3} / \mathrm{h}$ gas at $10 \mathrm{MPa}$ is $90 \mathrm{~kW}$. The density of CO2 is $467 \mathrm{~kg} / \mathrm{m}^{3}$ at $100 \mathrm{bar}$ and $30^{\circ} \mathrm{C}(130)$. Thus the electricity use to dehydrate $1 \mathrm{~kg} \mathrm{CO}_{2}$ is:

$$
90 \mathrm{~kW} \div\left(\frac{10^{5} \mathrm{~m}^{3}}{\mathrm{~h}} \times 467 \frac{\mathrm{kg}}{\mathrm{m}^{3}}\right)=0.000002 \mathrm{kWh} / \mathrm{kgCO}_{2}
$$

As introduced in "Compression" section, the life cycle energy use and GHG emissions of electricity production are $0.21 \mathrm{kgCO}_{2} \mathrm{e} / \mathrm{kWh}$ and $2.5 \mathrm{MJ} / \mathrm{kWh}$, respectively. Thus the life cycle energy use and GHG emissions of $\mathrm{CO}_{2}$ dehydration are 0.000005 
$\mathrm{MJ} / \mathrm{kg} \mathrm{CO}$ and $0.0000004 \mathrm{~kg} \mathrm{CO}_{2} \mathrm{e} / \mathrm{kg} \mathrm{CO}$, respectively. Since the life cycle GHG emissions of dehydration are several magnitudes smaller than compression, they are neglected in this study.

\section{Cooling}

The $\mathrm{CO}_{2}$ streams from an ammonia scrubbing unit are at $\sim 82^{\circ} \mathrm{C}$ and require cooling. Typically, cooling water is used to capture the heat, which can be recovered to supplement the energy use in other components within the plant (30). The energy use and heat recovery in cooling process are neglected in this study because they were found to be small compared with the other energy uses as shown in (30).

\section{LCI Summary}

The energy inputs labeled in Figure 5.3 are summarized in Table 5.1. The marginal life cycle inventory data for capturing $\mathrm{CO}_{2}$ from the four sources included in this analysis are summarized in Table 5.2.

Table 5.1 Values corresponding to material and energy flows in Figure 5.1.

\begin{tabular}{|l|l|l|l|}
\hline Energy flow & Description & Value & Reference \\
\hline e1 & $\begin{array}{l}\text { Electricity use for } \\
\text { compressing } \mathrm{CO}_{2} \text { from } \\
0.1 \mathrm{MPa} \text { to } 10.3 \mathrm{MPa}\end{array}$ & $95.5 \mathrm{kWh} / \mathrm{tCO}_{2}$ & $(127)$ \\
\hline e2, e4, e6 & $\begin{array}{l}\text { Electricity use for } \mathrm{CO}_{2} \\
\text { dehydration }\end{array}$ & $0.46 \mathrm{kWh} / \mathrm{tCO}_{2}$ & $(129)$ \\
\hline e5 & $\begin{array}{l}\text { Electricity use for } \\
\text { compressing } \mathrm{CO}_{2} \text { from } \\
0.8 \mathrm{MPa} \text { to } 10.3 \mathrm{MPa}\end{array}$ & $34.2 \mathrm{kWh} / \mathrm{tCO}_{2}$ & $(127)$ \\
\hline
\end{tabular}


Table 5.2 Summary of marginal life cycle burdens for capturing $\mathrm{CO}_{2}$ from four sources

\begin{tabular}{|l|l|l|l|l|}
\hline & $\begin{array}{l}\text { Life cycle } \\
\text { burden } \\
\left(\mathrm{MJ} / \mathrm{kgCO}_{2}\right)\end{array}$ & $\begin{array}{l}\text { Life cycle } \\
\text { burden } \\
\left(\mathrm{GHG} / \mathrm{kgCO}_{2}\right)\end{array}$ & $\begin{array}{l}\mathrm{CO}_{2} \text { credit } \\
\left(1 \mathrm{~kg} \mathrm{CO} \mathrm{CO}_{2}\right)\end{array}$ & $\begin{array}{l}\text { Net } \\
\text { emissions } \\
\left(\mathrm{kgCO}_{2} \mathrm{e} / \mathrm{kgCO}_{2}\right)\end{array}$ \\
\hline $\begin{array}{l}\text { Natural } \\
\text { wells }\end{array}$ & 3.024 & 0.148 & 0 & 0.148 \\
\hline $\begin{array}{l}\text { Ethanol } \\
\text { plant }\end{array}$ & 0.240 & 0.020 & -1 & -0.980 \\
\hline $\begin{array}{l}\text { Ammonia } \\
\text { plant }\end{array}$ & 0.240 & 0.020 & -1 & -0.980 \\
\hline $\begin{array}{l}\text { Natural gas } \\
\text { processing- } \\
\text { Acid gas } \\
\text { removal unit }\end{array}$ & 0.119 & 0.010 & & \\
\hline
\end{tabular}

\subsection{Results and Discussion}

Figure 5.4 provides a binary representation of $\mathrm{CO}_{2}$ availability in the United States at a resolution of $50 \mathrm{~km}$ x $50 \mathrm{~km}$ grid cells. White cells have no commercially available $\mathrm{CO}_{2}$ and colored cells have $\mathrm{CO}_{2}$ proportional to the height of the bar. Blue bars are representative of $\mathrm{CO}_{2}$ having lower life cycle impacts (negative net $\mathrm{CO}_{2}$ emissions per $\mathrm{kg} \mathrm{CO}_{2}$ produced) while red bars are for higher impact $\mathrm{CO}_{2}$ (positive net $\mathrm{CO}_{2}$ emissions per $\mathrm{kg} \mathrm{CO}_{2}$ produced). Many grid cells have more than one source in them and in those cases the $\mathrm{CO}_{2}$ supply is aggregated to provide an intuitive representation of regional $\mathrm{CO}_{2}$ availability.

Several important trends are apparent from this representation of the data. The supply of $\mathrm{CO}_{2}$ is dominated by natural wells (shown in red). The EPA reports that there are 13 of these wells in the United States. These are geographically clustered in a few 
areas and three grid cells dominate the landscape for absolute production. The contrast is stark between the natural wells, which produce very large amounts of relatively 'dirty' $\mathrm{CO}_{2}$ at a few select locations, and all other industrial sources, which could garner credits for emissions reductions. A much larger number of other industrial sources are plotted in blue. These are geographically dispersed but in general produce much lower quantities of $\mathrm{CO}_{2}$ than the natural wells. There are a number of regions with high concentrations of industrial sources, largely refineries on the California and Gulf coasts, that produce substantial quantities of byproduct $\mathrm{CO}_{2}$, but in general, the other industrial sources produce small quantities $\left(<50 \mathrm{Mt} \mathrm{CO}_{2} / \mathrm{yr}\right)$ of $\mathrm{CO}_{2}$. From a practical perspective, the distribution of 'clean' v. 'dirty' $\mathrm{CO}_{2}$ in the US poses both opportunities and challenges. This representation suggests that EOR operators or any other operation using $\mathrm{CO}_{2}$ could significantly improve their emissions profile by moving away from mined $\mathrm{CO}_{2}$. In many cases, this is likely to be a transportation challenge given the distributed nature of byproduct $\mathrm{CO}_{2}$ facilities. 


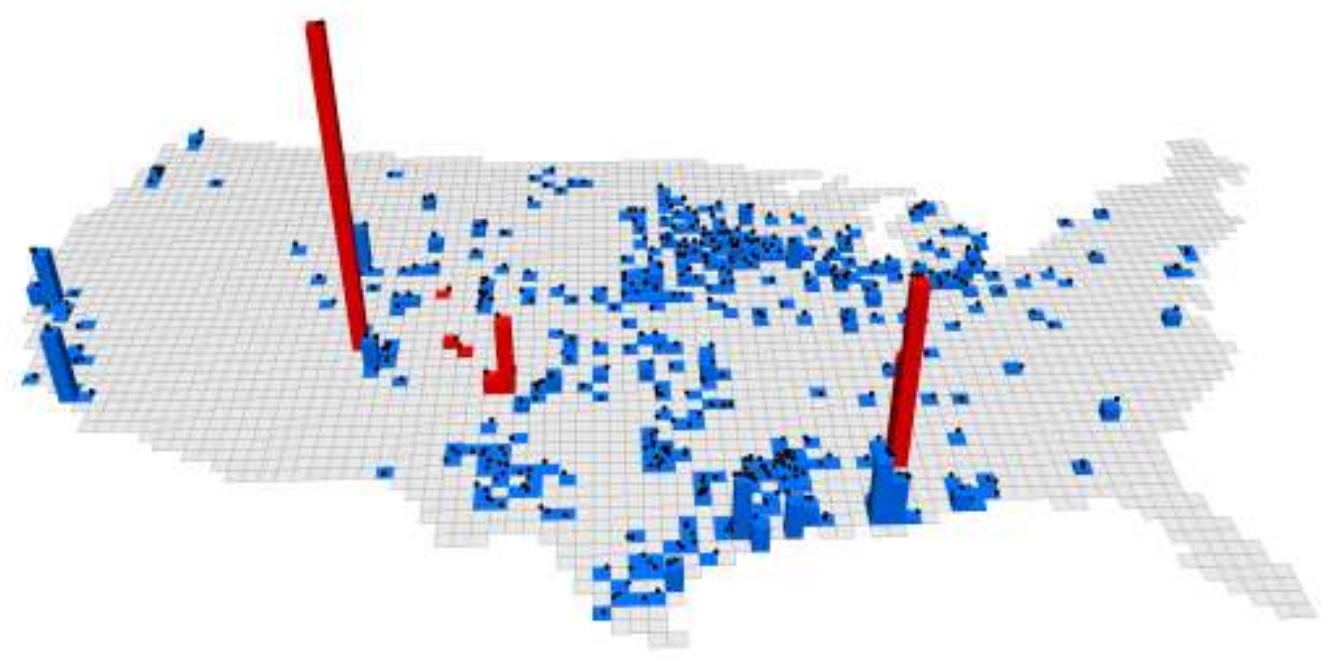

Figure 5.4 Map of the United States showing all commercial sources of $\mathrm{CO}_{2}$ (black dots) and the quantity of $\mathrm{CO}_{2}$ available in a given $50 \times 50 \mathrm{~km}$ grid cell. The color of the bars in each grid cell is proportional to the average environmental impact $\left(\mathrm{kgCO}_{2} \mathrm{e} / \mathrm{tCO}_{2}\right.$ supplied) associated with the $\mathrm{CO}_{2}$ that can be sourced in a particular region. $\mathrm{CO}_{2}$ extraction wells are much larger suppliers of dirty $\mathrm{CO}_{2}$ (red bars) than the clean $\mathrm{CO}_{2}$ available as a byproduct from industrial sectors (blue bars).

Figure 5.4 also indicates that there are large regions of the United States that lack viable sources of $\mathrm{CO}_{2}$. These ' $\mathrm{CO}_{2}$ deserts,' which are visible in the regions between the bars, are concentrated on the east coast, desert southwest, and pacific northwest. The nonuniform distribution of $\mathrm{CO}_{2}$ is important in the context of carbon management projects because many of the large sources do not overlap with some algae cultivation facilities. This interpretation of the data suggests that the scale of a utilization or sequestration effort will depend greatly on its location.

Figure 5.5 shows representations of the carbon deserts in the United States for four different levels of supply. Figure 5.5a shows the regions that do not have $1 \mathrm{Mt} / \mathrm{yr}$ 
available, Figure $5.5 \mathrm{~b}$ is for $5 \mathrm{Mt} / \mathrm{yr}, 4 \mathrm{c}$, is for $10 \mathrm{Mt} / \mathrm{yr}$ and Figure $5.5 \mathrm{~d}$ is for $50 \mathrm{Mt} / \mathrm{yr}$. As expected, the extent of the $\mathrm{CO}_{2}$ deserts grows as the demand for $\mathrm{CO}_{2}$ increases. For small operations needing $\sim 1$ Megatonne $\mathrm{CO}_{2} / \mathrm{yr}$, there are few places in the United States where that supply would be a challenge. The contrast becomes more apparent in Figure $5.5 \mathrm{~b}$ and $5.5 \mathrm{c}$ as the scale of the demand increases to 5 and $10 \mathrm{Mt} / \mathrm{yr}$ respectively. And at the scale of $5 \mathrm{Mt} / \mathrm{yr}$, we would need 400 such operations to capture and or sequester the roughly $2 \mathrm{Gt} / \mathrm{yr}$ of $\mathrm{CO}_{2}$ that is currently emitted from stationary sources such as power plants in the US each year. At the scale of $50 \mathrm{Mt} / \mathrm{yr}$ (Figure 5.5c), there are no regions in the US with enough $\mathrm{CO}_{2}$ supply currently available. In these maps, the darkest red regions indicate that $\mathrm{CO}_{2}$ would have to be transported $500 \mathrm{~km}$ or more to supply a sink.

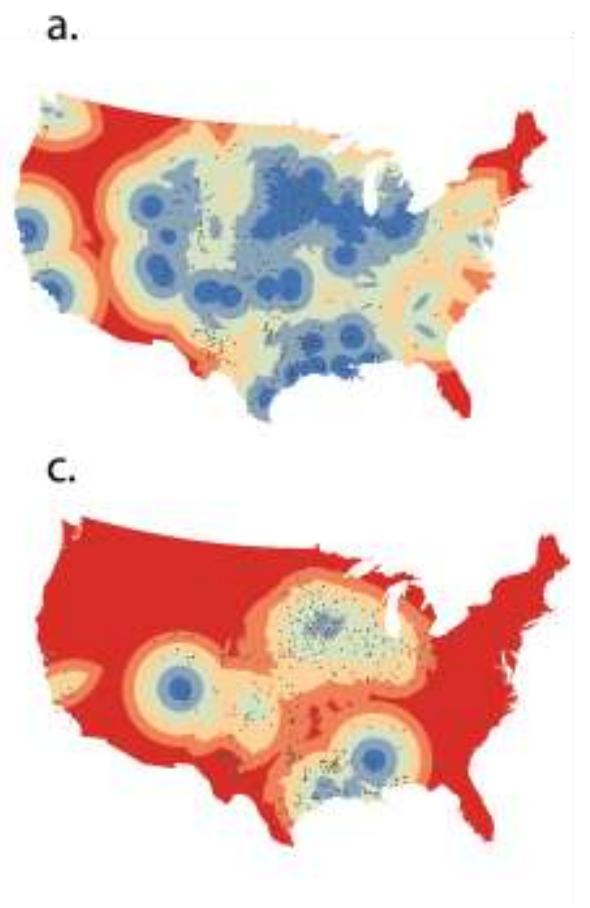

b.

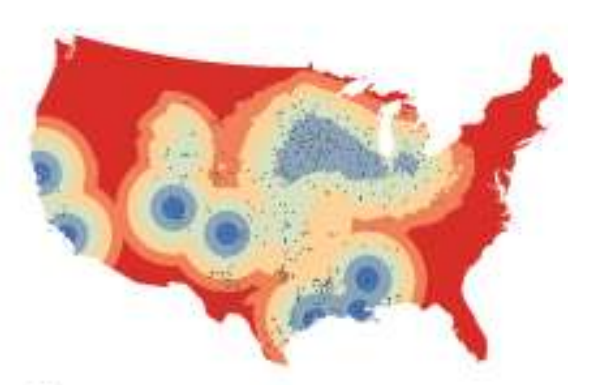

d.

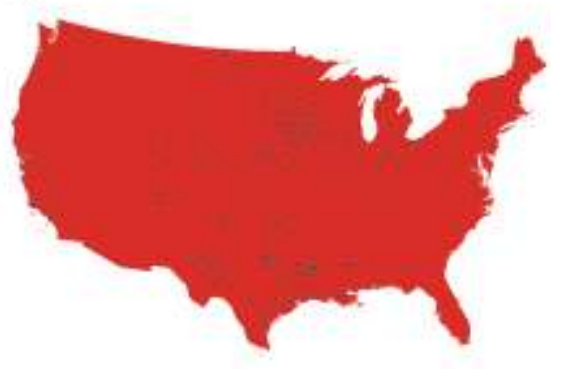


Figure 5.5 The impact of demand scale on the presence of $\mathrm{CO}_{2}$ deserts is pronounced. Here the supply amount was varied (in Mt/yr) (a) 1; (b) 5; (c) 10; (d) 50.

The existence of these $\mathrm{CO}_{2}$ deserts is a known problem in some industries, which consequently engage in large-scale movement of $\mathrm{CO}_{2}$ via pipeline networks. Some of these pipelines are quite large and have the capacity to move tens of megatonnes of $\mathrm{CO}_{2}$ each year. Figure 5.6 shows a detail map of the south central United States with pipeline networks in blue. The width of the pipelines in this figure is proportional to the $\mathrm{CO}_{2}$ capacity of the pipeline.

At this scale, the dramatic differences between source capacity result in there being several regions with adequate $\mathrm{CO}_{2}$ clustered around natural $\mathrm{CO}_{2}$ wells and a more diffuse source located by the ethanol refineries of the midwest. The existing pipeline networks are, unsurprisingly, built to take the $\mathrm{CO}_{2}$ from the large sources, e.g., natural wells and deliver it to the regions of highest demand. Even though these pipelines do alter the landscape somewhat in terms of where $\mathrm{CO}_{2}$ deserts exist, their prevalence is nonetheless a real and heretofore unreported challenge to carbon management. 


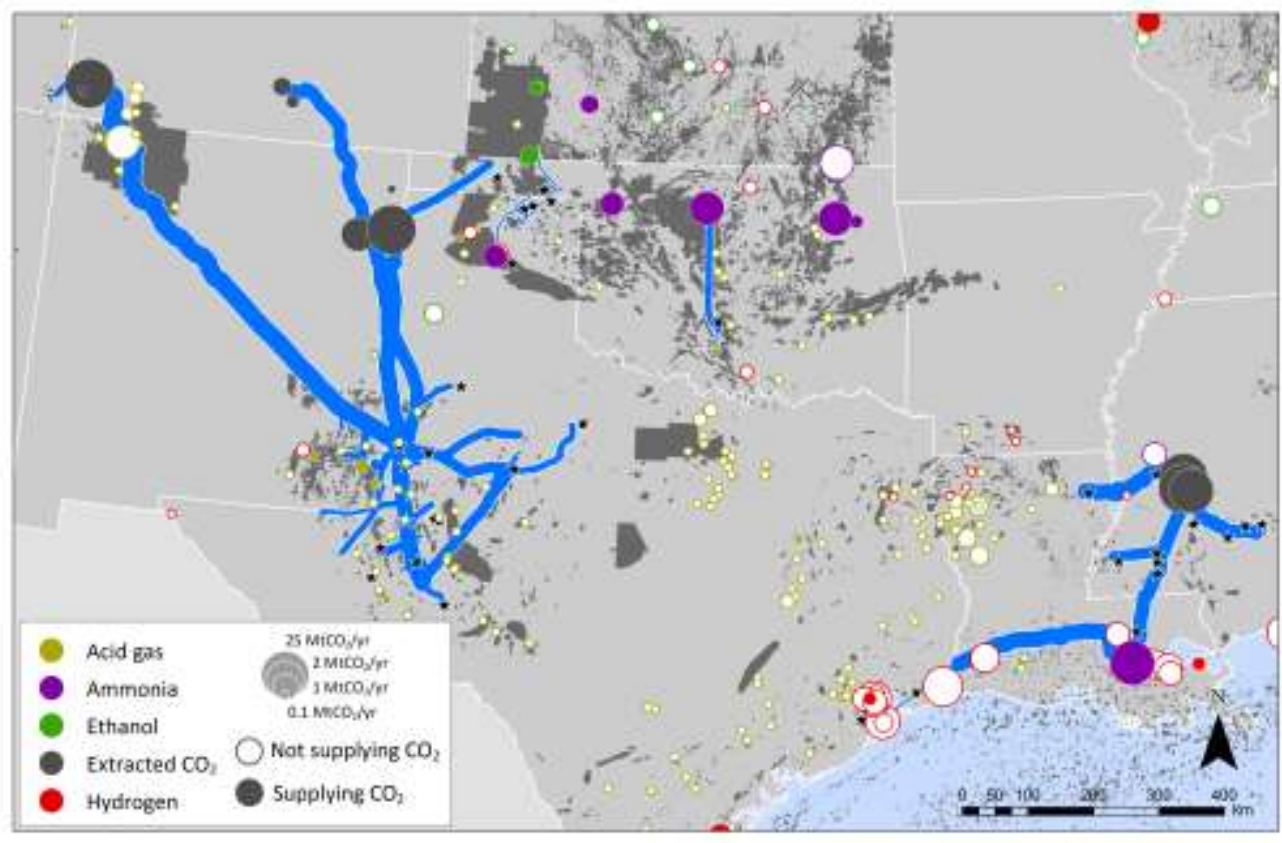

Figure 5.6 Regional pipeline networks have the capacity to alleviate some of the constraints associated with carbon deserts but their reach tends to be limited as shown in this detail of the south central United States. Here the thickness of the lines is proportional to their capacity and the dark grey regions indicate the location of oil and gas formations.

These results can be best interpreted in terms of the impacts that carbon deserts will have on large-scale algae cultivation. The cultivation of algae at large scales will require a number of key inputs and growing conditions that rapidly narrow the number of suitable regions in the US. Access to water, nutrient supplies, sunlight (the closer to the equator the better), and $\mathrm{CO}_{2}$ will all determine the viability of a growth operation and yet almost no attention has been paid to $\mathrm{CO}_{2}$ sources in the literature. Sapphire Energy Inc. has pilot facilities in New Mexico; the related carbon desert is shown in Figure 5.5 (16). Independent analysis has shown that the gulf coast might be the best place to grow algae from a water perspective and this region could be the most desirable in terms of $\mathrm{CO}_{2}$ 
availability as well (131). As shown in Figure 5.6, Louisiana has a number of large and currently untapped $\mathrm{CO}_{2}$ resources that are tied to the significant refining capacity of the Louisiana.

Meeting the demand for $\mathrm{CO}_{2}$ that the algae cultivation market represents will be a challenge. Meeting it in a way that minimizes overall life cycle emissions by using the lowest burden sources, adds another critical constraint that is being overlooked and that the $\mathrm{CO}_{2}$ deserts analysis should bring to light. $\mathrm{CO}_{2}$ from natural wells has a large environmental footprint and it represents a net addition of GHGs to the atmosphere. Using byproduct $\mathrm{CO}_{2}$ from other industries, and preventing that gas from being emitted to the atmosphere, could constitute a credit that could substantially reduce the nations' $\mathrm{CO}_{2}$ footprint. Either way, there is a large environmental opportunity cost that is lost when releasing byproduct $\mathrm{CO}_{2}$ that is locally sourced and importing, from large distances, extracted $\mathrm{CO}_{2}$ from dedicated wells.

\section{Environmental Implications}

This analysis suggests that carbon deserts are likely to have important ramifications for developing rational carbon management plans at the national scale. A full appreciation of their importance requires a description of some elements that were not fully captured in this preliminary analysis. The first is that carbon deserts exist for a combination of technological, economic, policy, and social reasons. Efforts to address the carbon deserts problem will need to consider all of these factors in order to be successful. As an example, of all the sources included here, ethanol refineries are the only source 
from which the $\mathrm{CO}_{2}$ is biogenic. That is, the $\mathrm{CO}_{2}$ emitted from the fermentation of corn originally came from the atmosphere and so this is the only source that would represent a net reduction in atmospheric $\mathrm{CO}_{2}$ emissions. For all the other industry types modeled here, the $\mathrm{CO}_{2}$ flows are fossil carbon emissions avoided (as opposed to removed from the atmosphere). Policy objectives will need to be consistent and, ideally, based on some life cycle framework, that compares different $\mathrm{CO}_{2}$ sources on an even basis to ensure that emissions impacts are minimized.

The importance of scale, in terms of $\mathrm{CO}_{2}$ supply and demand as well as spatial scales, is one that came up often in our analysis and it is worth reiterating as a final point here. Efforts to achieve deep reductions in carbon emissions will require that technologies be inherently capable of being scaled rapidly and that is a part of the reason that I interpreted these results in terms algae cultivation. That being said, there is already a market for $\mathrm{CO}_{2}$ and no effort was made to quantitatively parse which portion often $\mathrm{CO}_{2}$ is currently "off the table" for supply elsewhere and could not be considered for new projects. If data on $\mathrm{CO}_{2}$ receipts were available, the impact of limitations in supply volumes would be even more acute. 


\section{Chapter 6}

\section{Conclusions and Future work}

\subsection{Dissertation Purpose}

This dissertation research aims to explore the environmental implications of algae derived biofuels from several perspectives with the ultimate goal of understanding their climate implications. This knowledge is important for informing both technological and policy choices. My work relied heavily on lifecycle models used to simulate the algae-toenergy systems. Using these models, a number of biomass conversion pathways (e.g., lipid extraction, transesterification, hydrothermal liquefaction) were investigated. Both field data and literature data were collected as model input parameters to reflect the current and anticipated environmental performance of algae biofuels and to project future environmental performance of commercial-scale algal biofuel production systems. This 
work resulted in a number of interesting and important contributions to the academic literature and these are summarized briefly here:

\subsection{Conclusions and Major Contributions}

\subsubsection{Environmental performance of algae biodiesel}

The first major contribution of this work was to explore the inconsistencies that exist in the results of six LCA studies of algae biodiesel. The findings are reconciled to reach a consensus and benchmark the environmental performance to other non-algae biofuel options. After a three-step normalization of key model assumptions and parameters, it is concluded that these six LCA studies present a consistent story: algae biodiesel can achieve reduction in lifecycle GHG emissions that are on par with conventional biofuels (i.e., corn ethanol and soybean biodiesel). A number of scenarios are models and break-even energy return will be achieved in the base case scenario where bioelectricity is generated as a co-product and $\mathrm{CO}_{2}$ is sourced from an ammonia plant. It is worth noting that co-product offset plays an important role in altering the net energy return of algae biodiesel production. The general conclusion of this modeling is that the overall environmental performance of algae biodiesel is on par with that of traditional biofuels even though algae biofuels are relatively new and there is great potential to optimize the process as this emerging technology continues to develop. 


\subsubsection{Environmental performance of algae biofuels produced via hydrothermal liquefaction}

The second major contribution of this work was that for the first time field data of algae-to-energy systems are used to understand how large scale production might fare from a life cycle perspective. Specifically, I modeled hydrothermal liquefaction (HTL) as a means to produce energy from algae. The results from this analysis are more representative and reliable in terms of describing the current status as well as projecting the future development of this emerging industry. Three scenarios ('lab', 'pilot-scale' and 'full-scale') were defined based on different data sources to understand the effect of process scale on the lifecycle profile of algae biofuels generated via HTL. 'Pilot-scale' algae biofuels exhibit a GHG emission profile similar to traditional biofuels; 'full-scale' scenario, which represents the achievable performance of algae biofuels via HTL, demonstrates that algae derived liquid fuels can be economically feasible and reduce carbon emissions compared with their petroleum equivalents; 'lab' scenario performs slightly better than 'full-scale' but is not representative since lab conditions are not reproducible in the field. This exposed a major problem with much of the existing algaeto-energy LCA which relies heavily on lab-scale data Comparing the results of these three scenarios, I find that 'scale' matters and that some of the efficiencies that companies like Sapphire are working toward will be critical to the deployment of their processes in a sustainable manner. 


\subsubsection{Historic land use change accounting approach}

The third contribution from this dissertation was to develop a novel method for accounting of the land use change associated with biofuel feedstock cultivation. A new method called historic land use change (HLUC) is developed for quantifying the lifecycle carbon emissions from biofuel deployment. It employs historical cropland data and land characteristics to measure historical carbon emissions from agricultural land that is later diverted from growing food crops to biofuel feedstocks. This innovative approach can potentially address several issues that exist in current indirect land use change (iLUC) and direct land use change (DLUC) frameworks. Unlike iLUC results, HLUC estimates exhibit lower uncertainty because it does not rely on agro-economic models. In addition, iLUC provides a free path to biofuel feedstocks that are grown on croplands converted originally for agricultural purposes, which raises equity concerns. The HLUC approach avoids such issue by tying emission accounting to the actual physical process of biofuel feedstock production.

\subsubsection{Carbon deserts and lifecycle burdens of different $\mathrm{CO}_{2}$ supply sources}

The fourth major contribution of this dissertation is to develop a model of current supplies of $\mathrm{CO}_{2}$ in the United States and to interpret these supplies in the context of the life cycle burdens of the $\mathrm{CO}_{2}$ and the geospatial constraints of the $\mathrm{CO}_{2}$. Several regions in the US are not able to supply $\mathrm{CO}_{2}$ to algae ponds at the levels that would be needed to 
maintain a commercial cultivation operation. These regions are defined as ' $\mathrm{CO}_{2}$ deserts' in this study and are depicted in maps showing both locations and available quantities of $\mathrm{CO}_{2}$ suppliers. In addition to the geospatial constraints and limited quantities, the lifecycle impacts of five industrial sectors that currently supply $\mathrm{CO}_{2}$ to the market are quantified. These five $\mathrm{CO}_{2}$ supply sources are ammonia plants, hydrogen plants, natural $\mathrm{CO}_{2}$ wells, acid gas removal units in natural gas processing, and ethanol plants. Among these five types of suppliers, natural $\mathrm{CO}_{2}$ wells are the least environmentally favorable because $\mathrm{CO}_{2}$ as a sole product from such wells is net release of carbon from the ground. $\mathrm{CO}_{2}$ from the other four sources is by-product from processes that generate one or more main products; for example, ammonia plants produce $\mathrm{NH}_{3}$ as the main product while a pure stream of $\mathrm{CO}_{2}$ is generated as a by-product. $\mathrm{CO}_{2}$ from ammonia plants, hydrogen plants and acid gas removal unit is still from fossil source therefore if it is used in algae cultivation, it is not carbon neutral. Importantly, $\mathrm{CO}_{2}$ from ethanol plant is biogenic thus its use in algae biofuel production will result no combustion emissions in the fuel life cycle.

\subsection{Future Work}

This research could be expanded to explore a number of related areas. Specifically, I would like to investigate the following three research directions:

- Nutrient recycling technology options that can increase the efficiency of utilizing nutrients thus reduce the overall lifecycle GHG emissions. Nitrogen and phosphorus have an important effect on system life cycle impacts even though they are not a 
major focus of this work. They are being studied extensively by others in the context of growing algae in wastewater streams and using other effluent as feedstock for algae cultivation. My interest is specifically in the recycle of the HTL waters from the process being carried out by Sapphire to understand how the efficiency of the recycling process can impact the overall system carbon balance.

- Water impacts associated with the HTL conversion process. The nominal focus of this work was carbon emissions, and by extension energy efficiency, but the water impacts of HTL processing will be very important in site selection and in imposing constraints on the deployment of large scale facilities. A deeper analysis of water issues as it relates to HTL would be a valuable and interesting extension of this research.

- System optimization to explore how larger scale processes (outside of the control of an algae-to-energy producer) like $\mathrm{CO}_{2}$ supply can be leveraged to produce a truly sustainable and robust supply chain. At present the cultivation and conversion of algae to biofuel is carried out on a facility scale where upstream and downstream burdens are not being considered in an integrated way. The ultimate goal of this work would be to generate integrated models that would consider all of the pieces presented here plus economics to better inform engineers and decision makers in the government and in the industry. 


\section{References}

1. Lashof DA, Ahuja DR. Relative contributions of greenhouse gas emissions to global warming. Nature. 1990;344(5):529.

2. Dominguez-Faus, Powers SE, Burken JG, Alvarez PJ. The water footprint of biofuels: A drink or drive issue. Environmental Science \& Technology. 2009;43:3005.

3. Guilfor MC, Hall CAS, O'Connor P, Cleveland CJ. A new long term assessment of energy return on investment (EROI) for U.S. oil and gas discovery and production. Sustainability. 2011;3:1866.

4. US EPA. Renewable fuel standard program (RFS2) regulatory impact analysis. United States Environmental Protection Agency; 2010. Report No.: EPA-420-R-10-006.

5. Low carbon fuel standard [Internet].; 2013. Available from: http://www.arb.ca.gov/fuels/lcfs/lcfs.htm.

6. Farrell AE, Plevin RJ, Turner BT, Jones AD, O'Hare M, Kammen DM. Ethanol can contribute to energy and environmental goals. Science. 2006;311:506.

7. Landis AE, Miller SA, Theis TL. Life cycle of the corn-soybean agroecosystem for biobased production. Environmental Science \& Technology. 2007;41:1457.

8. Clarens AF, Resurrection EP, White MA, Colosi LM. Environmental life cycle comparison of algae to other energy feedstocks. Environmental Science and Technology. 2010;44(5):1813.

9. Hill J, Nelson E, Tilman D, Polasky S, Tiffany D. Environmental, economic, and energetic costs and benefits of biodiesel and ethanol biofuels. PNAS. 2006;103:11206.

10. Stephenson AL, Kazamia E, Dennis JS, Howe CJ, Scott SA, Smith AG. Life-cycle assessment of potential algal biodiesel production in the united kingdom: A comparison of raceways and air-lift tubular bioreactors. Energy Fuels. 2010;24:4062.

11. Sander K, Murthy GS. Life cycle analysis of algae biodiesel. International Journal of Life Cycle Assessment. 2010;15:704.

12. Lardon L, Hélias A, Sialve B, Steyer J, Bernard O. Life-cycle assessment of biodiesel production from microalgae. Environmental Science \& Technology. 2009;43:6475. 
13. Campbell PK, Beer T, Batten D. Life cycle assessment of biodiesel production from microalgae in ponds. Bioresource Technology. 2010.

14. Jorquera O, Kiperstok A, Sales EA, Embiruçu M, Ghirardi ML. Comparative energy life-cycle analyses of microalgal biomass production in open ponds and photobioreactors. Bioresource Technology. 2010;101:1406.

15. Clarens AF, Nassau H, Resurreccion EP, White MA, Colosi LM. Environmental impacts of algae-derived biodiesel and bioelectricity for transportation. Environmental Science and Technology. 2011;45:7554.

16. Liu X, Saydah B, Eranki P, Colosi LM, Mitchell BG, Rhodes J, et al. Pilot-scale data provide enhanced estimates of the life cycle energy and emissions profile of algae biofuels produced via hydrothermal liquefaction. Bioresource Technology. 2013;148:163.

17. Frank ED, Elgowainy A, Han J, Wang Z. Life cycle comparison of hydrothermal liquefaction and lipid extraction pathways to renewable diesel from algae. International Journal of Life Cycle Assessment. 2013;18:137.

18. Fortier M, Roberts GW, Stagg-Williams SM, Sturm BSM. Life cycle assessment of bio-jet fuel from hydrothermal liquefaction of microalgae. Applied Energy. 2014;122:73.

19. Luo D, Hu Z, Choi DG, Thomas VM, Realff MJ, Chance RR. Life cycle energy and greenhouse gas emissions for an ethanol production process based on blue-green algae. Environmental Science \& Technology. 2010;44(8670).

20. Sharma Y, Singh B. Development of biodiesel: Current scenario. Renewable and Sustainable Energy Reviews. 2009;13(6):1646.

21. McKendry P. Energy production from biomass (part 2): Conversion technologies. Bioresource Technology. 2002;83(1):47.

22. European Union. Biomass conversion technologies: Achievements and prospects for heat and power generation. EUR 18029 EN. European Commission Directorate-General Science, Research and Development. 1999:178.

\section{Goyal HB, Seal D, Saxena R. Bio-fuels from thermochemical conversion of renewable resources: A review. Renewable and Sustainable Energy Reviews. 2008;12(2):504.}

24. Clark J, Deswarte F, editors. Introduction to chemicals from biomass. Wiley; 2008. 
25. Searchinger T, Heimlich R, Houghton RA, Dong F, Elobeid A, Fabiosa J, et al. Use of U.S. croplands for biofuels increases greenhouse gases through emissions from landuse change. Science Magzine. 2008;319:1238,1239, 1240.

26. Kim H, Kim S, Dale BE. Biofuels, land use change, and greenhouse gas emissions: Some unexplored variables. Environmental Science \& Technology. 2009;43:961.

27. Plevin R, O'Hare M, Jones A, Torn M, Gibbs H. Greenhouse gas emissions from biofuels' indirect land use change are uncertain but may be much greater than previously estimated. Environmental Science and Technology. 2010;44:8015,8016 - 8021.

28. Fargione J, Hill J, Tilman D, Polasky S, Hawthorne P. Land clearing and the biofuel carbon debt. Science. 200829 February;319:1235.

29. U.S. Environmental Protection Agency. Inventory of U.S. greenhouse gas emissions and sinks: 1990 - 2006. Washington, DC: U.S. Environmental Protection Agency; 2008.

30. Overcash M, Li Y, Griffing E, Rice G. A life cycle inventory of carbon dioxide as a solvent and additive for industry and in products. Journal of Chemical Technology and Biotechnology. 2007;82:1023.

31. EPA facility level GHG emissions data [Internet].; 2013. Available from: http://ghgdata.epa.gov/ghgp/main.do.

32. Benemann JR, Oswald WJ. Systems and economic analysis of microalgae ponds for conversion of CO2 to biomass. Pittsburgh, PA: U.S. Department of Energy; 1996. Report No.: 201.

33. Sialve B, Bernet N, Bernard O. Anaerobic digestion of microalgae as a necessary step to make microalgae biodiesel sustainable. Biotechnology Advances. 2009;27:409.

34. Kadam KL. Environmental implications of power generation via coal-microalgae cofiring. Energy. 2002;27:905.

35. Yang J, Xu M, Zhang X, Hu Q, Sommerfeld M, Chen Y. Life-cycle analysis on biodiesel production from microalgae: Water footprint and nutrients balance. Bioresource Technology. 2011;102:159.

36. Beach ES, Eckelman MJ, Cui Z, Brentner L, Zimmerman JB. Preferential technological and life cycle environmental performance of chitosan flocculation for harvesting of the green algae neochloris oleoabundans. Bioresource Technology. 2012. 
37. Batan L, Quinn J, Willson B, Bradley T. Net energy and greenhouse gas emission evaluation of biodiesel derived from microalgae. Environmental Science \& Technology. 2010;44(7975):7975.

38. Liu X, Clarens AF, Colosi LM. Algae biodiesel has potential despite inconclusive results to date. Bioresource Technology. 2012;104:803.

39. Sheehan J, Camobreco V, Duffield J, Graboski M, Shapouri H. An overview of biodiesel and petroleum diesel life cycles. National Renewable Energy Laboratory (NREL) and US Department of Energy (USDOE); 1998.

40. Redfield AC. The biological control of chemical factors in the environment. American Scientist. 1958;46(3):205.

41. Drbal LF, Boston PG, Westra KL. Power plant engineering. New York: Chapman \& Hall; 1996.

42. Soda S, Iwai Y, Sei K, Shimod Y, Ike M. Model analysis of energy consumption and greenhouse gas emissions of sewage sludge treatment systems with different processes and scales. Water science and technology. 2010;61(2):365.

43. Hue NV, Sobieszczyk BA. Nutritional values of some biowastes as soil amendments. Compost Science. 1990;7:34.

44. Campbell JE, Lobell DB, Field CB. Greater transportation energy and GHG offsets from bioelectricity than ethanol. Science. 2009;324:1055.

45. Trimbur DE, Im C, Dillon HF, Day AG, Franklin S, Coragliotti A, inventors; Solazyme I, assignee. Lipid pathway modification in oil-bearing microorganisms. CA (US) 2009 .

46. Cranford RJ, Aravanis AM, Roussis SG, inventors; Sapphire Energy, Inc., San Diego, CA (US), assignee. Process for the recovery of oleaginous compounds from biomass. United States 2012 .

47. Oldenburg PD, Roberts V, Daage M, Berlowitz PJ, Long DC, Oumar-Mahamat H, inventors; ExxonMobil Research and Engineering Company, assignee. Catalyst recovery in hydrothermal treatment of biomass. United States 2012 .

48. Jena U, Das KC. Comparative evaluation of thermochemical liquefaction and pyrolysis for bio-oil production from microalgae. Energy Fuels. 2011;25:5472.

49. Duan P, Savage PE. Hydrothermal liquefaction of a microalgae with heterogeneous catalysts. Industrial and Engineering Chemistry Research. 2011;50(1):52. 
50. Brown TM, Duan P, Savage PE. Hydrothermal liquefaction and gasification of nannochloropsis sp. Energy Fuels. 2010;24:3639.

51. Minowa T, Yokoyama S, Kishimoto M, Okakura T. Oil production from algal cells of dunaliella tertiolecta by direct thermochemical liquefaction. Fuel. 1995;74(12):1735.

52. Dote Y, Sawayama S, Inoue S, Minowa T, Yokoyama S. Recovery of liquid fuel from hydrocarbon-rich microalgae by thermochemical liquefaction. Fuel. 1994;73(12): 1855.

53. Valdez PJ, Dickinson JG, Savage PE. Characterization of production fractions from hydrothermal liquefaction of nannochloropsis sp. and the influence of solvents. Energy Fuels. 2011;25:3235.

54. Sarma AK, Konwer D. Feasibility studies for conventional refinery distillation with a (1:1) w/w of a biocrude blend with petroleum crude oil. Energy \& Fuels. 2005;19:1755.

55. Yu G, Zhang Y, Schideman L, Funk T, Wang Z. Distributions of carbon and nitrogen in the products from hydrothermal liquefaction of low-lipid microalgae. Energy \& Environmental Science. 2011;4:4587.

56. Biller P, Ross AB. Potential yields and properties of oil from the hydrothermal liquefaction of microalgae with different biochemical content. Bioresource Technology. 2011;102:215.

57. Ross AB, Biller P, Kubacki ML, Li H, Lea-Langton A, Jones JM. Hydrothermal processing of microalgae using alkali and organic acids. Fuel. 2010;89:2234.

58. Yang YF, Feng CP, Inamori Y, Maekawa T. Analysis of energy conversion characteristics in liquefaction of algae. Resources Conservation \& Recycling. 2004;43:21.

59. Pellegrino J, Brueske S, Carole T, Andres H. Energy and environmental profile of the U.S. petroleum refining industry. Columbia, Maryland: Energetics Incorporate, Department of Energy; 2007.

60. Wang H, Liu X, Liu Y, Chen P, Sun J. Hydrothermal liquefaction of wheat straws for bio-oil and related analysis. Advanced Materials Research. 2012;347:2419.

61. Luo S, Li C, Yi C, Zhou Y. Bio-oil production by pyrolysis and liquefaction of biomass using blast furnace slag as heating source. Advanced Materials Research. 2012:2604. 
62. Frank ED, Han J, Palou-Rivera I, Elgowainy A, Wang MQ. User manual for algae life-cycle analysis with GREET: Version 0.0. Argonne, Illinois: Energy Systems Division, Argonne National Laboratory; 2011. Report No.: ANL/ESD/11-7.

63. Ruiz HA, Rodriguez-Jasso RM, Fernandes BD, Vicente AA, Teixeira JA.

Hydrothermal processing, as an alternative for upgrading agriculture residues and marine biomass according to the biorefinery concept: A review. Renewable and Sustainable Energy Reviews. 2012;21:35.

64. Dote Y, Sawayama, Shigeki, Inoue, S., Minowa T, Yokoyama S. Recovery of liquid fuel from hydrocarbon-rich microalgae by thermochemical liquefaction. Fuel. 1994;73(12):1855.

65. Holmes G, Keith D. An air-liquid contactor for large-scale capture of CO2 from air. Philosophical transactions of the royal society. 2012;370:4380.

66. Lackner KS, Brennan S, Matter JM, Park A-A, Wright A, Zwaan Bvd. The urgency of the development of CO2 capture from ambient air. Proceedings of the National Academy of Sciences. 2011;109:13156.

67. Alba LG, Torri C, Samori C, Fabbi D, Brilman DWF. Hydrothermal treatment (HTT) of microalgae: Evaluation of the process as conversion method in an algae biorefinery concept. Energy Fuels. 2011;26:642.

68. Vardon DR, Sharma BK, Scott J, Yu G, Wang Z, Schideman L, et al. Chemical properties of biocrude oil from the hydrothermal liquefaction of spirulina algae, swine manure, and digested anaerobic sludge. Bioresource Technology. 2011;102:8295.

69. Sim TS, Goh A, Becker WE. Comparison of centrifugation, dissolved air flotation and drum filtration techniques for harvesting sewage-grown algae. Biomass. 1988;16:51.

70. Vasudevan V, Stratton RW, Pearlson MN, Jersey GR, Beyene AG, Weissman JC, et al. Environmental performance of algal biofuel technology options. Environmental Science and Technology. 2012.

71. Welty JR, Wicks CE, Wilson RE. Fundamentals of heat transfer. In: Welty JR, Wicks CE, Wilson RE, editors. Fundamentals of momentum, heat, and mass transfer. ; 1984. p. 223.

72. California Air Resources Board. Detailed california-modified GREET pathway for corn ethanol. 2009. 
73. California Air Resources Board. Proposed regulation to implement the low carbon fuel standard, volume I, staff report: Initial statement of reasons . Sacramento, California: California Air Resource Board; 2009. Report No.: 374.

74. Wang M. GREET version 1.8b. 2010.

75. Berndes G, Hansson J. Bioenergy expansion in the EU: Cost-effective climate change mitigation, employment creation and reduced dependency on imported fuels. Energy policy. 2007;35:5965.

76. Rathmann R, Szklo A, Schaeffer R. Land use competition for production of food and liquid biofuels: An analysis of the arguments in the current debate. Renewable Energy. 2010;35:14.

77. Lapola DM, Schaldach R, Alcamo J, Bondeau A, Koch J, Koelking C, et al. Indirect land-use changes can overcome carbon savings from biofuels in brazil. Proceedings of the National Academy of Sciences. 2009;107(8):3388.

78. Renewable Fuel Standard Program (RFS2) Regulatory Impact Analysis, EPA-420-R10-006, , 2nd Sess. (2010).

79. Lambin EF, Geist HJ, Lepers E. Dynamics of land-use and land-cover change in tropical regions. Annual review of environment and resources. 2003;28:205.

80. Geist HJ, Lambin EF. Proximate causes and underlying driving forces of tropical deforestation. BioScience. 2002;52(2):143.

81. Hertel TW, Golub AA, Jones AD, O'Hare M, Plevin RJ, Kammen DM. Effects of US maize ethanol on global land use and greenhouse gas emissions: Estimating marketmediated responses. BioScience. 2010;60(3):223.

\section{Al-Riffai P, Dimaranan B, Laborde D. Global trade and environmental impact} study of the EU biofuels mandate . IFPRI; 2010. Report No.: SI2.537.787.

83. Heijungs R. Economic drama and the environmental stage: Formal derivation of algorithmic tools for environmental analysis and decision-support from unified epistemological principle [dissertation]. Center of Environmental Science, Leiden University; 1997.

84. Frischknecht R. Life cycle inventory analysis for decision-making [dissertation]. Swiss Federal Institute of Technology, Zurich, Switzerland; 1998. 
85. Brander M, Tipper R, Hutchison C, Davis G. Consequential and attributional approaches to LCA: A guide to policy makers with specific reference to greenhouse gas LCA of biofuels. Technical paper. Ecometrica Press; 2009. Report No.: TP-090403-A.

86. Thomassen MA, Dalgaard R, Heijungs R, Boer Id. Attributional and consequential LCA of milk production. International Journal of Life Cycle Assessment. 2007;13:339.

87. Notice of Data Availability Concerning Renewable Fuels Produced from Palm Oil Under the RFS Program, 2012).

88. ISO 14044: Environmental Management - Life Cycle Assessment - Requirements and Guidelines, , (2006).

89. European Parliment Legislative Resolution of 17 December 2008 on the Proposal for a Directive of the European Parliament and of the Council on the Promotion of the use of Energy from Renewable Sources (COM(2008)0019-C6-0046/2008-2008/0016(COD)), 2008).

90. Directive 2009/28/EC of the European Parliament and of the Council of 23 April 2009, Annex V2009).

91. Gibbs HK, Johnston M, Foley JA, Holloway T, Monfreda C, Ramankutty N, et al. Carbon payback times for crop-based biofuel expansion in the tropics: The effects of changing yield and technology. Environmental Research Letters. 2008;3.

92. Ramankutty N, Foley J. Estimating historical changes in global land cover: Croplands from 1700 to 1992. Global Biogeochemical Cycles. 1999;13(4):997-1027.

93. Miettinen J, Hooijer A, Tollenaar D, Page S, Malins C, Vernimmen R, et al. Historical analysis and projection of oil palm plantation expansion on peatland in southeast asia. White Paper. USA, Washington DC: International Council on Clean Transportation; 2012. Report No.: 17.

94. Houghton RA, Hobbie JE, Melillo JM, Moore HB, Peterson BJ, Shaver GR, et al. Changes in the carbon content of terrestrial biota and soils between 1860 and 1980: A net release of CO2 to the atmosphere. Ecological Monographs. 1983;53(3):235.

95. Houghton R,A. Chapter 4: Changes in the storage of terrestrial carbon since 1850. In: Soil and Global Change. USA, Florida: CRC Press Inc.; 1995. p. 45.

96. Houghton RA. The annual net flux of carbon to the atmosphere from changes in land use 1850-1990. Tellus. 1999;51(B):298. 
97. Germer J, Sauerborn J. Estimation of the impact of oil palm plantation establishment on greenhouse gas balance. Environment, Development and Sustainability. 2008;10:697.

98. Davidson E, Ackerman I. Changes in soil carbon inventories following cultivation of previously untilled soils. Biogeochemistry. 1993;20:161.

99. Joos F, Prentice IC, Sitch S, Meyer R, Hooss G, Plattner G, et al. Global warming feedbacks on terrestrial carbon uptake under the intergovernmental panel on climate change (IPCC) emissions scenarios. Global Biogeochemical Cycles. 2001;15:891.

100. Cao M, Woodward FI. Dynamic responses of terrestrial ecosystem carbon cycling to global climate change. Nature. 1998;393:249.

101. Joos F, Plattner G, Stocker TF, Marchal O, Schmittner A. Global warming and marine carbon cycle feedbacks on future atmospheric CO2. Science. 1999;284:464.

102. Nakic' enovic', Nebojs ă, Davidson O, Davis G, Grübler A, Kram T, Lebre La Rovere E, et al. Special report on emission scenarios. New York: Cambridge University Press; 2000.

103. O'Hare M, Plevin R, Martin J, Jones A, Kendall A, Hopson E. Proper accounting for time increases crop-based biofuels' greenhouse gas deficit versus petroleum.

Environmental Research Letters. 2009(2).

104. Solomon S, Qin D, Manning M, Marquis M, Averyt K, Tignor M, et al, editors. IPCC, 2007: Climate change 2007: The physical science basis. contribution of working group I to the fourth assessment report of the intergovernmental panel on climate change. 1st ed. Cambridge, United Kindom and New York, NY, USA: Cambridge University Press; 2007.

105. Schwietzke S, Griffin WM, Matthews HS. Relevance of emissions timing in biofuel greenhouse gases and climate impacts. Environmental Science \& Technology. 2011;45:8197.

106. Laborde D. Modeling land-use changes in a global CGE: Assessing the EU biofuel mandates with the MIRAGE-BioF model. Climate Change Economics. 2012;3(3).

107. Laborde D. Assessing the land use change consequences of european biofuel policies. ATLASS Consortium; 2011. Report No.: S12. 580403.

108. Global cropland and pasture land data from 1700 to 2007 [Internet].; 2012. Available from: http://www.geog.mcgill.ca/ nramankutty/Datasets/Datasets.html. 
109. Global potential vegetation dataset [Internet].; 2013. Available from: http://www.sage.wisc.edu/download/potveg/global_potveg.html.

110. Olson JS, Watts JA, Allison LJ, editors. Carbon in live vegetation of major world ecosystems. Springfield, Virginia: National Technocial Information Service; 1983.

111. Carre F, Hiederer R, Blujdea V, Koeble R. Background guide for the calculation of land carbon stocks in the biofuels sustainability scheme drawing on the 2006 IPCC guidelines for national greenhouse gas inventories. Luxembourg: Office for Official Publications of the European Communities; 2010. Report No.: EUR24573EN.

112. USDA. Agricultural statistics board national agricultural statistics service. Washington DC: U.S. Department of Agriculture; 2007. Report No.: Vol. 1.

113. Bockey D. Biodiesel production and marketing in germany. In press 2002.

114. Henard M. France bio-fuels biofuels update. Annual Report. USA: USDA Foreign Agricultural Service; 2008. Report No.: GAIN Report Number: FR8012.

115. Foreign agricultural service [Internet].; 2012. Available from: http://www.fas.usda.gov/.

116. Goldemberg J. The brazilian biofuels industry. Biotechnology for Biofuels. 2008;I(6).

117. US department of agriculture, national agricultural statistics service [Internet].; 2012. Available from: http://www.nass.usda.gov/.

118. United nations, food and agriculture organization [Internet].; 2012. Available from: http://faostat.fao.org/site/567/default.aspx\#ancor.

119. Rashid U, Anwar F. Production of biodiesel through optimized alkaline-catalyzed transesterification of rapeseed oil. Fuel. 2007;87:265.

120. Galdos MV, Cerri CC, Cerri CEP. Soil carbon stocks under burned and unburned sugarcane in brazil. Geoderma. 2009;153:347.

121. Montgomery D, Runger G, Hubele N, editors. Engineering statistics. 4th ed. USA: John Wiley \& Sons, Inc; 2007.

122. California Air Resources Board. Detailed california-modified GREET pathway for compressed natural gas (CNG) from north american natural gas. 2009. 
123. Doctor R, Palmer A, Coleman D, Davison J, Hendriks C, Kaarstad O, et al. IPCC special report on carbon dioxide capture and storage $<$ br $/>$ Chapter 4 transport of $\mathrm{CO} 2$. 2005.

124. Lee SJ, Kim SH, Kang KH, Yoo YD, Yun Y. Development of a pilot-scale acid gas removal system for coal syngas. Korean Journal of Chemical Engineering. 2007;24(6):1128.

125. Xu Y, Isom L, Hanna MA. Adding values to carbon dioxide from ethanol fermentations. Bioresource Technology. 2010;101:3311.

126. Knoope MMJ, Ramirez A, Faaij APC. A state-of-the-art review of techno-economic models predicting the costs of $\mathrm{CO} 2$ pipeline transport. International Journal of Greenhouse Gas Control. 2013.

127. McCollum DL, Ogden JM. Techno-economic models for carbon dioxide compression, transport, and storage \& correlations for estimating carbon dioxide density and viscosity. University of California, Davis, Institute of Transportation Studies; 2006.

128. Weidema B. Ecoinvent data v2.0.

129. Netusil M, Ditl P. Comparison of three methods for natural gas dehydration. Journal of Natural Gas Chemistry. 2011;20:471.

130. Freund P, Bachu S, Simbeck D, Thambimuthu K, Gupta M. IPCC special report on carbon dioxide capture and storage: Annex I properties of $\mathrm{CO} 2$ and carbon-based fuels. 2005.

131. Venteris ER, Skaggs RL, Coleman AM, Wigmosta MS. A GIS cost model to assess the availability of freshwater, seawater, and saline groundwater for algal biofuel production in the united states. Environmental Science \& Technology. 2013;47. 


\section{Appendix}

\section{Base case:}

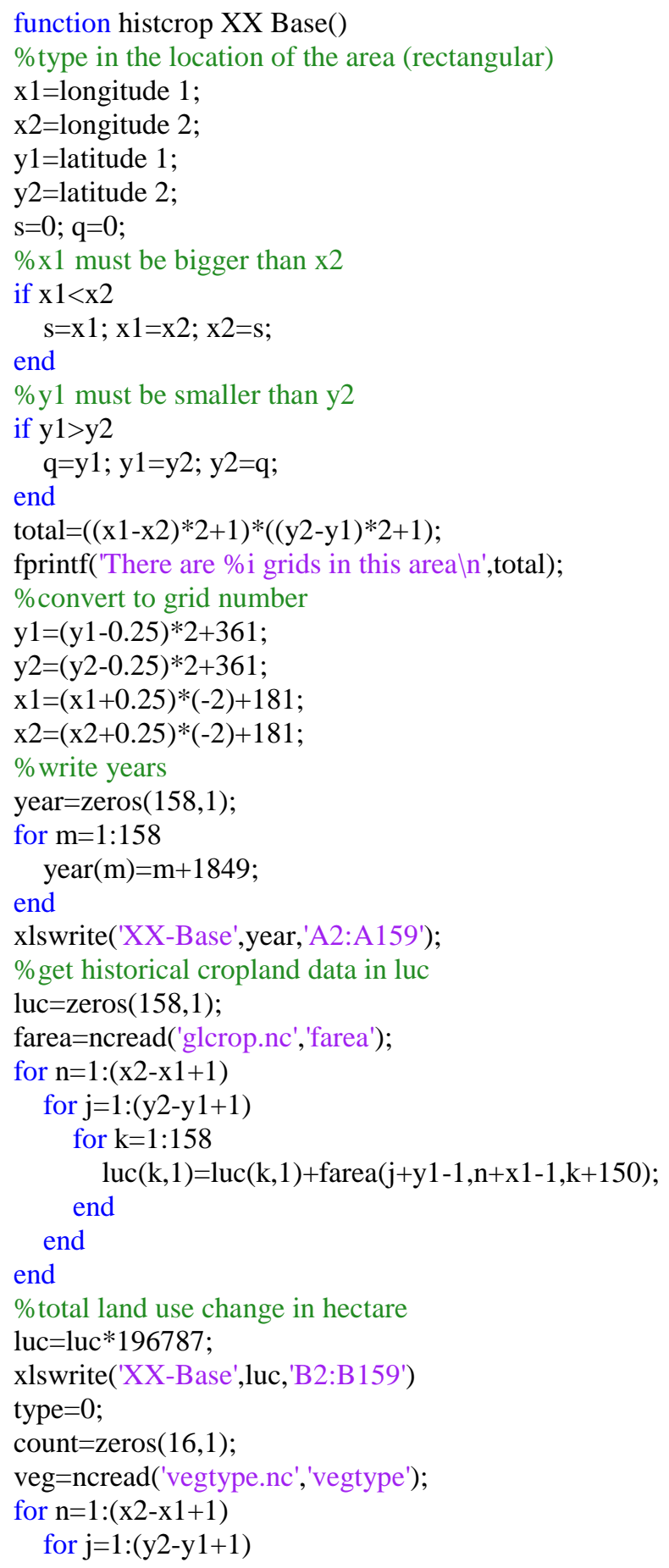




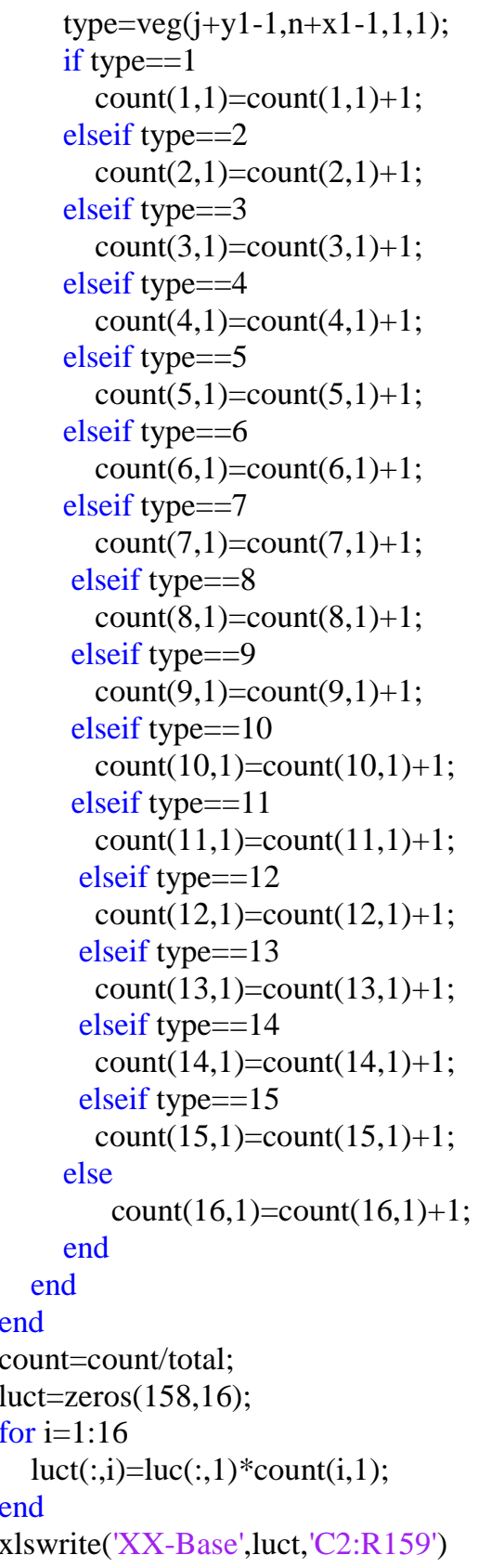

\section{High resolution:}

function histcropHRXX()

\%type in the location of the area (rectangular)

$\mathrm{x} 1=$ longitude 1 ;

$\mathrm{x} 2=$ longitude 2 ;

y1=latitude 1 ;

y2=latitude 2 ;

$\mathrm{s}=0 ; \mathrm{q}=0$;

$\% x 1$ must be bigger than $\mathrm{x} 2$ 


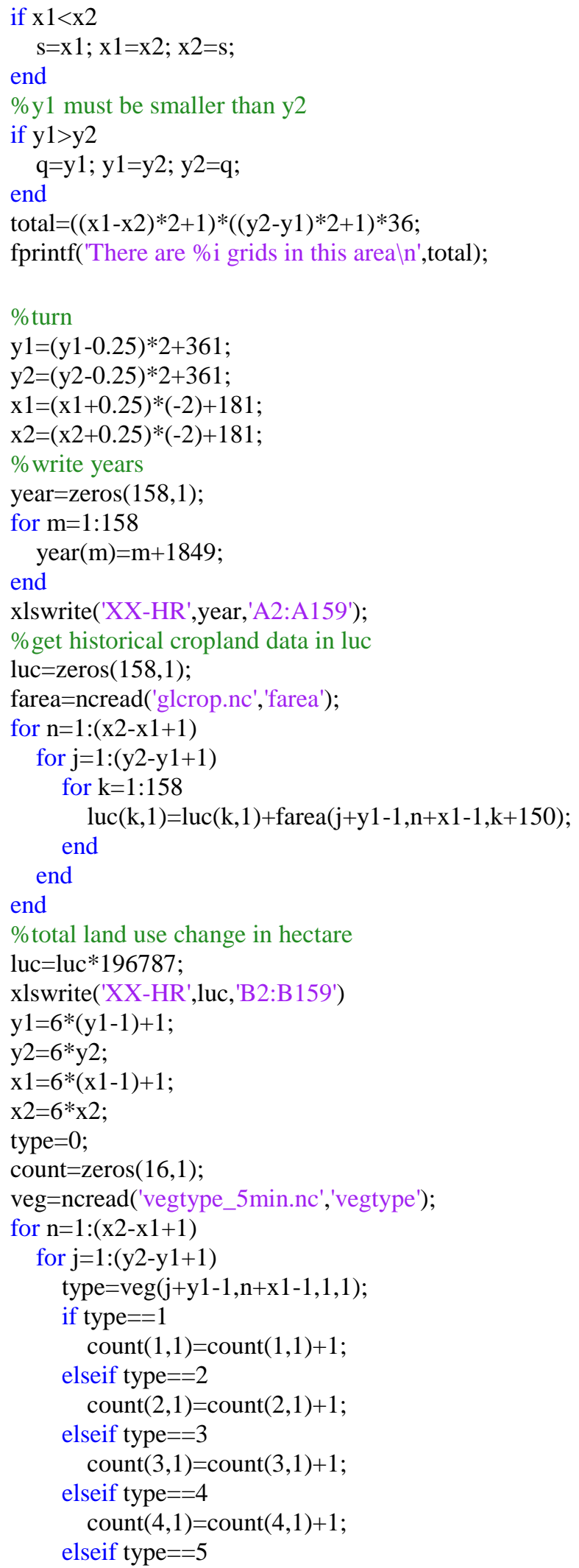




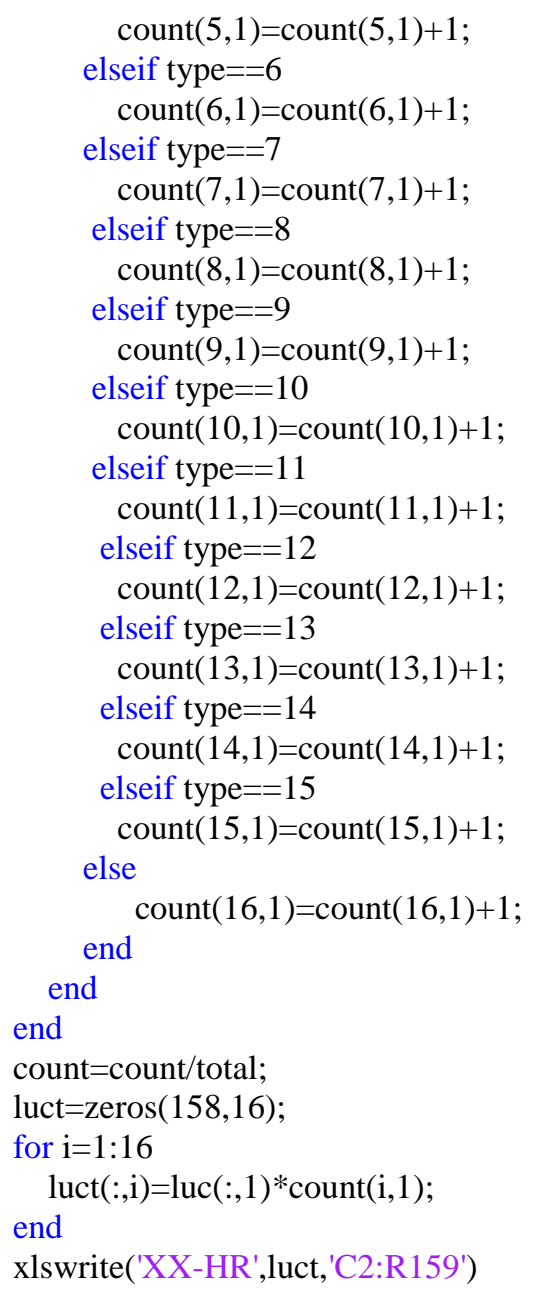

\section{Low resolution:}

function histcropLRXX()

$\%$ type in the location of the area (rectangular)

$\mathrm{x} 1=$ longitude 1 ;

$\mathrm{x} 2=$ longitude 2 ;

y1=latitude 1 ;

y2=latitude 2 ;

$\mathrm{s}=0 ; \mathrm{q}=0$;

$\% \times 1$ must be bigger than $\mathrm{x} 2$

if $\mathrm{x} 1<\mathrm{x} 2$

$\mathrm{s}=\mathrm{x} 1 ; \mathrm{x} 1=\mathrm{x} 2 ; \mathrm{x} 2=\mathrm{s}$;

end

$\% y 1$ must be smaller than y2

if $\mathrm{y} 1>\mathrm{y} 2$

$$
\text { end }
$$$$
\mathrm{q}=\mathrm{y} 1 ; \mathrm{y} 1=\mathrm{y} 2 ; \mathrm{y} 2=\mathrm{q} \text {; }
$$

total $=((\mathrm{x} 1-\mathrm{x} 2)+1) *((\mathrm{y} 2-\mathrm{y} 1)+1)$;

fprintf('There are \%i grids in this arealn',total);

\%convert 


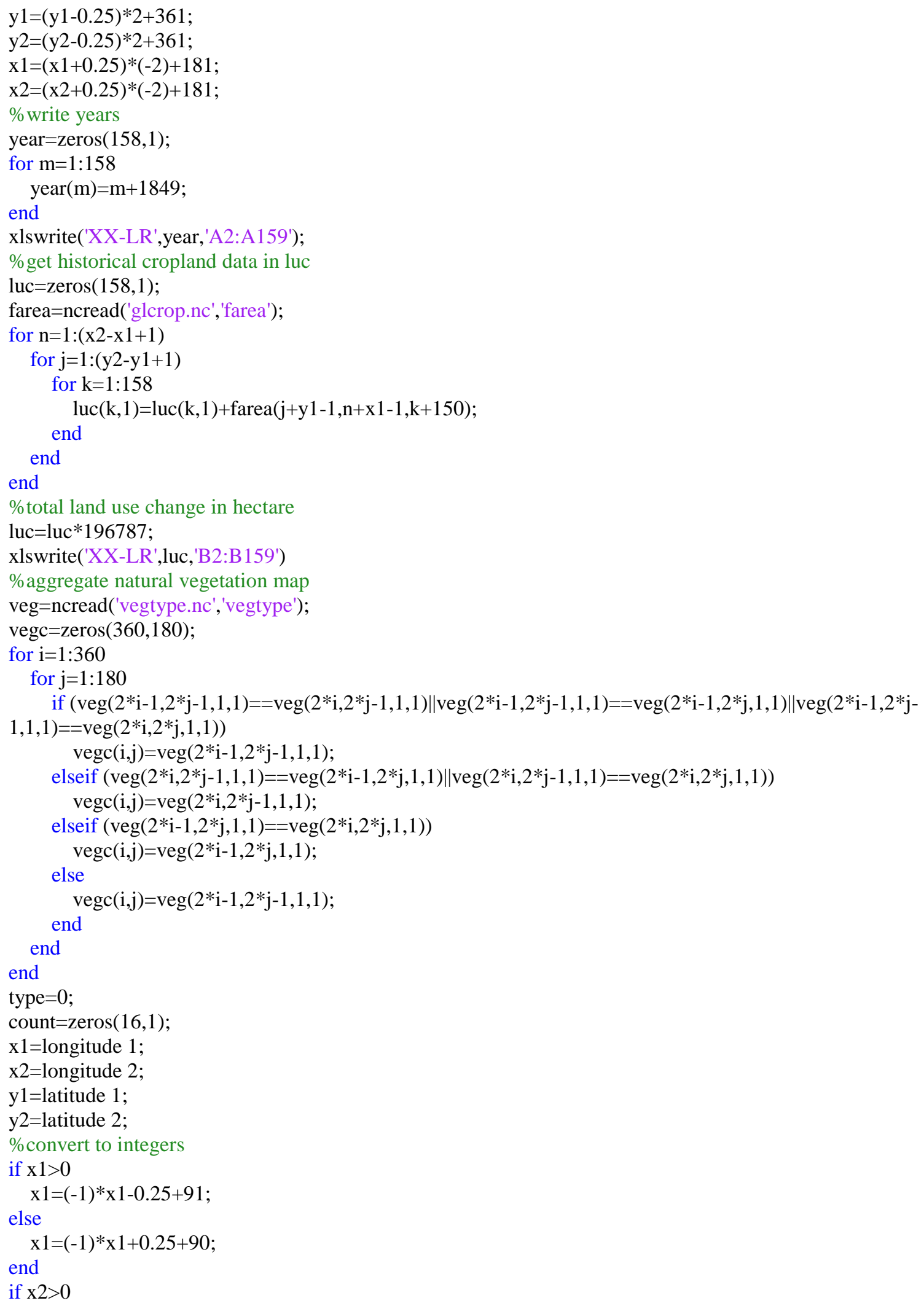




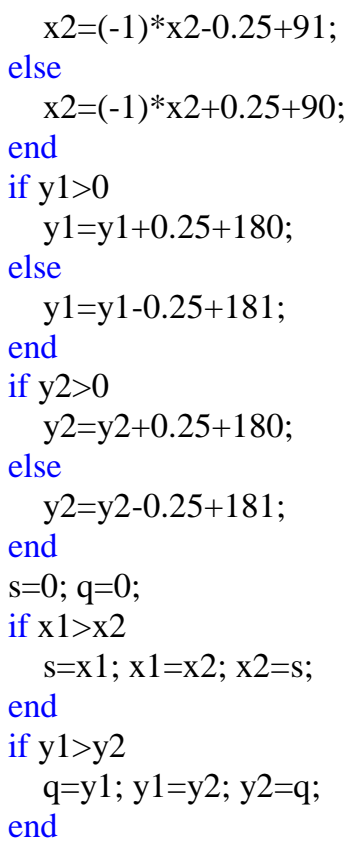

for $\mathrm{n}=1:(\mathrm{x} 2-\mathrm{x} 1+1)$

for $\mathrm{j}=1:(\mathrm{y} 2-\mathrm{y} 1+1)$

type $=\operatorname{vegc}(\mathrm{y} 1+\mathrm{j}-1, \mathrm{x} 1+\mathrm{n}-1)$;

if type $==1$

$\operatorname{count}(1,1)=\operatorname{count}(1,1)+1$;

elseif type $==2$

$\operatorname{count}(2,1)=\operatorname{count}(2,1)+1$;

elseif type $==3$

$\operatorname{count}(3,1)=\operatorname{count}(3,1)+1$;

elseif type $==4$

$\operatorname{count}(4,1)=\operatorname{count}(4,1)+1$;

elseif type $==5$

$\operatorname{count}(5,1)=\operatorname{count}(5,1)+1$;

elseif type $==6$

$\operatorname{count}(6,1)=\operatorname{count}(6,1)+1$;

elseif type $==7$

$\operatorname{count}(7,1)=\operatorname{count}(7,1)+1$;

elseif type $==8$

$\operatorname{count}(8,1)=\operatorname{count}(8,1)+1$;

elseif type $==9$

$\operatorname{count}(9,1)=\operatorname{count}(9,1)+1$;

elseif type $==10$

$\operatorname{count}(10,1)=\operatorname{count}(10,1)+1$;

elseif type $==11$

$\operatorname{count}(11,1)=\operatorname{count}(11,1)+1$;

elseif type $==12$

$\operatorname{count}(12,1)=\operatorname{count}(12,1)+1$;

elseif type $==13$

$\operatorname{count}(13,1)=\operatorname{count}(13,1)+1$;

elseif type $==14$

$\operatorname{count}(14,1)=\operatorname{count}(14,1)+1$; 


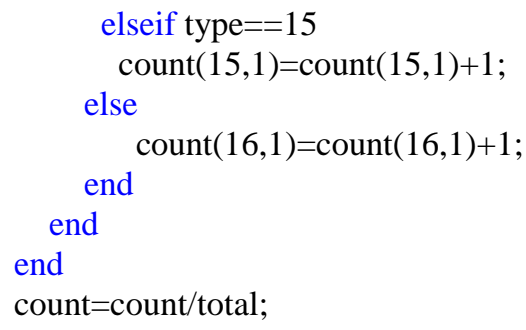

